\title{
VALUING WARM HOMES - EXPLORING NEW ZEALANDERS' HOME HEATING CHOICES
}

by

\author{
Hayley Vujcich \\ Thesis \\ ENVIRONMENTAL STUDIES 593
}

2008

A 90 point thesis submitted to Victoria University of Wellington,

as partial fulfilment for the degree of Master of Environmental Studies

School of Geography, Environment and Earth Sciences

Victoria University of Wellington

March, 2008 


\title{
VALUING WARM HOMES - AN INVESTIGATION OF NEW ZEALANDERS' HOME HEATING CHOICES
}

\author{
Hayley Vujcich
}

\begin{abstract}
New Zealand homes have a record of being poorly heated and inadequately energy efficient. While policy makers increasingly recognise the many benefits associated with energy efficient warm homes, there is currently a lack of understanding of how New Zealanders make choices about space heating. This thesis takes a mixed method approach in order to 1) understand how New Zealanders value energy efficient heating and 2) further explore how people make decisions about home heating. Capturing the economic value of the range of benefits associated with home heating is investigated through analysing a contingent valuation study undertaken by the Housing, Heating and Health Study (University of Otago). Participants show 'willingness to pay' and related values below heater market prices. It is argued that there is some indication of split incentives issues and income constraint, and increased familiarisation with space heaters may increase willingness to pay. Evidence from focus group research suggests that while attitudes and norms are conducive to efficiently heated homes, other market and non-market factors impede pro-environmental choices. The widely recognised Kiwi stoicism of living in cold homes is not evidenced; choosing to go cold in the home may instead be rationalised as mitigating the environmental impacts associated with heating. This analysis sheds light on how intervention and how provision of information to fill the 'energy efficiency gap' could move outside the 'rational person' model of how New Zealanders make home heating choices.
\end{abstract}

Key words: Space heating, warm homes, energy efficiency, contingent valuation, focus group. 


\section{Acknowledgments}

Thanks must go firstly to my supervisor, Ralph Chapman, for seeing me through this long and sometimes arduous task, and for advice and encouragement. I am grateful to Euan Smith for his valued assistance with the statistical analysis, to Alison Adams-Smith for her help with the focus groups, and to the Housing, Heating and Health team, particularly Nevil Pearse, Helen Viggers and Phillippa Howden-Chapman for their generosity, time and assistance. My heart goes out to my lovely partner, Paul, for absolutely unerring support, to Amélie for invaluable advice, and to my office mate, Sara, for always being there to listen and share my problems, and water the plants when I was away. Thanks too to my parents who send me love from across the world and pushed me through this process, to my sister and brothers for always believing and to my friends for keeping me laughing. I am forever grateful to my fellow Masters students for their humour, shared frustrations, advice and talking in corridors. It is done! 


\section{Contents}

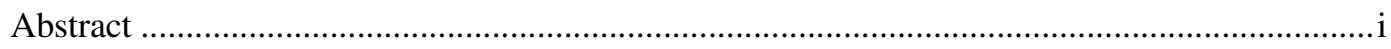

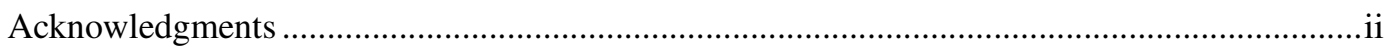

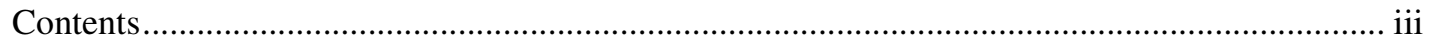

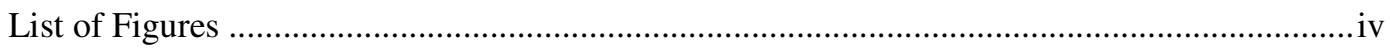

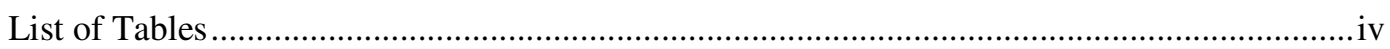

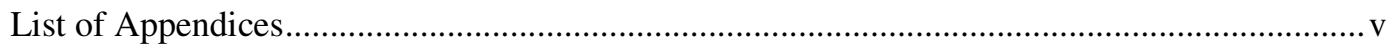

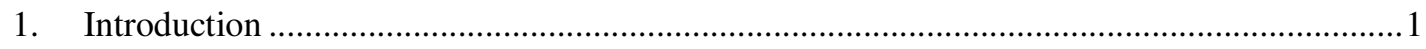

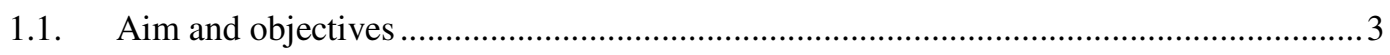

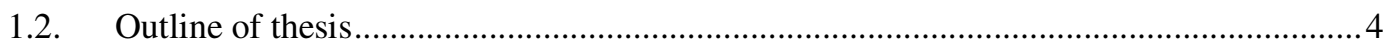

2. Setting the context - energy efficiency in New Zealand ........................................................5

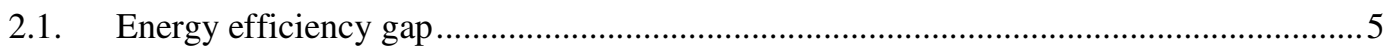

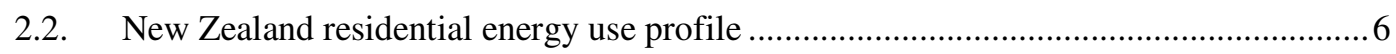

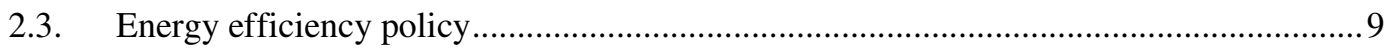

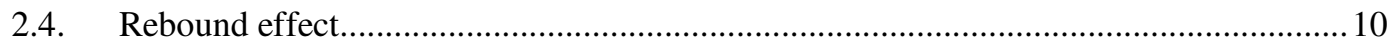

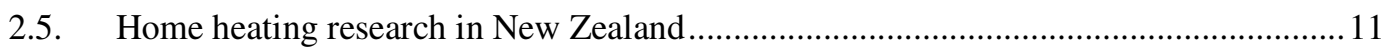

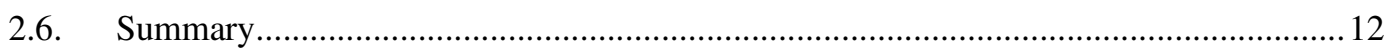

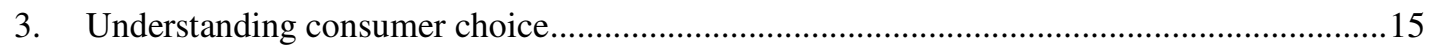

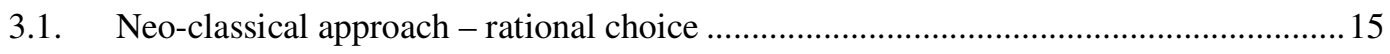

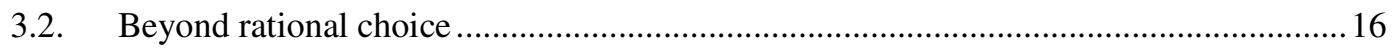

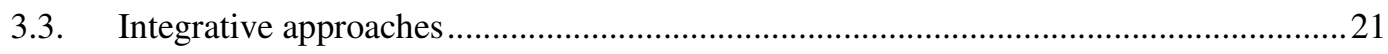

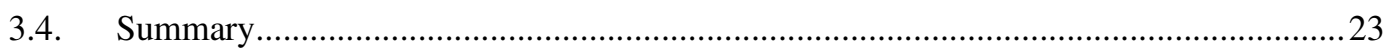

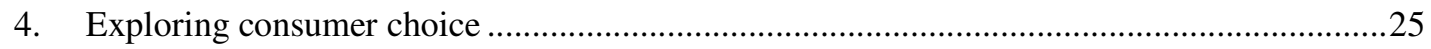

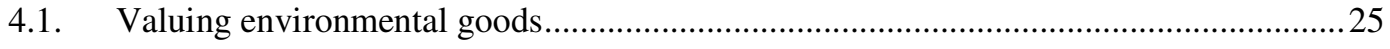

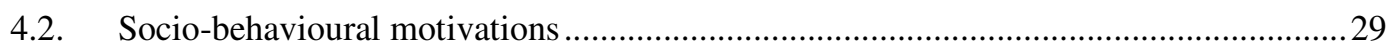

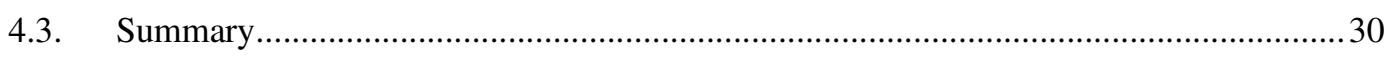

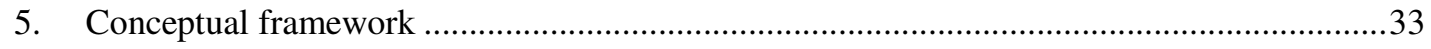

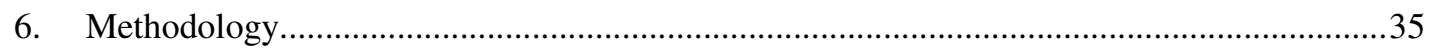




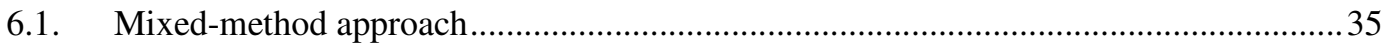

6.2. Quantitative method - HHHS contingent valuation survey …….................................... 35

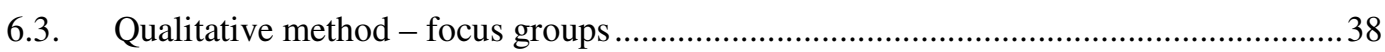

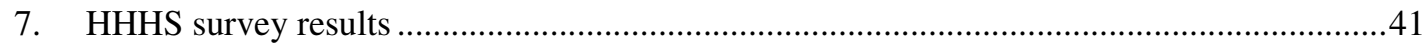

7.1. Willingness to pay and willingness to accept ............................................................... 41

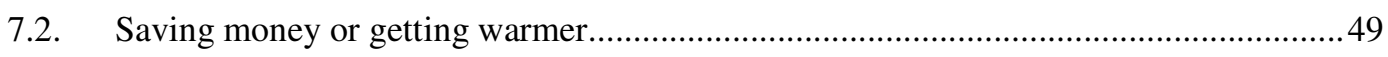

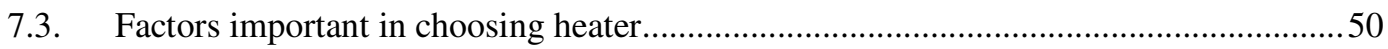

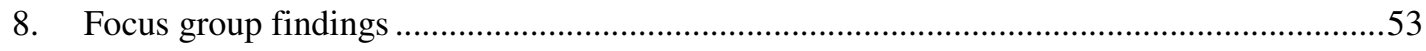

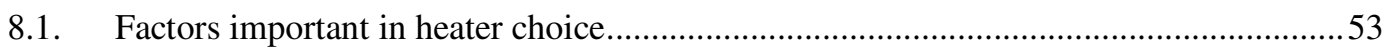

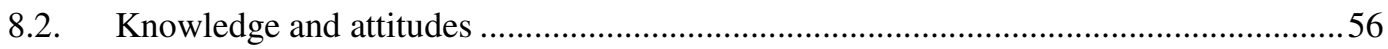

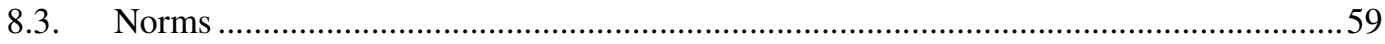

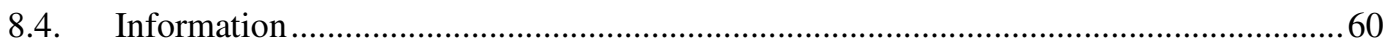

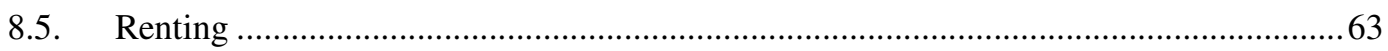

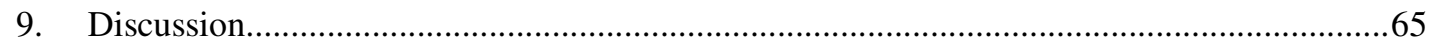

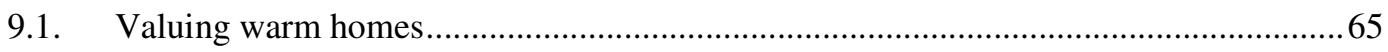

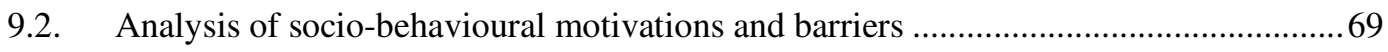

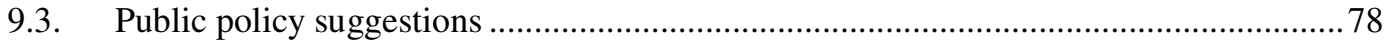

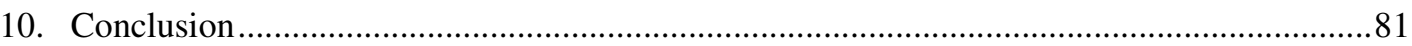

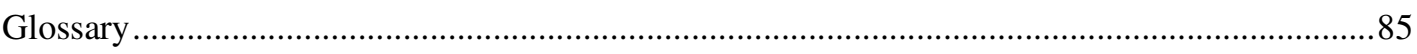

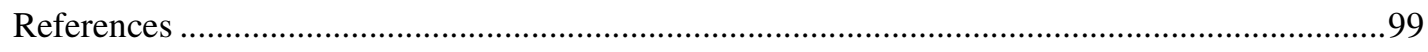

\section{List of Figures}

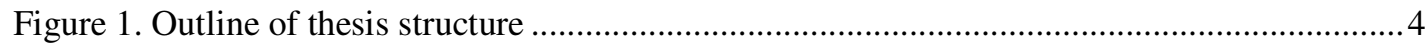

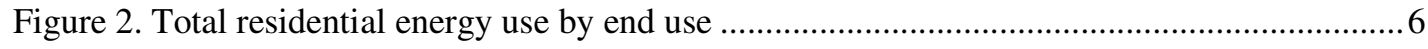

Figure 3. Household space heating energy use (gross) by fuel type ...............................................

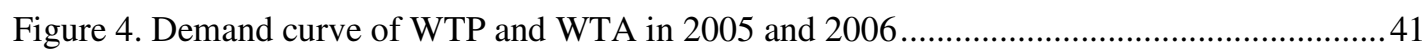

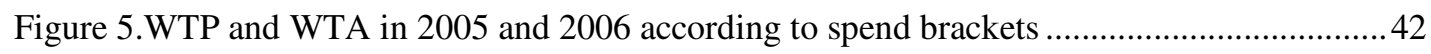

Figure 6. WTP and WTA in 2005 and 2006 according spend bracket mid-point. .......................... 42

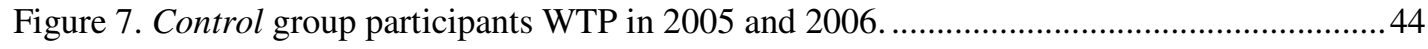

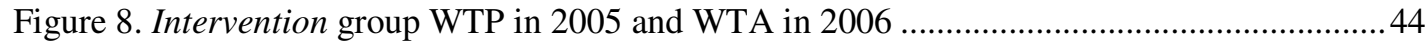




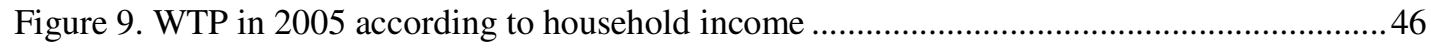

Figure 10. Control group WTP in 2006 according to household income........................................46

Figure 11. Intervention group WTA in 2006 according to household income.................................46

Figure 12. Saving money or greater warmth trade-off choices in 2005 and 2006 .......................50

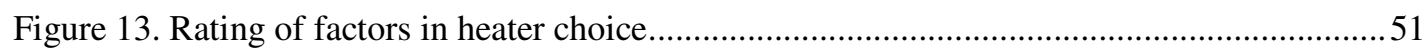

Figure 14. Rating of factors in heater choice - percentage of respondents. ...................................51

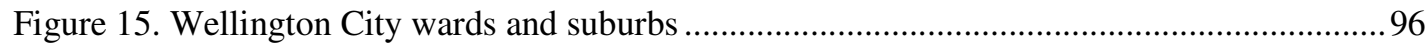

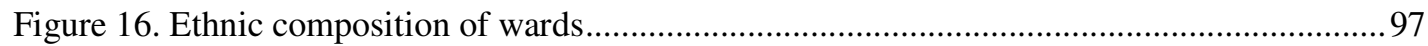

\section{List of Tables}

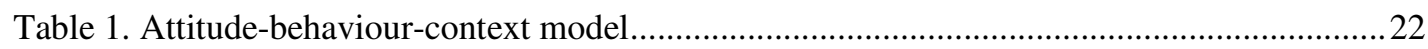

Table 2. A causal model of resource-consumption behaviour with examples from residential home

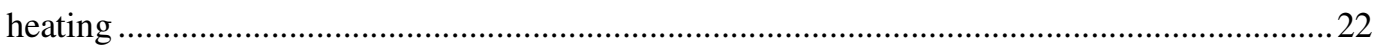

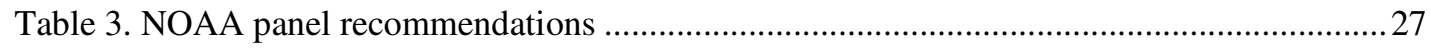

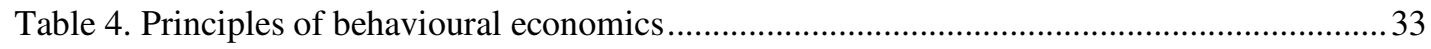

Table 5. Median and variance of WTP and WTA for all HHHS participants................................. 43

Table 6. Mann-Whitney U test Z statistic comparing WTP and WTA. .........................................43

Table 7. Median WTP and WTA and variance for control and intervention groups. .....................4 44

Table 8. Wilcoxon Signed Rank test $Z$ statistic for intervention and control group WTP/A......... 45

Table 9. Median WTP and WTA and variance according to income group. .................................... 45

Table 10. Median WTP and WTA and variance according to ownership or tenancy .....................47

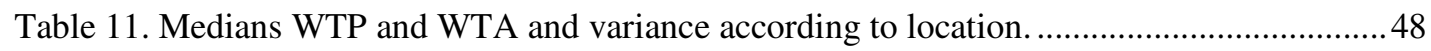

Table 12. Median WTP and WTA and variance according to North or South Island location...... 48

Table 13. Median WTP and WTA and variance according to heater type ..................................... 49

Table 14. Participants' WTP and WTA and actual prices for different heater types. ......................49

Table 15. Motivations for and barriers to energy efficient warm homes. …….............................. 70

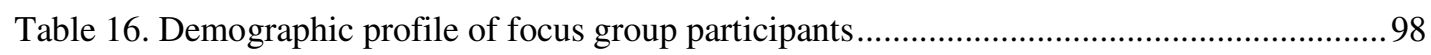

\section{List of Appendices}

Appendix 1 - Housing Heating and Health Study Householder Survey questions..........................86

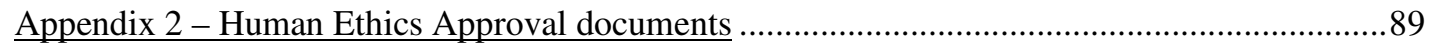

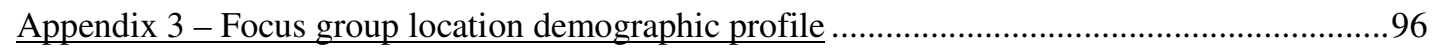

Appendix 4 - Focus group participant demographics ................................................................. 98 


\section{Introduction}

Around 34\% of residential energy demand in New Zealand is used in space heating, making it the greatest consumer of energy in the home (Isaacs, et al., 2006; McChesney, et al., 2006). ${ }^{1}$ Improving the efficiency of residential energy use, including space heating, has an important role to play in New Zealand's energy future. Increased energy efficiency is crucial for helping reduce greenhouse gas emissions and mitigating security of energy supply issues (IEA, 2006; IPCC, 2007). It is also important for other social and environmental objectives that tend to be forgotten or ignored, including addressing air pollution, tackling social equity issues such as fuel poverty, and improving health outcomes.

Like governments around the world, the New Zealand government has taken many different policy avenues in order to improve residential energy efficiency. And like international experience, the government has found it difficult to achieve efficiency gains (MED, 2006; de T'Serclaes, 2007). For example, education campaigns in New Zealand to promote residential energy efficiency have had a poor record (Wilton, 2005). A 2006 review of residential energy policy found that the current approaches are unlikely to promote investment in energy efficiency to an optimal level (McChesney, et al., 2006). And recently, the Energy Efficiency and Conservation Authority (EECA) admitted that no one had taken up their $\$ 500$ subsidy for solar water heating during the last financial year ("Solar hot water subsidy off to a slow start", 2008).

Residential heating energy efficiency can be improved in a number of different ways, including improving space heating efficiency, improving building fabric performance, increasing solar gains and adopting more effective behaviours. This thesis focuses on the interaction between home heating technologies and the people who use them. It is important to understand home heating as this interaction, since "no purely functional account of material goods [such as heaters] is going to deliver a robust model for understanding consumer behaviour" (Jackson, 2005, p. 17).

There are many benefits of efficient home heating, including improved indoor and outdoor air quality, improved physical and mental health outcomes, reduced greenhouse gas emissions and improved local air quality (Howden-Chapman, et al., 2007; Wilkinson, et al., 2007). Recent policy for improving residential energy efficiency may not be sufficient to fully capture these benefits. For example, a study looking at policy options for improving particulate air pollution $\left(\mathrm{PM}_{10}\right)$ in Tokoroa found that without intervention (i.e. natural attrition of old heating systems), $\mathrm{PM}_{10}$ reductions required under the National Environmental Standard (NES) for Air (MfE, 2004) would not be met by the 2013 target date (Barns, in press).

\footnotetext{
${ }^{1}$ In this thesis, residential energy refers to energy consumed in the home. This excludes transport energy.
} 
Moreover, improvements in energy efficiency are, at present, eclipsed by growth in energy demand. Growth in energy demand in New Zealand's residential sector is predicted to increase on average at 2.1\% per annum between 1998 and 2020 (EECA, 2000). Despite residential energy intensity having decreased 19\% between 1975 and 1998, total demand increased almost 30\% during the same period (EECA, 2000). At present, this demand makes up around 13\% of the total annual observed consumer energy demand in New Zealand (MED, 2007), equating to around $10 \%$ of the total energy sector greenhouse gas emissions (New Zealand Government, 2007b). Although New Zealand's contribution to global greenhouse gas emissions is small ( $0.2 \%$ of the total), we have a high per capita emissions rate, ranking eleventh highest in the world (WRI, 2005). On a business as usual trajectory, New Zealand's total energy-related greenhouse gas emissions would be projected to rise $39 \%$ by 2030 , despite our commitment to the Kyoto Protocol to reduce emissions, or pay for reductions, to 1990 levels by 2012 (New Zealand Government, 2007c).

While residential greenhouse gas emissions may be relatively small compared to other sectors', there is still a strong imperative to mitigate these emissions. In addressing a complex problem such as climate change, it is important to effectively engage with all actors in society, in all facets of their lives, and this includes the general public in their day-to-day life. Encouraging people to engage in apparently small acts such as improving energy efficiency in their homes may be a good way to address two of the principles of creating agency: understanding the need to act and believing that one's own action will make a difference (Bandura, 1989). Furthermore, while individual energy savings made through improved can be small, aggregating these savings across society may be very important (de T'Serclaes and Jollands, 2007).

Finding cost-effective answers to climate change mitigation is an important goal. Many emissions reduction actions are cost effective at present, and a great many of these are energy efficiency measures (Vattenfall, 2007). In New Zealand, research has indicated that for every dollar spent on basic energy efficiency improvements (such as insulation and draught-stopping) the household makes around two dollars in energy and health savings (Chapman, et al., in review). Given that these measures are cost effective, why are New Zealanders' homes more energy efficient?

As examined in the next chapter, it is difficult to answer this at present as there is a dearth of energy demand research in New Zealand. In the past, much energy research has focused on supply-side issues. In particular, research has focussed on alternative means of generation, distribution and, more recently, on small-scale, localised energy generation. This focus on supplyside issues has also been a feature of government activity, as acknowledged in the recently updated New Zealand Energy Efficiency and Conservation Strategy (NZEECS), in which there is now a "clearer focus on consumer (demand-side) action" (New Zealand Government, 2007b, p. 
10). At present, then, the demand-side complexities of New Zealand's energy sector are not well researched or understood (Isaacs, et al., 2004).

One way to assess how energy efficiency uptake may be improved that is important for policy analysis is the identification of market barriers, as without intervention there will be underinvestment in energy efficiency (Golove and Eto, 1996; de T'Serclaes, 2007). However, identifying non-market barriers and looking outside the neo-classical economic paradigm is equally important. For instance, one way of explaining the difference between 'rational' expectations of the level of investment in energy efficiency and what is really happening - the energy efficiency gap - is by looking at the role of behavioural factors at play (Sathaye and Murtishaw, 2004).

Understanding how New Zealand consumers take up energy efficient heating is important for a sustainable and secure energy future. In order to develop policy to promote energy efficient and warm homes, it is important to understand how people make investment decisions about heaters and their willingness to pay for energy efficiency in the home (Banfi, et al., 2008). Furthermore, Gardner and Stern (2002) suggest that when looking to influence environmentally significant behaviour, it is important to understand the situation under investigation from the agent's perspective. Accordingly this thesis investigates the situation of the very people who could be acting in a more energy efficient manner in their home heating, exploring how people value and make decisions about home heating.

\subsection{Aim and objectives}

\subsubsection{Aim}

To develop a picture of how New Zealanders value energy efficient home heating, and to explore New Zealanders' home heating choices.

\subsubsection{Objectives}

1. Develop a conceptual framework from a detailed literature review.

2. Analyse how people value energy efficient home heaters.

3. Identify and analyse socio-behavioural motivations and barriers to energy efficient home heating choices, including investigating the role of information.

4. Discuss implications of findings for public policy measures promoting the uptake of energy efficient home heaters. 


\subsection{Outline of thesis}

The next chapter looks at the energy efficiency gap and describes how this is expressed in residential space heating, outlining the energy use characteristics of New Zealand homes, energy efficiency policy and research. This is followed in Chapter 3 by a review of the theoretical understandings of consumer behaviour that may be in part responsible for the energy efficiency gap. Chapter 4 explores methods for investigating consumer choice, taking two approaches -1) how to value goods with non-market attributes, such as energy efficient heaters, and 2), how to explore non-market motivations of consumer behaviour. Then Chapter 5 gives the conceptual framework developed from the literature reviewed in Chapters 2-4.

The methodology and the two methods used in this thesis follow in Chapter 6. They are a quantitative survey drawing on the work of the Heating Housing and Health Study (University of Otago, Wellington); and focus group research. Thus, this thesis adopts a mixed-method research methodology. The results of these two strands of investigation are presented (Chapter 7 and 8), followed by discussion of these findings and suggestions for how they might apply to residential energy efficiency policy in New Zealand (Chapter 9) and the conclusion (Chapter 10).

The following diagram is an outline of the structure of this thesis (Figure 1).

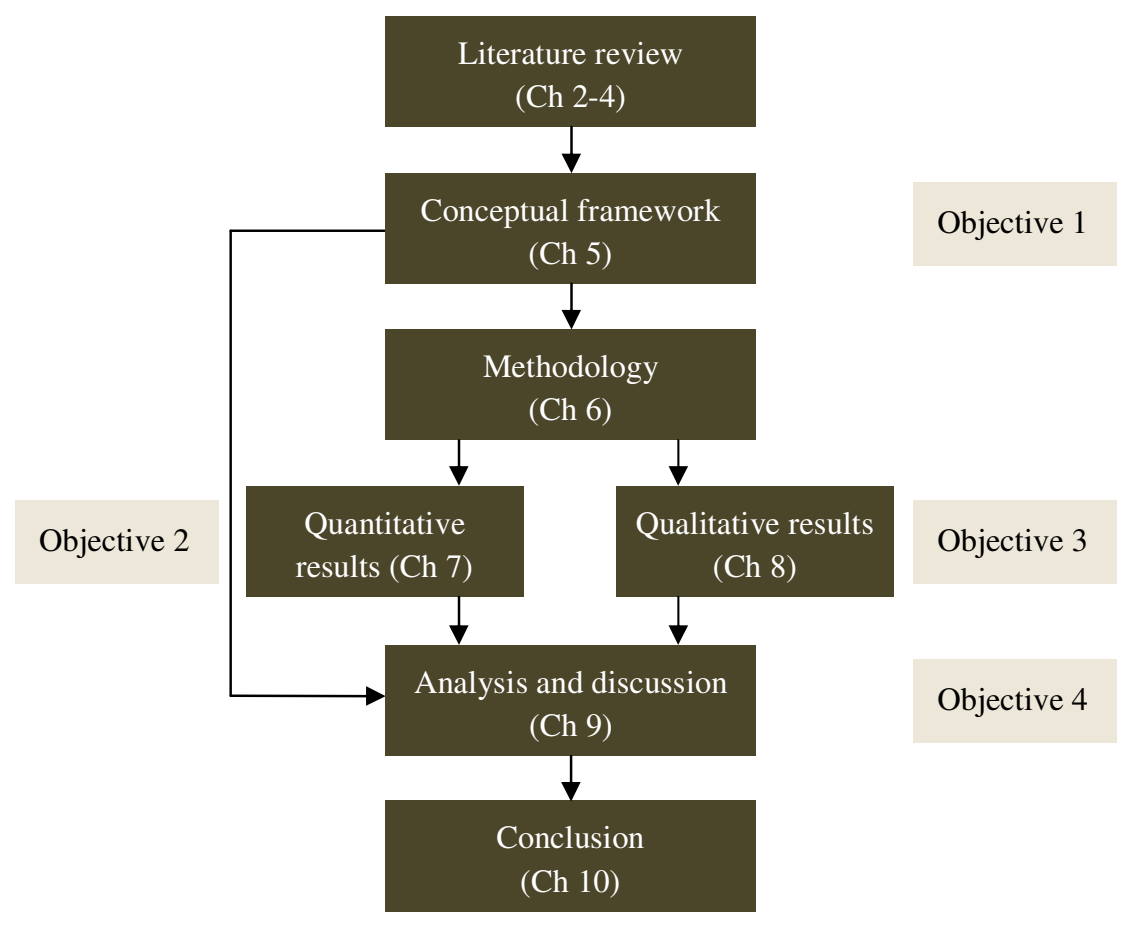

Figure 1. Outline of thesis structure

The next three chapters constitute the literature review, starting with setting the context of energy efficiency theory and the use of energy in New Zealand homes. 


\section{Setting the context - energy efficiency in New Zealand}

Energy efficiency is a technical and historical process of improving the ratio of energy services (or outputs) to the energy input (Herring, 2006). Energy efficiency is affected by the behaviour of many different groups operating at many different levels including energy consumers, manufacturers of end-use equipment and infrastructure, energy generators, energy distributors and government institutions (Reddy, 1991). The interactions of these groups, and the market in which they operate, present considerable complexities affecting society's ability to become more energy efficient.

This chapter examines the literature around energy efficiency, including a brief explanation of the energy efficiency gap. It then provides the context of this thesis, outlining energy use and heating characteristics of New Zealand homes, energy efficiency policy affecting the residential sector and residential heating research in New Zealand.

\subsection{Energy efficiency gap}

The energy efficiency gap is the difference that exists between the socially optimal and the actual level of investment in energy efficiency improvements (Jaffe and Stavins, 1994). It is a phenomenon that has been widely discussed in literature for over thirty years (Scheraga, 1994; Brown, et al., 1998). There are a number of rationalisations of why this gap exists. The market barriers that contribute to the gap are well recognised, and include:

- low priority of energy issues;

- access to capital;

- incomplete markets for energy efficiency;

- $\quad$ split incentives (principal-agent problem) ${ }^{2}$

- insufficient and inaccurate information;

- unpriced costs (externalities); and

- unpriced (public) goods (Levine, et al., 1995; Golove and Eto, 1996; Sathaye and Murtishaw, 2004; de T'Serclaes, 2007; de T'Serclaes and Jollands, 2007).

The latter five of these barriers are often classed as market failures. These barriers are important in home heating efficiency - for instance, split incentives mean that residential tenants will often not have the opportunity to influence the choice of heating system or energy efficiency goods such as insulation (de T'Serclaes and Jollands, 2007).

\footnotetext{
${ }^{2}$ The split incentives problem describes a situation where participants in an economic exchange have different incentives or goals, consequently undermining the level of investment (de T'Serclaes and Jollands, 2007). This is most often depicted in terms of the different goals of landlords and tenants.
} 
Non-market energy efficiency research and reviews indicate that the role of interpersonal influence, imitation of other's behaviour and choices, communication, the momentum of past behaviour, commitment, motivation and the expression of personal values and norms as social psychological processes that affect energy users' choices (e.g. Stern and Aronson, 1984; Stern, 1986; Ball, et al., 1999). These processes are all part of the 'socio-behavioural' factors that affect potential energy efficiency gains and the energy efficiency gap. Both market barriers and these non-market factors relate to individual decision-making, so understanding how consumers behave and make choices is vital for intervention (Wilson and Dowlatabadi, 2007).

\subsection{New Zealand residential energy use profile}

\subsubsection{Energy use in the home}

New Zealand households currently have the lowest energy consumption per capita of all OECD countries, consuming around $10000 \mathrm{kWh} /$ year of energy (excluding transport energy) (MED, 2007). This is around $30 \%$ less than our Australian counterparts, half as much as residential consumption in the United Kingdom, and around 70\% less than in Canada - this in spite of having low electricity prices compared to other OECD countries (Schipper, et al., 1996; Amitrano, 2004). While residential electricity consumption per occupant has risen by $14 \%$ in the since the 1970 s (Isaacs, et al., 2006), meaning that New Zealanders now demand more electricity in their homes per person than ever before, this comparatively low profile may indicate that there is room for further demand growth.

Of the total energy use in the home, around $34 \%$ is consumed by space heating, more than any other energy service in the home (Figure 2) (Isaacs, et al., 2006; McChesney, et al., 2006).

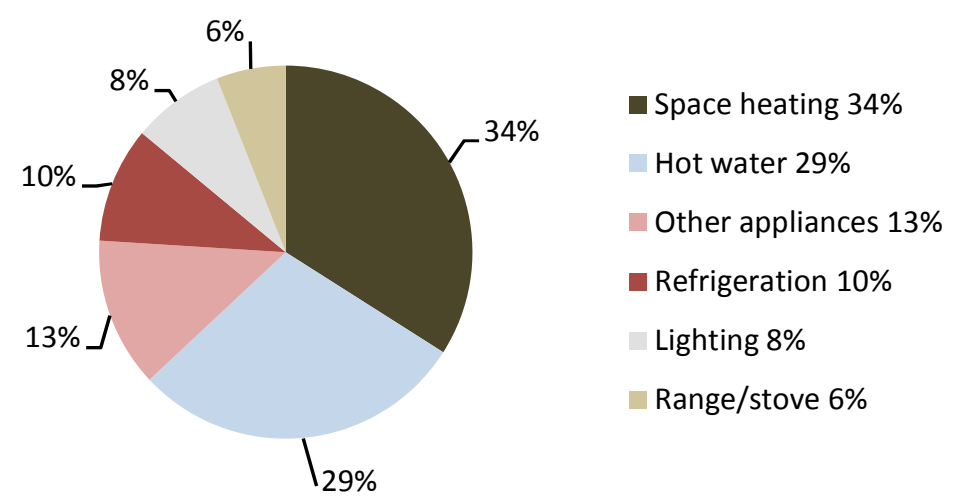

Figure 2. Total residential energy use by end use. Source: Isaacs et al. (2006)

Electric portable heaters are the most popular form of heating in New Zealand, found in $72 \%$ of homes in the Household Economic Survey (Statistics New Zealand, 2004). Solid fuel burners are found in $48 \%$ of houses, and unflued gas heaters in $34 \%$ of houses (ibid). Recent growth in the 
use of heat pumps has been huge, with sales tripling in the five years to 2006, so that an estimated $11 \%$ of homes now have them (Buckett, 2007). Around $2.4 \%$ of houses have no heating at all (Statistics New Zealand, 2006). While the most important overall fuel source for households is electricity, the Housing Energy End Use Project (HEEP) (Building Research Association of New Zealand $^{3}$, a ten year study of energy end-use in the home, found that the most important space heating fuel sources are solid fuels (wood and coal), making up around 56\% of the total use (Figure 3) (Isaacs, et al., 2006). Newer houses tend to use electricity or gas for space heating, whereas older houses tend to rely more on solid fuels (ibid). If conversion from solid fuel burners to electric heaters (such as heat pumps) should occur, there could be a significant effect on electricity demand, particularly at peak load times (Isaacs, et al., 2006; Lloyd, et al., 2007).

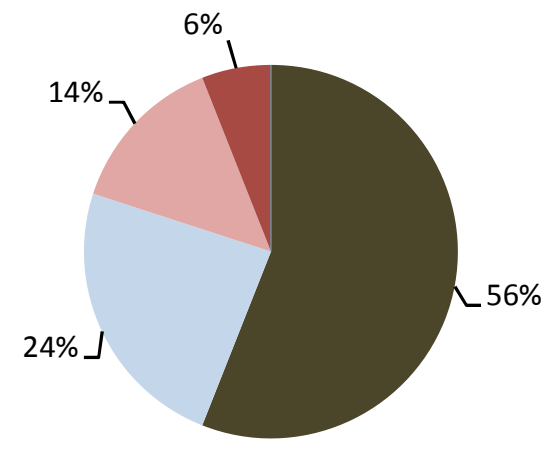

Solid fuel $56 \%$

Electric $24 \%$

Reticulated gas $14 \%$

- LPG 6\%

Figure 3. Household space heating energy use (gross) by fuel type. Source: Isaacs et al. (2006)

Solid fuel heating may be particularly important for rural areas and smaller cities and towns. The HEEP study found that for small settlements and rural areas, nearly $77 \%$ of energy for space heating came from solid fuels, though it is important to note that sample sizes of these groups were small, reducing the reliability of these data (Isaacs, et al., 2006).

\subsubsection{Cold homes}

Research indicates that New Zealand houses are generally cold (Howden-Chapman, et al., 1999; Isaacs, et al., 2006), and they certainly have a reputation as such (Wright, 2007). New Zealand homes have the lowest space heating intensity of all International Energy Agency (IEA) member countries, and rates of space heating that are very low compared to other OECD countries (Schipper, et al., 1996; Amitrano, 2004). The World Health Organisation (WHO) recommends that living area temperatures should be between $18^{\circ}$ and $21^{\circ} \mathrm{C}$ during winter, with temperatures below $16^{\circ} \mathrm{C}$ leading to adverse health effects (WHO, 1987). ${ }^{4}$ The HEEP study found that the

\footnotetext{
${ }^{3}$ See www.branz.co.nz.

${ }^{4}$ Though specification of acceptable thermal comfort levels in the home is greatly debated, the WHO recommendations provide a base level for acceptable temperatures (Nicoll and Parsons, 2002).
} 
average evening winter temperature in living rooms was $17.9^{\circ} \mathrm{C}$ - and the living room was typically the warmest room in the house (Isaacs, et al., 2006).

New Zealand has a history of low spending on both heating and insulation (Schipper, et al., 2000). Insulation of houses has only been compulsory since 1978 with the introduction of minimum thermal installation requirements, which even then only required insulation of floors and ceilings. ${ }^{5}$ It is estimated that around one third of New Zealand houses currently have no insulation at all (Clark, et al., 2000). In a study of the housing of university students in Dunedin, the researchers point out that "houses in New Zealand are energy efficient, in the respect that they use little energy, but are poorly heated" (Shannon, et al., 2003, p. 6). While these households may conserve energy because they do not use much heating, to call them efficient is charitable: these houses are cold probably at least in part because they are ineffective at retaining heat, and perhaps also because people often do not have sufficient income to pay for heating. The poor energy efficiency record of New Zealand houses has been described as a "manifestation of the housing life-cycle: energy was cheap for decades ... and energy efficient building practices were not [economical] for the times" (Grimes, et al., 2004, p. 50). More precisely, it is the interaction of these factors with fuel availability and cost, household behaviour and entrenched cultural practices and beliefs.

\subsubsection{Health effects}

New Zealand's cold homes have translated into poor health outcomes. Because cold houses are also often damp, mould growth is promoted. Research indicates that low indoor temperatures, dampness and mould spores are all associated with detrimental health effects, particularly affecting the respiratory system, but also affecting cardio-vascular health (Howden-Chapman and Tobias, 2000; Carrer, et al., 2001; Bonnefoy, et al., 2003). Emissions from domestic heating are estimated to cause health effects, contributing to an estimated 426 premature deaths a year and more excess bronchial illnesses, respiratory and cardiac hospital admissions than the air pollution effects from vehicles and industry combined (Fisher, et al., 2007). Indoor air quality is also affected by heating type - for instance, there is some evidence that unflued gas heaters, found in a third of New Zealand of homes (Statistics New Zealand, 2006), are associated with negative respiratory health effects, particularly amongst children (Phoa, et al., 2004; Pilotto, et al., 2004).

Furthermore, New Zealand has a higher excess winter mortality rates than other developed nations (Isaacs and Dunn, 1993; Davie, et al., 2007). These health effects have greatest impact amongst the elderly and the very young, as well as those living in substandard housing conditions or in a state of fuel poverty (Boardman, 1991; Howden-Chapman and Tobias, 2000; Rudge and

\footnotetext{
${ }^{5}$ New Zealand Standard 4218P:1977 Minimum thermal insulation requirements for residential buildings.
} 
Winder, 2002; Davie, et al., 2007). ${ }^{6}$ Fuel poverty may be a considerable problem in New Zealand (Lloyd, 2006; McChesney, et al., 2006). Research indicates that around 10-14\% of households in New Zealand are in fuel poverty, though this figure may be higher for households in the South Island (Lloyd, 2006).

\subsubsection{Comfort and lifestyle changes}

Lifestyle choices that make homes more energy intensive are a serious threat to efforts to reduce the risk of an upward trajectory in energy consumption (Chappells and Shove, 2005). As noted above, New Zealanders currently display very low home heating energy consumption levels, in spite of having both poor levels of home insulation and a low price of energy compared to other OECD countries (Schipper, et al., 1996). There is, therefore, room for growth of comfort and increased energy demand if a higher level of space heating were to occur. The IEA reports that "space heating energy intensity may rise as indoor heating standards and comfort improve, so could insulation levels to offset this increase or even lead to a decline in space heating energy use" (Schipper, et al., 1996, p. 5). While a rise in energy demand balanced by increased efficiency is possible, considering New Zealand's poor energy efficiency gains in the last two decades, this seems optimistic without both successful implementation of recent policy initiatives and further policy change.

\subsection{Energy efficiency policy}

At present, the definition of energy efficiency used by the New Zealand government under the Energy Efficiency and Conservation Act 2000 (s3) is: 'a change of energy use that results in an increase in net benefits per unit of energy'. This definition has been criticised as being "incomplete and unhelpfully narrow" as it ignores the interconnections and synergies that exist between energy efficiency and environmental, social and economic policy, actions and outcomes (Isaacs, et al., 2004; McChesney, et al., 2006, p. iv). The recently released NZEECS aims to improve energy efficiency uptake and sets a number of national targets (New Zealand Government, 2007b). These targets mean that New Zealand needs to increase its current energy efficiency improvement rate from the current $0.5 \%$ per year, by around $40 \%$, in order to achieve the OECD average of $0.7 \%$ per year ( $i b i d$ ).

Residential energy policy includes minimum energy performance standards and the EnergyStar scheme for some household appliances, the EnergyWise Homes scheme, the Home Energy Rating scheme (EECA), the Warm Homes programme (Ministry for the Environment (MfE)) and the

\footnotetext{
${ }^{6}$ The definition of fuel poverty has been widely debated. However, a broadly accepted definition is that fuel poverty is the need to spend more than $10 \%$ of annual household income on household fuel, sufficient to heat the house to 'satisfactory' heating conditions of $21^{\circ} \mathrm{C}$ in living areas, and $18^{\circ} \mathrm{C}$ elsewhere (DEFRA, 2003; Lloyd, 2006).
} 
New Zealand Housing Strategy (Housing New Zealand Corporation). EECA, the organisation charged with enhancing the efficiency of energy end-use in New Zealand, is currently promoting residential energy efficiency through the EnergyWise Homes scheme, and has reached over 30,000 homes (New Zealand Government, 2007b). The scheme provides subsidies, grants to lowincome households, interest-free loans for some appliances, and a partial subsidy scheme for landlords to improve rental accommodation energy efficiency.

There has also been considerable action taken by local and regional councils, predominantly on the basis of concerns about winter-time air pollution. Active players include the Christchurch City Council and Environment Canterbury, whose Clean Heat scheme - providing subsidies for energy efficient home heating systems - aims to reduce Christchurch's wintertime air pollution. The scheme has been characterised by an increasing subsidy level for efficient heating appliances as the project has progressed (Smith, et al., 2005b). These authors suggest that is 'natural' progression at work and that, to have all non-complying households install low emissions heating systems, the subsidy level will inevitably have to increase.

While the EnergyWise Homes and Clean Heat schemes have reached thousands of homes, the problem of ever-increasing subsidy levels noted by Smith et al. (2005b) suggests that other policy options besides subsidies need to be investigated. As indicated above, New Zealanders live in cold and often unhealthy homes. It is vital to understand how to improve this situation if we are to reach the NZEECS goal of "warm, dry, healthy homes, improved air quality and reduced energy costs" (New Zealand Government, 2007a, p. 12). Accordingly, it is important to develop an understanding of how consumers make energy efficiency decisions and to understand what people value and respond to (Oxera, 2006).

\subsection{Rebound effect}

One issue faced by proponents of energy efficiency is the rebound effect, originally identified by Khazzoom (1980). This is the process whereby savings made through improved energy efficiency are taken back in the form of increased consumption (Herring, 2006). There are four types of rebound: the direct rebound (increased demand of the good for which the efficiency gain has been made), the indirect rebound effect (increased demand for other goods or services), economy-wide effects and transformational effects (Sanne, 2000). Reviews indicate that quantifying the rebound effect is difficult due to the range of methods used (Greening, et al., 2000; Sorrell and Dimitropoulos, 2007). Sorrel and Dimitropoulos (2007) find that the 'best guess' range of rebound effect in home heating is $10-30 \%$, higher than the rebound for any other residential energy service (Sorrell and Dimitropoulos, 2007). However, Sanne (2000) suggests that secondary effects, which usually go unmeasured, could be larger still. 
The existence of the rebound effect presents difficulties for attempts to reduce energy demand through greater energy efficiency, but it may not have wholly negative implications - for instance, households previously unable to heat their houses sufficiently (WHO, 1987) may be able to achieve higher temperatures with more energy efficient technology (Hong, et al., 2006). In such cases, households in fuel poverty may be better able to afford heating.

\subsection{Home heating research in New Zealand}

In order to understand where a need for research exists in the area of understanding home heating choices in New Zealand, it is useful to examine the research landscape. Most prominently, the MfE's Warm Homes project has produced two reports on why people heat their homes as they do, identifying the 'social drivers' of household energy efficiency and heating in New Zealand (Smith, et al., 2005a; 2005b). This research identifies a number of barriers to the uptake of less polluting forms of heating, including affordability issues, fuel supply and reliability, and a lack of awareness and understanding, with affordability as the most important barrier (ibid). The social drivers were identified using workshops with representatives of a range of organisations (including local and regional councils, social support groups and retailers), and not from the general public themselves. While this Warm Homes research provides a useful backdrop to the range of barriers to the uptake of greater energy efficiency in the home, this understanding of how people make home heating choices is mediated through their representatives, and does not ask the very people who could be making more energy efficient choices themselves.

A recent study by Cupples et al. (2007) takes a participative approach, investigating the role of cultural constructions - such as the stoic, tough New Zealand masculine identity - in how Christchurch residents heat their homes. The study argues that resistance to reducing the use of wood burners by residents is in some part due to reinforcement of this tough, masculine cultural identity (ibid). As the article's title - Put on a jacket you wuss - suggests, New Zealanders are more likely to tough out the cold by putting on another layer of clothing or hiding under a blanket, rather than consider using a more efficient heating system (ibid). Hence, masculine identity appears to be part of the reluctance to move away from the current inefficient modes of heating towards more sustainable heating systems. This stoic identity may also be an ex-post rationalisation of the heating choices people have made which may in fact be driven by other factors, including poverty or other spending priorities.

There is additional evidence of a culture of acceptance of the very low level of home heating in New Zealand. In a study of student housing in Dunedin, despite $90 \%$ of living areas being on average below the WHO (1987) recommended $18^{\circ} \mathrm{C}$ (and $80 \%$ below $16^{\circ} \mathrm{C}$ ), and only $34 \%$ of the participants responding that they were 'comfortable' in their homes during winter, there appeared 
to be a "certain level of acceptance of these conditions by the students who live in them" (Shannon et al., 2003, p. 29). These students were almost all living in rental properties, often on short-term tenancies, meaning that there were split incentives to improve the house heating system (de T'Serclaes and Jollands, 2007). However, there appears to be little desire or effort to change either the heating system or the level of insulation so that they might live in warm homes.

While this stoic aspect of New Zealand cultural identity is widely recognised within popular culture - see for instance Crump (1960) and Meros (2007) - it is by no means the only cultural identity that exists. However, cultural meanings, such as identified by Cupples et al. (2007) may be in part responsible for the gap between attitudes and behaviour in pro-environmental behaviour - a well recognised phenomenon in environmental psychology (Barr, 2004) - in household energy efficiency in New Zealand. Understanding why people make pro-environmental choices such as using energy efficient home heating systems is important if we are to help institute sustainable living practices and help bring about change in people's behaviours and choices.

\subsection{Summary}

New Zealand's homes are often cold, damp and unhealthy. Inefficient heating systems contribute to these factors as well as to greenhouse gas emissions and particulate air pollution. There has been a substantial amount of policy intervention to help improve energy efficiency and home heating, through programmes such as EECA's EnergyWise home insulation retrofitting and 'clean' heater subsidy schemes. However, it is unclear how effective these are at present.

There is a large amount of theory to apply to understanding barriers to residential energy efficiency in New Zealand - this is reviewed in the next chapter. However, as acknowledged above, there exists little empirical research into the complexities of the demand side at present. While the MfE's Warm Homes Project reports (Smith, et al., 2005a; 2005b) have taken one step towards identifying social barriers to efficient home heating, there is a dearth of information about how New Zealanders themselves value energy efficient heaters, and about how they are making choices about home heating.

Work by Cupples et al. (2007) has identified that a cultural norm exists to live in cold homes, drawing on the oft depicted stoic Kiwi, and how this identity construction may hinder the uptake of energy efficiency heating. This illustrates how the dynamics of energy demand are embedded in social processes. Therefore, residential energy efficiency is likely to not only depend on the technologies available, but also on how people take up these technologies and the behavioural factors that influence this (Jackson, 2005). Research that investigates directly what people are thinking about, by asking the people themselves, may be able to provide a deeper and more meaningful picture of residential energy efficiency choices - this thesis aims to fill this research 
gap in the area of home heating. First though, the next chapter reviews approaches to understanding how people make consumption choices within the context of environmentally significant behaviour, ultimately informing the methodology of this thesis. 


\section{Understanding consumer choice}

Understanding how consumers make choices is an important issue for environmental management and for exploring the energy efficiency gap. There is much psychological and sociological research on explanation of behaviour. Economics is, however, the field most drawn on in policy development. These approaches to understanding behaviour not only hold different factors responsible for choice; they also provide differing accounts of how social and individual change comes about (Jackson, 2005). Not surprisingly, the different approaches to behaviour imply different ways of perceiving and influencing the barriers to consumer change.

This section outlines rational choice theory, non-rational choice approaches such as described by psychological models, and diffusion of innovation and social learning perspectives. This section then discusses the implications of these for policy, followed by a review of integrated approaches to understanding consumer behaviour. This chapter draws substantially on Tim Jackson's (2005) Motivating Sustainable Consumption.

\subsection{Neo-classical approach - rational choice}

Rational choice theory - closely linked to neo-classical economic theory - asserts that humans act so as to maximise their individual utility for any particular action. A prominent strand of rational choice theory is consumer preference theory, which asserts that any consumer choice is a function of the consumer's available income, the cost of the good or service, the assumption of utility maximisation and the consumer's own preferences or tastes (Begg, et al., 2003).

Rational choice theory is predicated on the idea that people are both able to make calculations to assess the costs and benefits of an action, and have the necessary information to make the decision. However, people may display bounded rationality in their decision making (Simon, 1957; Kahneman, 2003). This is due to a number of factors including difficulty in computing, difficultly in collating information and other transaction costs, the use of heuristics (rules of thumb) (Tversky and Kahneman, 1973), the role of social norms and peer pressure (what other people are thinking and doing) (Cialdini, et al., 1990), 'satisficing' (Simon, 1956), and the role of values, worldviews, beliefs and attitudes (Dunlap and Van Liere, 1978; Dunlap, et al., 2000).

While consumer preference theory may be able to explain choices for simple goods, it is weaker at explaining more complex choices with social or ethical dimensions - for instance, behaviours that are not in the agent's apparent short-term rational self-interest. Here there are motivations other than utility maximisation, such as altruism, biospheric and pro-social motivations. 


\subsubsection{Implications for intervention}

The neo-classic perspective on policy intervention for energy efficiency is predicated mainly on the presence of imperfect and asymmetric information and financial barriers (Wittmann, et al., 2006). Consequently information programmes have proved to be particularly popular within energy efficiency public policy (Newell, et al., 2006). However, they are not an effective way to address behaviour change (McKenzie-Mohr and Smith, 1999).

Two information failures tend to be identified for residential energy efficiency: a lack of understanding of the benefits of energy efficiency and a difficulty in obtaining the information needed to help bring about change, once people have recognised the need for it (de T'Serclaes, 2007). Because people tend to buy new technologies such as home heaters infrequently, there is an added difficulty of understanding new technologies that have emerged since the previous purchase (Wittmann, et al., 2006). Furthermore, understanding energy consumption may not be an easy task for consumers. Price and consumption data are often difficult to acquire (Hewett, 1998) and difficult to analyse, as the consumer receives energy services but is billed on the basis of electricity consumed in the aggregated and "irrelevant" kilowatt hours, which does not promote understanding or feedback on energy use behaviour (Kempton and Layne, 1994, p. 857). Moreover, bills are often based on 'estimated' use.

Rational choice theory also recommends for policy development the use of incentives and penalties as a way to bring about pro-environmental change. A lack of uptake of energy efficiency measures has been attributed to high discount rates. Studies indicate that implicit discount rates for space heating range from around 20\% up to nearly 130\% (Hausman, 1979; Dubin and McFadden, 1984; Ruderman, et al., 1987). Furthermore, there is indication that the upfront costs of purchasing residential energy technologies are more important than ongoing operating expenses and may constrain technology uptake (Hassett and Metcalf, 1995; Jaffe and Stavins, 1995). Therefore, policy needs to underline to the consumer the longer term environmental, health and other wider benefits of energy efficient heating.

\subsection{Beyond rational choice}

The imagining of consumers as rational decision makers may be simplistic and misleading for designing effective policy intervention. The reliance on the consumer-preference model steers policy development towards information provision, and while information may be lacking or access asymmetric, even when information is provided, people may not necessarily heed it and make the 'rational' choice. And while financial constraints factors may have an affect on a consumer's utility calculations, monetary motivations may be reliant on the impact of other conditions. 


\subsubsection{Psychological approaches}

Psychology has supplied a large body of research and models of why people do not act in a rational manner and instead make choices on the basis of a great number of other factors, including attitudes, norms, values and beliefs about ability to act. Models range from the Theory of Reasoned Action and the subsequent Theory of Planned Behaviour (Fishbein and Ajzen, 1975; Ajzen, 1991) to the New Ecological Paradigm (Dunlap, et al., 2000), Schwartz's Norm Activation Theory (Schwartz, 1977) and the Value-Belief-Norm model (Stern, et al., 1999). The application of these models in the prediction of behaviours constitutes the psychological approach to understanding environmentally significant behaviour. While it is not possible to explain and evaluate the many psychological approaches, this section reviews the principles behind a select few and their relevance for policy development.

\section{Values, beliefs and attitudes}

Beliefs and attitudes play a role in decision-making. Generally, these are considered to be based on a person's values (Schultz and Zelezny, 1999), which themselves are defined as "important life goals or standards that serve as guiding principles in life" (Poortinga, et al., 2004, p. 71).

Therefore identifying values, and the attitudes they help form, is important for understanding motivations where behaviours are of environmental significance. For instance, application of the New Ecological Paradigm (NEP) (Dunlap, et al., 2000) in a study of why people chose to take part in a 'green' electricity scheme indicated that the factors most likely to predict participation were bio-altruistic and pro-social (altruistic) attitudes (Clark, et al., 2003). Attitudes towards frugality have also been identified as important in determining energy efficiency behaviours (Fujii, 2006). And frugality may be of great importance in the pursuit of sustainability (Smil, 2002).

The Theory of Planned Behaviour (TRA) holds that awareness of outcomes means that behavioural intentions will translate into action. Therefore, behavioural change programmes based on the TRA aim to change attitudes towards a behaviour in order change the intention to act. However, intentions are not always translated into action. For instance, a positive attitude toward energy efficiency does not necessarily predict reduced energy consumption (Ritchie, et al., 1981). The Theory of Planned Behaviour (TPB) recognises this and consequently adds a 'perceived behavioural control' variable to the TRA. However, these models exist within a paradigm which may be too close to the assumption of human rationality (Jackson, 2005). Furthermore, the underlying emphasis on individual self-interest does not reflect the role of norms and morals in choice. Attempts to make the TPB better reflect normative and moral influences have improved its predictive power (Manstead, 2000). 


\section{Normative approaches}

Normative and moral approaches encompass considerations beyond self-interest. Personal norms are internalised personal standards, while social norms refer to other people's standards (Stern, 2005). Social norms can be either descriptive - acting out a usual behaviour - or injunctive acting out what ought to be done (Cialdini, et al., 1990). Social norms may explain why people participate in pro-environmental actions even though they may not be predisposed to take action. For example, Viemeir and Verbeke (2006) found that social pressure through norms best explained why young people intended to buy sustainably produced food.

The most widely applied model of normative conduct is Schwartz's (1977) Norm Activation Theory (NAT). In both NAT and the later Value-Belief-Norm theory (VBN) (Stern, et al., 1999), it is the awareness of consequences (AC) and the ascription of responsibility (AR) that trigger a personal norm to act. Because the VBN model also considers the role of altruistic and biospheric attitudes, it underlines that "personal norms to take pro-environmental action are activated by beliefs that environmental concerns threaten things the individual values (AC) and that the individual can act to reduce the threat (AR)" (Stern, 2000, p. 413). ${ }^{7}$ The VBN is supported by research indicating that personal norms best explain people's disposition to act in a proenvironmental manner (Widegren, 1998; Bratt, 1999; Stern, et al., 1999). Research combining the NAT with the TPB suggests that the combination of the personal-normative variable of the former and the perceived behavioural control variable of the latter can be powerful. For example, these were the only significant predictors of commuting transport intentions, indicating that combining models has some value predicting behaviours that the individual models alone lack (Wall, et al., 2007).

\subsubsection{Diffusion of innovation}

Another way of understanding how people make choices that has particular relevance to energy efficiency is the theory of the diffusion of innovation (DoI). This is the process by which technology is communicated, over time, amongst members of a social system (Rogers, 2003). The theory argues that "the public['s] relationship with technologies is influenced by a range of factors ... strong enough to change the trajectory of technology uptake and, in the case of low emission energy technologies, the path of emission reductions" (Littleboy, et al., 2006, p. 6). The DoI is not a linear process; it is instead an ongoing process wherein social influences shape the development of technologies and these technologies in turn shape society.

\footnotetext{
${ }^{7}$ Concern about the environment has been likened to the NAT model's 'awareness of consequences' factor, in that concern about the environment is likely to activate people's norm to act in a pro-environmental way (Garling, et al., 2003; Fujii, 2006).
} 
Conventional economic theory assumes that tastes are essentially fixed and therefore the rate of diffusion of innovation is determined by price and information. However, diffusion may also depend on how "individuals engage in understanding the technology, which is more a function of social processes than straightforward information acquisition" (Niemeyer and Littleboy, 2005, p. 53). DoI theory thereby acknowledges heterogeneity of preferences within the population. This factor may go some way to explain why technologies may appear superior to some consumers and are therefore adopted, but remain inferior to (and therefore not adopted by) other consumers (Jaffe, et al., 2002). Uncertainty may also impede the adoption of innovative technology. Energy efficiency technologies, including heaters, are often high in cost, large in size and complex to install, and so uncertainty may be high (Hassett and Metcalf, 1993). Therefore, there exists a complexity in how people take up technologies that the fixed-preference characterisation of neoclassical economic theory does not acknowledge.

Diffusion of innovation theory indicates that decision-making is centred "on the influence of an innovation's attributes on attitude formation" (Wilson and Dowlatabadi, 2007, p. 179). This may or may not be linked to social learning processes. For example, Ball et al. (1999) found that it was interpersonal communication and not the attributes of the good that best explained people's consideration to adopt energy efficient lighting and refrigerators. Therefore it may be the representation of the attributes of the good rather than the attributes themselves that is important.

\subsubsection{Sociological approaches}

Sociological approaches to understanding behavioural choices look at the role of social structure and interaction in the construction of identity and choice. These sometimes criticise psychology for removing people and their decision-making from their social context (Crosbie, 2006). ${ }^{8}$

Understanding social structure is particularly important as it can "continuously create and recreate a set of routine practices ... which become so much a feature of 'normal behaviour'" (Jackson, 2006, p. 377). The social structuration of behaviour and ideas of 'self' explicitly deny the imagining of humans in rational choice models. While care must be taken to avoid the concept of social determinism, these approaches posit that cultural normative beliefs shape the way in which people react to environmental problems. Energy research in this area include understandings of how socially constructed ideas of air pollution may affect policy (Bickerstaff and Walker, 2003), the interaction between identity formation, heating choices and cultural understandings of comfort (Wilhite, et al., 1996; Cupples, et al., 2007), and the uptake of new heating technologies (Henning, 2004).

\footnotetext{
${ }^{8}$ Social psychological approaches aim to bridge this gap, emphasizing the role of agency and reflection as well as social influence. For a more detailed understanding of social psychology and its resonance for environmentally significant behaviour, see Jackson (2005).
} 


\section{Social learning theory}

One sociological approach of potential importance is social learning theory, whereby people learn from others through observing and following their behaviour (Bandura, 1971). This does not imply mimicry of others' behaviours; rather, social learning is the process of taking the essential elements of another's behaviour and adapting them to one's own situation (Rogers, 2003). People do not learn from others in a consistent manner - we tend to learn most effectively from models who are influential or attractive to us such as parents, celebrities, people of power and respect, or people who are similar to ourselves (Jackson, 2005).

Social learning theory supposes that both external influences and internal motivations affect a person's action (Darby, 2006). Most important to this theory is the mechanism of self-efficacy - a person's belief in their ability to control circumstances that affect their lives. Social learning theory suggests that peoples' self-regulatory and reflective abilities mean that we can continue to adapt and change how we react to the world. Application of social learning theory to environmental management does not appear to be widespread at present. ${ }^{9}$ However, social learning may be important for long-term sustainability as it describes an ongoing process through which it is possible to promote energy efficiency choices (Darby, 2006).

\subsubsection{Implications for intervention}

In the short term, Gardner and Stern (2002) suggest that education and information are most useful when the main barriers to action are internal to the consumer. However, in the long term, education and information may have positive effects on knowledge and attitudes (Gardner and Stern, 2002; Abrahamse, et al., 2005). Therefore the question is, how best to provide information?

Following social learning theory, information provision should ensure that credible and influential sources are used (Jackson, 2005). For instance, research indicates that New Zealanders view the government and scientists as highly trusted sources of information about the environment (Cullen, et al., 2006). Information provision can use existing social networks to spread information to allow diffusion of information and technology to occur through these already trusted and accessible channels (Gardner and Stern, 2002; Uzzell, et al., 2006). These principles are reinforced by Stern, who argues that information is most likely to be effective when it is provided at the "time and place of decision, is linked to available choices, is delivered from trusted sources, and is delivered personally" (Stern, 2005, p. 10789). Moreover, information provision needs to be aware of cognitive dissonance (Festinger, 1957). This comes about where a person holds two cognitions that are psychologically inconsistent, causing the person attempt to reduce the dissonance by changing one or other cognition (Massaro, 1997). Where a person's pro-

\footnotetext{
${ }^{9}$ There is some application of social learning theory to water management (Pahl-Wostl, et al., 2007; 2008).
} 
environmental attitudes and actions do not align, care must be taken to ensure that information promotes that the action is changed to match the attitude, and not the other way around.

Feedback is a means of both linking residential energy use behaviour to energy use (making energy use visible) and providing motivation to conserve. Both social learning and the theory of diffusion of innovation indicate that the provision of feedback may be important in supporting positive attitude formation (Wilson and Dowlatabadi, 2007). Providing feedback on energy use and savings is also important in reducing household energy consumption (Brandon and Lewis, 1999; Gardner and Stern, 2002).

The acknowledgement of the heterogeneity of people's preferences by these models means that policy intervention needs to respond differently to consumers with different attitudes and preferences, or at least provide a range of responses (Egmond, et al., 2006). This may include promoting positive attitudes towards resource frugality as one way of improving resource use efficiency (Fujii, 2006). However, reducing residential energy use may have side-effects, for instance where heating is below WHO (1987) recommendations, so any promotion of this attitude in policy would have to be differentiated and undertaken with care.

\subsection{Integrative approaches}

One problem that these theories face is acknowledging the role of both external and internal variables. For instance, while attitudinal (internal) variables may explain some part of people's motivations to act, they may be too limited to explain environmentally significant behaviour (Poortinga, et al., 2004). For example, a study of energy conservation in Massachusetts households found that $59 \%$ of the small reductions in household temperature could be attributed to attitudes of the householder, but attitudes were responsible for only $25 \%$ of variation in major energy efficiency investments, indicating that other barriers are present (Black, et al., (1985) cited in Gardner and Stern, 2002). Though external constraints may be implicit in variables such as perceived behavioural control (Theory of Planned Behaviour), more explicit recognition of internal and external factors and their interactions is required. A number of calls for the need to develop an integrated and interdisciplinary understanding of environmentally significant behaviour and energy demand have been made (Stern, 2000; Henning, 2004; Wilson and Dowlatabadi, 2007).

\subsubsection{Attitude-behaviour-context model}

The Attitude-Behaviour-Context (ABC) model takes a social psychological approach to decisionmaking, acknowledging both external and internal determinants of behaviour and identifying four types of variables (see Table 1) (Stern, 2000). 
Table 1. Attitude-behaviour-context model. Source: Stern (2000)

Attitudinal factors: beliefs, values, attitudes, perceived costs and benefits of action;

Contextual forces: institutional factors, monetary incentives and cost, social norms, infrastructural capacities and limitations;

- Personal capabilities: skills, availability of resources such as literacy, money and social status; and

Habit or routine.

These different variables apply to different behaviours in different ways. For instance, where initial capital costs are high, such as for the purchase and installation of a new heat pump, the contextual factors and personal capabilities may be more important than attitudinal factors in determining action than when the behaviour requires purchasing a good of lower cost. Earlier research into recycling behaviours by the same authors found evidence to support this model (Guagnano, et al., 1995). The recognition of habit and routine in the ABC model is also potentially important. Habits are essentially bypasses to cognitive thought (Jackson, 2006). This means that much habitual behaviour is made without consideration of costs and benefits, as rational choice models would assume.

The ABC model has helped inform Gardner and Stern's (2002) causal model of resource consumption behaviour, described in Table 2 below.

Table 2. A causal model of resource-consumption behaviour with examples from residential home heating. Adapted from Gardner and Stern (2002)

\begin{tabular}{|c|c|c|}
\hline Level of causality & Type of variable & Examples \\
\hline 7 & Household background & $\begin{array}{l}\text { Household income, number of household } \\
\text { members, education }\end{array}$ \\
\hline 6 & $\begin{array}{l}\text { External incentives and } \\
\text { constraints }\end{array}$ & $\begin{array}{l}\text { Energy prices, split incentives, technological } \\
\text { availability, capital costs, social norms }\end{array}$ \\
\hline 5 & Values and worldviews & $\begin{array}{l}\text { Biospheric, altruistic, post-materialistic, } \\
\text { egotistic }\end{array}$ \\
\hline 4 & Attitudes and beliefs & $\begin{array}{l}\text { Awareness of energy security situation, } \\
\text { ascription of personal responsibility for } \\
\text { reducing emissions }\end{array}$ \\
\hline 3 & Knowledge & $\begin{array}{l}\text { Knowing how to operate wood burner } \\
\text { efficiently }\end{array}$ \\
\hline 2 & $\begin{array}{l}\text { Attention, behavioural } \\
\text { commitment }\end{array}$ & Remembering to store and dry wood for fuel \\
\hline 1 & $\begin{array}{l}\text { Resource-using or resource- } \\
\text { saving behaviour }\end{array}$ & Decreasing use of heater, using thermostat \\
\hline
\end{tabular}


In this model, the interactions between the variables are important, though these are not represented in the figure. However, the ordinal conceptualisation of levels of causality may be problematic - it is arguable that household background variables such as household income have more or less causal effect on behaviour than, for instance, knowledge or attitudes. Similarly, it is important to recognise that values, beliefs, attitudes and world views can be post-rationalised in terms of the context or situation people find themselves in. For example, someone who finds themselves greatly concerned about climate change may feel frustrated by their inability to do what they feel may make a difference because of other variables, such as the under-availability of appropriate technology. This may then feed back to attitudes, to reduce cognitive dissonance (Festinger, 1957).

\subsubsection{Implications for intervention}

An integrated approach, acknowledging the interactions between variables, means solution strategies can best take the approach of addressing a combination of factors (Gardner and Stern, 2002). It provides a pragmatic guide to investigating environmentally significant behaviours, such as residential energy consumption choices.

One method for bringing about pro-environmental change that draws on an integrated understanding of barriers is social marketing. Social marketing has been described as "tightening the link between attitude and behaviour - using reminders and prompts, getting public commitment, and highlighting attitudes and norms" (Gardner and Stern, 2002, p. 85). This includes the use of community-based social marketing programmes, which explicitly identify and then address the barriers to pro-environmental action, such as habits, on a case-by-case, small scale basis (McKenzie-Mohr and Smith, 1999). Community level intervention may also be appropriate for cases where domestic social norms hinder adoption of more efficient technologies or behaviours (Wilson and Dowlatabadi, 2007).

\subsection{Summary}

While conventional economics can explain how people make some choices, it falters in handling bounded rationality and it cannot well explain consumption choices that reflect social factors such as citizenship. In this case, psychology has provided a number of explanations, though there are many competing descriptions, and which model best describes consumer choice is a matter of ongoing debate (Stern, 2005). There is evidence that social norms are particularly important in determining people's behaviours that have pro-environmental outcomes (Widegren, 1998; Bratt, 1999; Stern, et al., 1999; Viemeir and Verbeke, 2006). There is also evidence that attitudes and beliefs are also important drivers of pro-environmental consumer choice (Clark, et al., 2003; Garling, et al., 2003; Fujii, 2006). However, studies that have combined normative and expectancy-value theories have indicated that combinations of these factors better predict 
behaviour than any one model alone (Manstead, 2000; Wall, et al., 2007). It appears from this review that the awareness of consequences and the ascription of responsibility are particularly important in choice.

Social psychology models, such as social learning theory, emphasise the role of reflection and thought in the way that people learn. The role of self-reflection and agency (Bandura, 1971) is particularly important to underline and is a factor missing from behaviouralist models of choice, which tend to posit that people's choices are a reaction to environmental stimuli (Crosbie, 2006; Darby, 2006).

Integrated approaches that acknowledge both external and internal determinants of behaviour can provide better real-life descriptions of how people make choices. While it may be possible to elucidate and understand the different contributing factors to behaviour, it is their interaction and their context which produce actual behaviour. This chapter indicates that the way in which people interact with technology is a complex social and psychological process, and needs to be understood from a number of dimensions. Given these approaches to understanding consumer choice and the need for interdisciplinary investigations of energy demand, the next chapter outlines how these might be investigated. 


\section{Exploring consumer choice}

This chapter examines methods for how consumer choice may be investigated. As informed by the previous chapter, this is based on the understanding that people will make decisions based on a range of factors, so that while financial constraint and cost is important in consumer choice, there are also other factors to consider. Subsequently this chapter is split into two parts - firstly, it investigates how to value goods, such as energy efficient heaters, that embody a range of environmental goods, and secondly, looks at how to explore non-economic motivations.

\subsection{Valuing environmental goods}

Energy efficient technologies embody many values, including environmental benefits.

Understanding how people value such goods is one way of understanding how consumers make choices. This chapter outlines methods for establishing the value of goods with non-market value and looks in particular at the role of contingent valuation for this task. It then outlines the willingness to pay technique of contingent valuation and its application in energy studies.

\subsubsection{Market and non-market goods}

Markets can only place value on certain goods while many others, including most environmental processes and services, cannot adequately be traded in the market. Marketplace provision depends on whether the good in question is excludable and rival, and many environmental goods and services do not fit this category (Vatn, 2005). The recognition by economists of the existence of these public or non-market goods such as environmental services can be traced back to the work of Clark (1915) and Hines (1951) (Carson and Hanemann, 2005).

\subsubsection{Non-market valuation}

Finding an economic value for non-market goods can be approached through two methods: using revealed preferences (observed behaviour) or using stated preference models (hypothetical behaviour). ${ }^{10}$ Revealed preference approaches include hedonic pricing and travel cost models while stated preference methods include contingent valuation (Tietenberg, 2006). Non-market valuation techniques are based on the assumption that it is possible to place a monetary value on an environmental good. This assumes that peoples' values of the good are commensurable into a single metric value, which may be problematic where there are ethical or moral dimensions to choice (Vatn, 2005). However, these methods can produce a picture of valuation that is pragmatic and useful for policy.

\footnotetext{
${ }^{10}$ Economic approaches to the environment and non-market valuation are not without their critics - for an interesting review of environmental values literature from a broader perspective, see Kalof and Satterfield (2005).
} 
Both forms of non-market valuation have their advantages: contingent valuation asks people to put a hypothetical price on the full range of benefit streams of a good or service, including those benefits not currently recognised by the market. Alternatively, by being based on actual behaviour, revealed preference methods avoid the problem of relying upon people's ability to sufficiently translate the range of benefits they perceive into a hypothetical value.

Hedonic pricing works on the principle that environmental values can be determined from the market price of goods whose value varies depending on the environmental characteristics of the good. However, hedonic pricing assumes that consumers already understand the value of the environmental characteristics of the good; this is an assumption contingent valuation addresses through informing consumers as to the trade-offs to be made (Vatn, 2005). The travel cost method is based on people's 'willingness to travel' to consume goods - this requires the type of good or service that can be travelled to, and so is not appropriate for this thesis. Contingent valuation is, therefore, a more appropriate method for elucidating the total value of a good such as home heaters in a situation where households are not directly facing an actual consumption choice (as explained below).

\subsubsection{Contingent valuation}

Contingent valuation $(\mathrm{CV})$ requires people to put a monetary value on a good or service under investigation. Studies are conducted by informing participants of the streams of benefits of a good and then asking them in a survey to indicate their willingness to pay (or accept compensation for) the good in question. The contingent valuation method is a popular but controversial tool (Carson, et al., 1995). ${ }^{11}$ Some economists do not like to employ surveys to gain an understanding of value, instead preferring revealed preferences as the use of survey is argued to be a process that creates values, and does not measure consumer economic preferences (Diamond, et al., 1993; Diamond and Hausman, 1994; Hanemann, 1994). This means that CV does not fulfil the utility maximisation principle; while it is widely regarded that $\mathrm{CV}$ includes measures outside individual utility, whether this is a problem or not for neo-classical economics and policy is a matter of contention (Veisten, 2007). Others question whether CV studies have any reference to actual behavioural intentions, or whether the hypothetical nature of the method is just that (Meyerhoff, 2006). Criticism also comes from social science, where the method, "insofar as it tries to make respondents express preferences rather than deliberate about ideas, denies their status as thinking political beings" (Sagoff, 1988, p. 88). Others, though, claim that people act as political beings in $\mathrm{CV}$, and not preference-driven in the neo-classical rational sense (Faber, et al., 2002).

\footnotetext{
${ }^{11}$ For example see the fourth issue of the 1994 Journal of Economic Perspectives.
} 
A number of methodological biases in CV have been identified (Tietenberg, 2006). Strategic bias occurs where a response is given in order to influence a particular outcome, and may particularly be a problem where a respondent feels there is a socially desirable response. Information bias occurs where participants are asked to value a good or service about which they are uninformed or have little experience. Tietenberg's (2006, p. 39) comment that this may lead to an "entirely false perception" of value is hyperbolic, especially given that many market choices are also relatively uninformed. However, a respondent's lack of knowledge about a CV situation creates hurdles that the researcher must address in order to maintain the validity of their study. Starting point bias arises when a respondent is asked to indicate how they value a good according to cost-bands (e.g. $\$ 100-200)$ and may create difficultly when interpreting results.

In the wake of the 1989 Exxon-Valdez oil spill, during which CV was used with some controversy, a panel was set up by the United States of America National Oceanic and Atmospheric Administration (NOAA) in order to enquire into the validity of CV (Arrow, et al., 1993). The NOAA panel validated the use of CV but also developed a set of requirements for CV studies (see Table 3). Conducting research in the field is, however, not always as straightforward as following the rules below. While the ruling of the NOAA panel effectively gave the green light to $\mathrm{CV}$, some authors have criticised the requirements, describing them as too prescriptive (Green and Tunstall, 2001). Hence, the NOAA recommendations can be used as principles that support, but do not dictate, the development of a CV study. In particular, it is important that studies emphasise participant understanding (Markandya and Richardson, 1993; Hanemann, 1994; Plott and Zeiler, 2003). Some understanding of economic value via the contingent valuation method, is, therefore, better than none.

Table 3. NOAA panel recommendations. Source: Arrow et al. (1993)

1. An introduction;

2. Questions on prior knowledge and established attitudes towards the situation;

3. Indication of how the CV scenario will be implemented and paid for and an outline of the status quo;

4. Questions on the participant's willingness to pay for the good;

5. A debrief to establish how well the participants understood the scenario; and

6. Demographic questions.

\subsubsection{Willingness to pay and willingness to accept}

Willingness to pay (WTP) and willingness to accept (WTA) are the tools by which contingent valuation establishes valuation of a good. Willingness to pay is used to measure the value of a good in a situation where an agent wishes to acquire a good; willingness to accept is the value of a good when the agent already has the good and is being asked how much compensation is 
required in order for her/him to give it up (Carson, 2005). Green and Tunstall (2001) argue that WTP reflects the interaction of taste and ability to pay:

$$
\mathrm{WTP}=\text { preference or taste*ability to pay }
$$

This explanation is, however, highly simplified, and obscures the number of factors likely to affect WTP values. For instance, there is evidence that people with strong pro-environmental and biospheric attitudes may have higher WTP values than those with weak pro-environmental attitudes (Aldrich, et al., 2005; Hansla, et al., 2008).

\subsubsection{WTP-WTA disparity}

At an early stage in the use of $\mathrm{CV}$, it was discovered that there was often a disparity between WTP and WTA when valuing the same good (e.g. Hammack and Brown, 1974). The magnitude of this disparity differs greatly in literature - one review found that WTA is on average around seven times higher than WTP (Horowitz and McConnell, 2002), whereas other authors argue that there is no disparity, only artefacts of poor process (Plott and Zeiler, 2003).

The disparity has a number of explanations. Markandya (1993) argues that the calculation of WTP is constrained by a person's income while WTA is not. Others suggest that the disparity may be due either to a weak survey method meaning that preferences are not adequately captured, or that participants do not have neo-classical preferences (Horowitz and McConnell, 2002). There is also evidence that the WTP and WTA values tend to diverge in studies of non-market goods (which often do not have good substitutes), whereas values tend to converge in the case of common market goods with close substitutes (Shogren, et al., 1994). Plott and Zeiler (2003) found no support for a WTP-WTA divergence, though this study used common market goods with close substitutes, which Shogren, et al., (1994) indicate are not the type of good likely to show a divergence. The quality of information given to contingent valuation participants has also been proposed as a driver of the WTP-WTA divergence, though research provides conflicting findings (Plott and Zeiler, 2003; Zarnikau, 2003).

The psychological explanation for the disparity is that people are more averse to a loss than they are to the equivalent gain. This theory, formally presented by Kahneman and Tversky (1979), is known as prospect theory. Social science suggests that people are around twice as averse to a loss of a particular amount as they are to a gain of the same amount (Layard, 2005), and will consequently give higher WTA values than WTP values for the same good. 


\subsubsection{WTP and energy efficiency}

WTP in energy studies has found considerable application in WTP for 'green'/renewable energy generation (e.g. Roe, et al., 2001; Zarnikau, 2003; Nomura and Akai, 2004; Longo, et al., in press), but there also exists some literature on energy efficiency. Studies of energy efficiency measures in homes, including insulation, indicate that WTP values are close to or exceed the actual market costs of these measures (O’Dea, et al., 2005; Banfi, et al., 2008). Given this, and given that the value of the many health and energy benefits associated with improved insulation in homes are likely to exceed the market value of insulation, the former authors ask "is it rational for households not to have installed such insulation?" (O'Dea, et al., 2005, p. 13). The way in which we understand this rationality is related to the paradigm of understanding consumption choices, as described in the previous chapter. Put another way, WTP/WTA values may give us an additional insight into the sort of preferences and other factors at work in heating choices.

\subsection{Socio-behavioural motivations}

The CV method aggregates values into one representative value. While this may be useful for policy, this process obscures any heterogeneity of attitudes and preference and the difference in the way people adopt behaviours, something acknowledged by approaches outside conventional economics (e.g. Rogers, 2003). Interventions based on this homogenisation through aggregation may be unable to adequately address different consumer preferences (Wilson and Dowlatabadi, 2007).

To further investigate how people are making choices about heating their homes from a perspective that acknowledges socio-behavioural factors in decision-making, it is necessary to find a tool that allows for exploration. There have been a number of calls to produce integrated and interdisciplinary approaches to understanding environmentally significant behaviour and energy demand (Stern, 2000; Henning, 2004; Wilson and Dowlatabadi, 2007). Thus this research takes a mixed-methods approach and explores socio-behavioural factors.

While survey techniques have been shown to be useful in energy efficiency research, surveys tend to be relatively limited in scope and depth (Stern, et al., 1987). Psychological approaches that test the applicability of models to particular behaviours have been widely used to investigate environmentally significant behaviours (Stern, et al., 1999; Clark, et al., 2003; Poortinga, at al,. 2004; Viemeir and Verbeke, 2006). However, as noted earlier, these methods tend to analyse people's behaviour and choices as individual units, something that has been criticised for detaching people from their socio-cultural context (Crosbie, 2006).

One method that has been used to explore energy consumption choices and that acknowledges the social context of decision making is focus group research (group discussion). For example, both 
New Zealand research (Smith, et al., 2005b; Cupples, et al., 2007) and international research (Wilhite, et al., 1996; Henning, 2004) into energy efficiency and home heating has been conducted via focus group and group workshop methods. The focus group method allows for investigation and is "ideal for exploring people's experiences, opinions, wishes and concerns" (Kitzinger and Barbour, 2001, p. 5). Focus groups are semi-structured, and tend to be more flexible than survey or interview situations, meaning that the participants can express what is important to them and are not restricted to responding to what the survey writer or interviewer thinks is important (Morgan, 1998). Therefore, this method helps elucidate responses which are more emic (data that arises in it 'natural' form) than etic (data that represents the researcher's idea of the situation) (Stewart and Shamdasani, 1990). However, the self-reporting aspect of the focus group method leaves it open to bias.

Group discussion processes, including focus group research, allow for detailed investigation of the motivations and thinking of the participants in a way that is not possible in interview methods (Morgan, 1998). Furthermore, focus groups are an important method for discovery and exploration in areas where little is known, or, as is the case with this research, where a preliminary picture of a subject is being developed (Stewart and Shamdasani, 1990)

The focus group method is a deliberative evaluation process, a process that requires reflection upon an issue in a group session that is free of coercion (Vatn, 2005). The deliberative nature of focus groups is based on Jorgen Habermas's theory of communicative rationality (Habermas, 1984), centred on the idea that understanding is created through dialogue and argument, so that what emerges is a "form of common reasoning where consensus is obtained by mutual learning, understanding and changed preferences" (Vatn, 2005, p. 351). Allowing and encouraging public participation is an emerging principle of behavioural economics (Dawnay and Shah, 2005). For these reasons, focus groups, along with other participative methods, can be important for policy development that has acceptance amongst the wider community.

\subsection{Summary}

Contingent valuation is a useful form of economic non-market valuation for establishing the value of home heaters as it can capture values currently outside consumer experience. The NOAA panel (1993) recommendations provide a sound basis for the method. In particular, studies should endeavour to provide the participants with the best possible understanding of the CV situation in question (Arrow, et al., 1993; Markandya and Richardson, 1993). The disparity between WTP and WTA is an area of ongoing contention and research (Plott and Zeiler, 2003; Horowitz and McConnell, 2002). While there is considerable debate over the validity of CV as a method and its adequacy (its philosophical basis) for capturing value, it is one way of understanding how people value goods and services that otherwise do not have full or any market description, an advantage 
lacking in revealed preference approaches. Therefore CV provides one tool for policy makers in understanding consumer behaviour, particularly where the goods may have attributes with complex benefits.

While we can suppose that a well-implemented CV study gives us an idea of the non-market value of a good, it is difficult to know what this value constitutes. Social science critics such as Sagoff (1988) suggest that CV denies people the right to deliberate about ideas and is constrained as to the values it can represent. Furthermore, the previous chapter indicated that neo-classical economics' approach to understanding behaviour is short-sighted, though it is arguable whether $\mathrm{CV}$ is really within neo-classical economics or not (Veisten, 2007). Exploring motivations of behaviour is another important facet of understanding choice that can be used alongside CV studies in policy. Given this, the next section explores how to investigate in greater depth how people make home heating choices.

The mixed method approach of this thesis allows for the investigation of another dimension of peoples' home heating decisions. Focus group research is one such method, allowing for exploration of ideas outside the stricture of interview processes. The disadvantages of the focus group method include the potential tendencies for participants to answer with socially desirable responses and that any discussion of behaviours is reported and not observed. However, as the focus group method allows for in depth investigation of motivations within a social context, this method will be used to explore how people are making choices about heating and energy efficiency decisions in their homes. 


\section{Conceptual framework}

Drawing on the literature review, this chapter lays out the conceptual framework for the thesis (Objective 1). This conceptual framework will then be applied to the analysis of the two strands of research in the discussion (Chapter 9).

This investigation takes a pragmatic or applied research approach. Such an approach focuses "attention on the research problem ... and then [uses] pluralistic approaches to derive knowledge about the problem" (Creswell, 2003, p. 11). Because this approach addresses real world issues and adopts a pluralistic, interdisciplinary approach, it is particularly suited to research that aims to make suggestions for policy development (Hogwood and Gunn, 1984). At the same time, pragmatism does not reject theory in favour of purely empirical study.

Theoretically, this thesis is grounded within the study of social science and environmental economics. This area has recently been integrated into economics as behavioural economics, an approach that acknowledges the role of psychological and sociological factors in decision making. These factors, reviewed in the previous chapters are summarised in Table 4 below.

Table 4. Principles of behavioural economics. Source: Dawnay and Shah (2005)

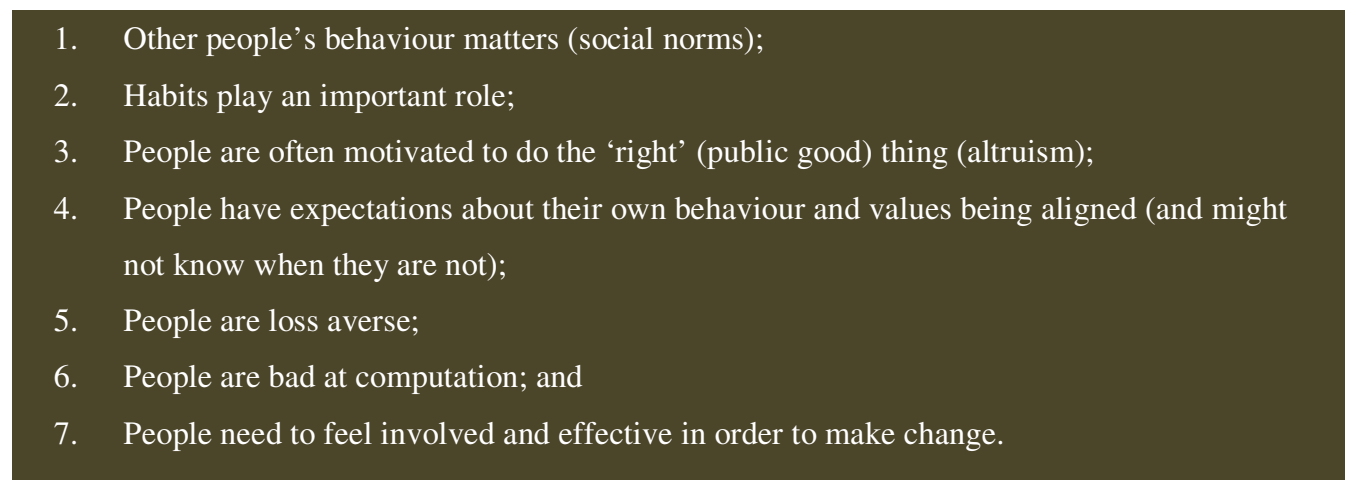

The conceptual framework adopted in this thesis recognises the principles of economics, including the roles of market barriers in consumer decision-making. But it also notes that the conventional economic approach to understanding consumption is simplistic. That people do not necessarily act in an economically rational way, as summarised in Table 4, needs also to be accepted. Therefore, following Jackson (2006), this conceptual framework recognises that consumption choices should be understood as socially constructed, but also acknowledges the existence and importance of agency (Bandura, 1971). The choice of mixed methods also reflects this acknowledgement of both market and non-market motivations in choice, and allows for an interdisciplinary approach to understanding how people make choices about home heating. 
This thesis takes a relativistic approach to environmental valuation. This is in opposition to an axiomatic approach which "operates on the premise that certain categories of value are better, 'truer', more important, necessary to life, self evident and/or intellectually defensible than others, and these priorities should provide the basis from which environmental policy is derived" (Satterfield and Kalof, 2005, p. xxii). A relativistic approach allows for the existence of a range of positions on what constitutes value. This acknowledges heterogeneity of preferences and attitudes - such as those that psychological approaches and the diffusion of innovation model suggest within the general public and the importance of these non-rational motivations in economic decision making, particularly for policy.

While the quantitative research of this study is fairly straightforward - using the contingent valuation approach to establish a monetary value for energy efficient home heaters - finding a way to explore the ways in which people make home heating decisions is more difficult. Taking a pragmatic approach, the qualitative investigation rests principally on a framework of resourceconsumption behaviour developed by Gardner and Stern (2002) (see Table 1). Following Stern's (2000) definition, the qualitative research takes an exploratory approach to people's beliefs, knowledge, norms and motivations with regard to home heating and energy efficiency decisionmaking.

This research recognises that understanding these behaviours is "dauntingly complex, both in its variety and in the causal influences on it" (Stern, 2000, p. 241). Therefore, the conceptual framework used in this thesis, instead of trying to propose any clean description of causality or the significance of any particular variable (driver), acknowledges the existence of a range of variables as defined by Gardner and Stern (2002) and the multiple interconnections and interactions among them. It is clear, however, that behaviour in the area of energy efficiency, motivated as it is partly by environmental aspirations, is complex, and consequently it is difficult to identify a definitive conceptual model.

Like many environmental problems, understanding the interface between people and energy use is highly complex (Capra, 1997). A pragmatic and an interdisciplinary approach, such as that promoted by environmental and behavioural economics, may therefore be a useful way to investigate environmentally significant behaviour. This is in line with calls to develop more integrated and interdisciplinary research into environmentally significant behaviours and energy demand topics (e.g. Stern, 2000; Henning, 2004; Wilson and Dowlatabadi, 2007). Consequently the framework used here recognises the many interconnections between the factors in decisionmaking, but still goes in search of elucidation and exploration of the values, beliefs and norms that exist in New Zealand with regard to home heating. This will help to broaden the understanding that economic methods of valuation such as contingent valuation offer us. 


\section{Methodology}

\subsection{Mixed-method approach}

The empirical part of this thesis falls into two distinct but parallel parts. The two parts comprise a quantitative survey and a qualitative investigation and together represent a form of mixed-method research. Mixed methods research is characterised as being consequence oriented, problemcentred and pluralistic (Creswell, 2003). The manner in which the qualitative data and quantitative data are brought together is through the 'merge' method (ibid). This brings together the findings (Objective 2 and 3 ) in the discussion (Chapter 10), looking towards how policy can promote warm and energy efficient homes for all New Zealanders (Objective 4). The rest of this chapter outlines the two methods employed in this research.

\subsection{Quantitative method - HHHS contingent valuation survey}

The purpose of this quantitative strand of research is to establish how people value energy efficient home heaters using the contingent valuation method (Objective 2). For this, I was given access to data from the University of Otago's Housing Heating and Health Study.

\subsubsection{Housing Heating and Health Study}

The Housing Heating and Health Study (HHHS) of the He Kainga Oranga/Housing and Health Research Programme (University of Otago, Wellington) began in 2005 with the aim of investigating the role of home heating on childhood asthma. Households were recruited from Porirua, the Hutt Valley, Christchurch, Dunedin and Bluff, through a number of community organisations. Participant inclusion criteria were: a 6-12 year old child with doctor diagnosed asthma, living in a home where the main form of heating was either a plug-in electric heater or unflued gas heater. 412 households were recruited and 349 households completed the study (85\% retention rate).

All participating households were offered, in return for their participation, a heating system of their choice to be installed in their home at no cost (a considerable incentive of continued participation). ${ }^{12}$ Participants chose a heater from three different heating systems types that the HHHS researchers elected. These heaters were:

1. flued gas heaters; ${ }^{13}$

2. heat pumps; and

3. wood pellet burners.

\footnotetext{
${ }^{12}$ All participants in houses without insulation had floor and ceiling insulation installed in order to create a 'level playing field'.

${ }^{13}$ Only available to North Island communities due to presence of reticulated mains gas.
} 
Selection of the type of heating system was made by the householders themselves unless the participants were tenants, in which case the choice was made by, or in conjunction with, their landlord. ${ }^{14}$ The study participants were randomly assigned to either the intervention group or the control group after the first year of the study. The intervention group received their chosen heating system after the winter of 2005 (and before the winter of 2006), while the control group received their chosen heating systems after the winter of 2006.

The HHHS collected a wide range of data over 2005 and 2006 - this thesis concentrates on the information collected in the householder surveys. ${ }^{15}$

\subsubsection{Householder Surveys}

Over the course of the HHHS, two householder surveys were completed. Surveys were taken directly to the house of each participating family by a trained HHHS fieldworker and were filled out by a representative of the household. The first questionnaire was completed during September-October 2005, prior to the installation of any heaters; the second was completed at the end of the winter of 2006, during which the intervention group had their chosen heating systems operating whereas the control group did not. Included in both years' surveys was a contingent valuation question.

\subsubsection{Contingent valuation study}

At the outset of the study, all participants were required to attend an information session on the heater options. The HHHS researchers provided written and verbal information on the heater options, as well as providing the opportunity for participants to ask questions about each heating choice from the expert facilitators. Participants were provided with information on:

1. Associations between health outcomes and indoor air quality, particularly in relation to asthma;

2. Outdoor air pollution levels;

3. The 'sustainability' of different heaters; and

4. Access to further work through HHHS.

This information forms the backdrop for the contingent valuation study questions in the householder surveys.

\footnotetext{
${ }^{14}$ All the heaters in the HHHS were permanently installed, hence the decisions for tenants being made in conjunction with landlords.

${ }^{15}$ More information is available on the official website: www.wnmeds.ac.nz.healthyhousing.html
} 
In one sense, home heaters are a market good that have relatively evident personal benefits.

However, in the context of the HHHS, it was clear to participants that heaters also have a range of other potential benefits, particularly for health and the environment (typically non-market values). It was this broader sense of value that this exercise sought to elicit from participants. The 2005 willingness to pay study data represent the valuation of all the study participants before their new heaters were installed; the 2006 willingness to pay data represent the control group's valuation of the heaters, still before they were installed; the 2006 willingness to accept represents the value that the intervention group placed on their new heaters. In 2006, the survey question for the control group read:

29. Bii) We would like to measure how much your household values your new heater. One way of doing this is to imagine how much you would pay for your new heater. (In fact, the heater will be free to you - you will not be asked to pay). Would this be:

Nothing

$\$ 1-300$

$\$ 301-1000$

$1001-2000$

2001-5000

over $\$ 5000$

For a copy of all questions in the survey used in this thesis, see Appendix 1.

Other questions from the survey are also used in this thesis, including asking people to rank, on a Likert scale, how important a list of issues were to them when they chose their study heater, and the trade-off between heating and saving money would people make upon the installation of their new heater. This information was used to supplement the contingent valuation data. Demographic information was also used.

The HHHS researchers provided me with the raw data from the householder surveys and other demographic data. This was then analysed using Excel and SPSS. The results and analysis of this can be found in Chapter 8 . 


\subsection{Qualitative method - focus groups}

The purpose of the focus group process was to explore and elucidate people's motivation for and choices about home heating (Objective 3).

\subsubsection{Focus group set-up}

For practical reasons, this research population was limited to one urban area, therefore the target population is the Wellington general public over the age of 18 years. ${ }^{16}$ Because of the breadth of this population, three Wellington suburbs were targeted: Newtown, Mount Victoria, and Karori. These suburbs were selected due to their different demographic profiles (see Appendix 3). To recruit participants, flyers were placed in community centres, shops, libraries, crèches, churches, cafes and other well frequented places in the selected suburbs, and a small article was placed in local newspapers. This allowed for the targeting of the specific suburbs chosen for the study. Attendance at the sessions was incentivised by offering the participants a $\$ 20$ supermarket voucher.

Permission for this research was sought and granted from the Victoria University Human Ethics committee (Ethics Approval number 15 243). A copy of the ethics approval and the relevant documentation for the research participants and the group facilitator is available in Appendix 2.

Two focus groups were held with a total of 13 participants. While this is a small number, focus group research is often characterised by a small numbers of groups and being statistically representative is not the aim of focus group research (Strauss and Corbin, 1990; Kitzinger and Barbour, 2001). The MfE Warm Homes project (Smith, et al., 2005b) undertook a total of four group discussion sessions. The method of recruitment is self-selection, and consequently there is a problem of response bias. Those choosing to participate in the focus groups may be disposed to be more concerned or interested in home energy efficiency than the wider public. While particular suburbs were targeted because of their difference demographic profiles, it is not the expectation that these groups are 'representative' of the wider population of Wellington.

\subsubsection{Focus group themes}

The focus group discussions followed three basic themes, in which each contained a series of questions. These are outlined below.

\footnotetext{
${ }^{16}$ The qualitative section of this research did not go back to participants of the HHHS due to concerns that this group may be overtly aware of health considerations, due to the nature of the HHHS itself.
} 
Theme 1: Household heating and energy use - choices and values

- How do you heat your home?

- When you heat your home, what factors are important to you?

- e.g. When choosing a heater for your home, what factors are important?

Theme 1 opened with a relatively simple question for the participants, providing a way into the discussion. Each participant was asked to introduce themselves to the group and talk about how they heat their home. This theme then aimed to explore further, with the second question, how people value home heating and the factors important in their home heating choices.

\section{Theme 2: Knowledge, attitudes and norms}

Knowledge

- What does energy efficiency mean to you?

- What do you know about the energy you use when you heat your home?

- What do you know about security of electricity supply?

Attitudes and beliefs

- What role do you think your home heating plays in climate change? (or other issue)

- What role do you see your heating choices play in possible solutions to climate change?

\section{Social norms}

- What do you think is important to other people in their home heating choices?

- Are there any ways of heating that you think aren't acceptable? e.g. If a friend heated their house through opening the door to their gas oven, how would you feel? How would you respond?

The Theme 2 set of questions was designed to explore some of the motivations behind home heating and energy use behaviours, as described in the conceptual framework above. The attitudes and beliefs questions reflect the factors identified in the NAT and VBN model the awareness of consequences and the ascription of responsibility (Schwartz, 1977; Stern, et al, 1999).

\section{Theme 3: Role of information and how people learn about energy efficiency}

- How do you learn or seek information about energy efficiency and home heating?

- Who do you feel you trust to ask about these matters?

This question aimed to explore the role of information in energy efficiency choices. Within energy efficiency studies, a lack of understanding of the benefits of energy efficiency has been noted (PCE, 2000; Smith, et al., 2005b; Oxera, 2006; de T'Serclaes, 2007). While the literature review indicates that the consumer-preference theory that information provision is based on is too simplistic, ensuring that consumers are well educated about their decision still has an important 
role to play in policy development. Therefore, information needs to be well targeted and be responsive to the other behavioural factors at play in consumers' decision-making (Niemeyer and Littleboy, 2005).

The focus groups were facilitated by a colleague from the School of Geography, Environment and Earth Studies. Having a facilitator meant that I could listen to the group discussions and pay more attention to what people were saying and how they were interacting, rather than controlling how the session ran. The sessions were digitally recorded and extra notes were taken during the session. All participants were required to fill in a demographic questionnaire (see Appendix 4 for results). As well as the $\$ 20$ supermarket voucher, participants were provided with tea, coffee and biscuits.

The recordings were transcribed and then, using a basic coding system, the transcripts were divided into the themes as outlined below. An additional theme of 'tenancy' also emerged. Participants were then given the opportunity to proof the focus group findings. Particular care was taken to consider the frequency, extensiveness and intensity of comments made, and consideration was also given to what was not said (Krueger, 1998). Quotes were extracted from the transcription, giving due consideration to the ethical implications of this, and ensuring that their context was clear. These results can be found in Chapter 8 . 


\section{HHHS survey results}

This chapter gives the results of the quantitative section of research - the data from Householder Surveys of the Housing, Heating and Health Study. For a full copy of the questions asked in these surveys, see Appendix 1.

\subsection{Willingness to pay and willingness to accept}

In 2005 and 2006, the HHHS participants were asked what they were willing to pay (or accept) for the heater they had chosen from the study (Q32 in the 2005; Q29Aii and Bii in the 2006 survey). It is possible to use these data to construct demand curves showing the range of different valuations provided by households. We can compare willingness to pay and to accept, and also compare the two years of the survey. The mid-point for the 'over $\$ 5000$ ' spend bracket is represented as $\$ 6000$, based on the increases in size of the previous brackets, though this is essentially a guesstimate.

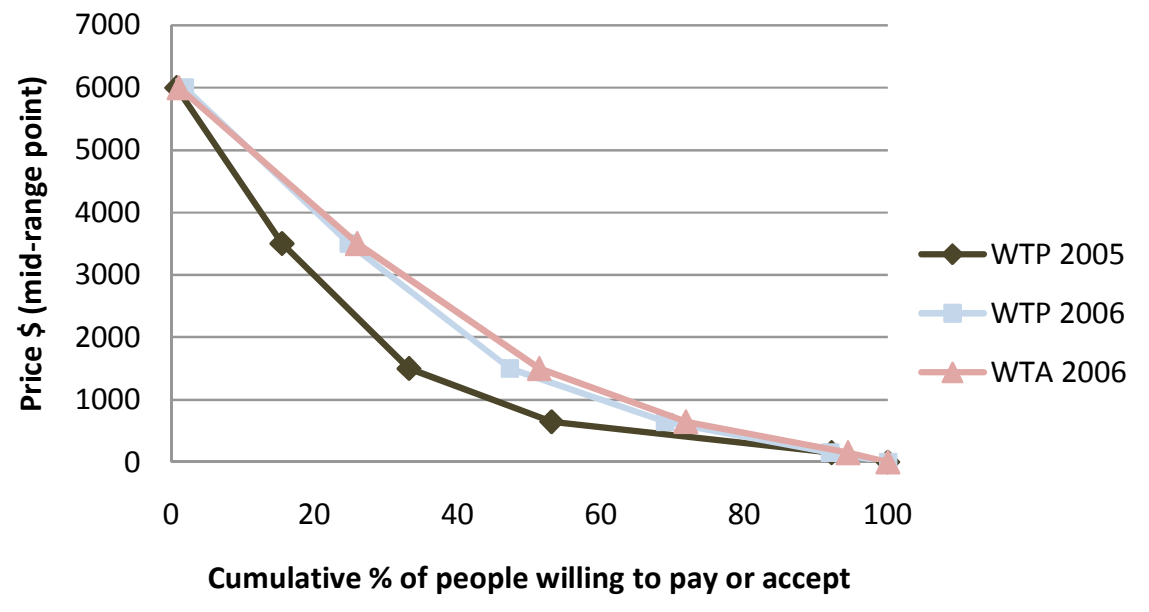

Figure 4. Demand curve of WTP and WTA in 2005 and 2006. nWTP 2005 = 407, nWTP $2006=166$, nWTA $2006=163$

As might be expected, Figure 4 shows a downward slope - that is, a high proportion of respondents valued their new heater at a low price, while only a small number of respondents valued their new heaters highly, with less than $20 \%$ of participants valuing their heater at $\$ 3500$ or more in 2005. The figure also shows that the curves for responses in 2006 are higher than in 2005 , indicating that a greater proportion of participants were willing to pay or accept a higher given value for their heaters in 2006 than in 2005.

The willingness to pay and willingness to accept data are plotted by the percentage of people willing to pay and willing to accept by the 'spend bracket' in Figure 5 below. There appears to be a small difference in people's willingness to pay and in their willingness to accept between the 
first and the second year, with the responses for both WTP and WTA values in the second year showing a flatter distribution than in the first year WTP values.

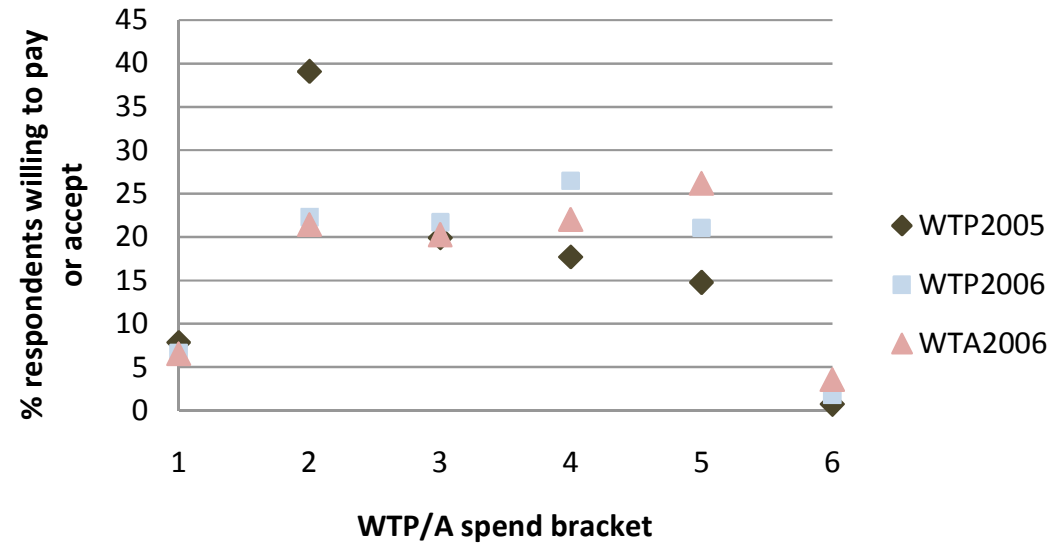

Figure 5.WTP and WTA in 2005 and 2006 according to spend brackets. $1=$ nothing; $2=\$ 1-300 ; 3=$ $\$ 301-1000 ; 4=\$ 1001-2000 ; 5=\$ 2001-5000 ; 6=$ More than $\$ 5000$.

Because the WTP/A spend brackets are not regular in size, these data are presented according to the mid-point of each bracket to give a more accurate description of the distribution of the data (Figure 6).

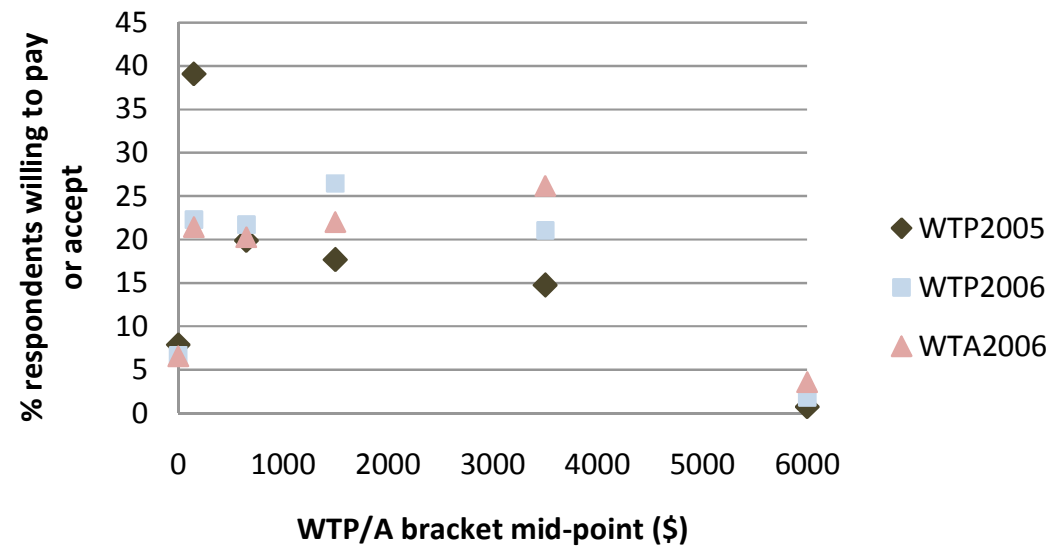

Figure 6. WTP and WTA in 2005 and 2006 according to spend bracket mid-point.

The distribution of WTP responses is skewed to the left in the 2005 survey, with nearly $50 \%$ of participants willing to pay less than $\$ 300$ for their heater. By comparison, both the WTP and WTA in the 2006 survey indicate a fairly even spread of participants willing to spend within the middle four spend brackets, with around $20-25 \%$ of participants in each of these categories of willingness to pay/accept. In all the surveys, only a very few participants were willing to pay/accept above $\$ 5000$ (the top spend bracket). These skewed distributions indicate that nonparametric tests should be used in comparing values. 
The median values of WTP and WTA were calculated using mid-points of the WTP/A spend brackets in SPSS (see Table 4).

Table 5. Median and variance of WTP and WTA for all HHHS participants.

\begin{tabular}{|l|r|r|}
\hline & \multicolumn{1}{|c|}{ Median (\$) } & \multicolumn{1}{|c|}{ Variance } \\
\hline WTP 2005 & 533.33 & 1538733.0 \\
\hline WTP 2006 & 1011.25 & 1701229.6 \\
\hline WTA 2006 & 1069.01 & 1920748.1 \\
\hline
\end{tabular}

To assess the difference between the participants' responses over the two years, a Mann-Whitney $U$ test (a non-parametric ranking test) is used.

Table 6. Mann-Whitney $U$ test $Z$ statistic comparing WTP and WTA. * indicates significance at $\mathrm{p}<0.05$.

\begin{tabular}{|l|c|}
\hline \multicolumn{1}{|c|}{ Comparing distributions } & K-S test statistic \\
\hline WTP 2005 to WTP 2006 & $-3.86^{*}$ \\
\hline WTP 2005 to WTA 2006 & $-4.15^{*}$ \\
\hline WTP 2006 to WTA 2006 & -0.39 \\
\hline
\end{tabular}

The test indicates that there is a significant difference $(\mathrm{p}<0.05)$ between both the control (WTP) and intervention (WTA) 2006 demand curves compared to the combined group's 2005 WTP demand curve (Table 5). This indicates that over the first year of the study, both the intervention and control group increased their valuation of their heaters, but that the difference between the two groups' valuations in 2006 was not significant. It is notable that a similar increase in valuation occurred for both control (WTP) and intervention (WTA) values in 2006, and this requires further investigation.

To test what is happening in this situation, it is helpful to analyse the 2005 WTP responses according to the group the participants were later assigned to. The WTP and WTA values as given by the control group are plotted in Figure 7 and those given by the intervention group are plotted in Figure 8 below. 


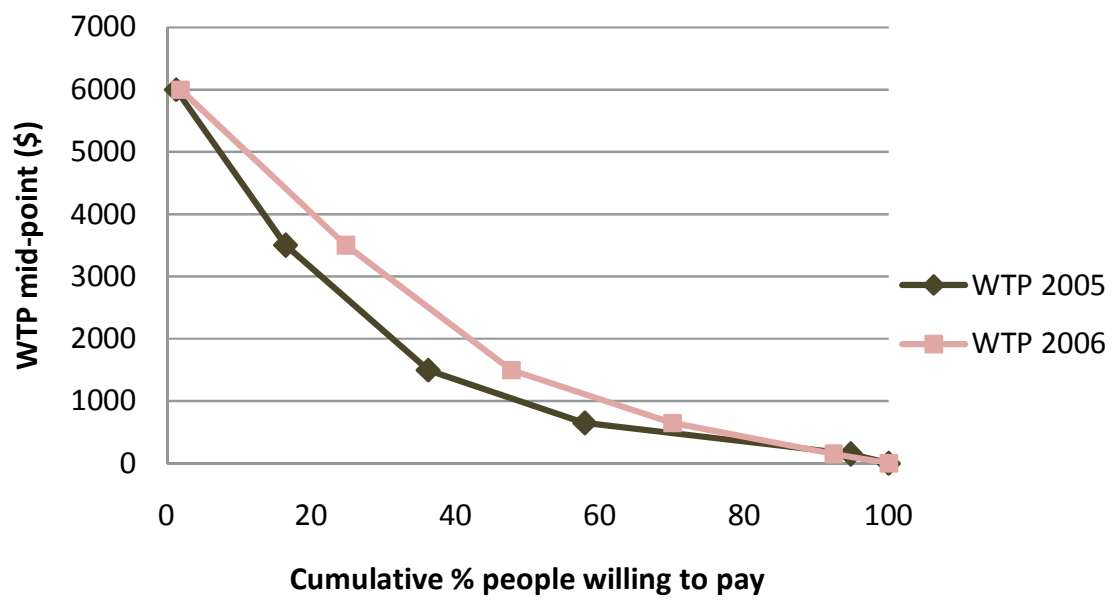

Figure 7. Control group participants WTP in 2005 and 2006. Control group: Median WTP $2005=$ $\$ 553.36, \mathrm{n}=199 ;$ Median WTP $2006=\$ 1011.25, \mathrm{n}=166$.

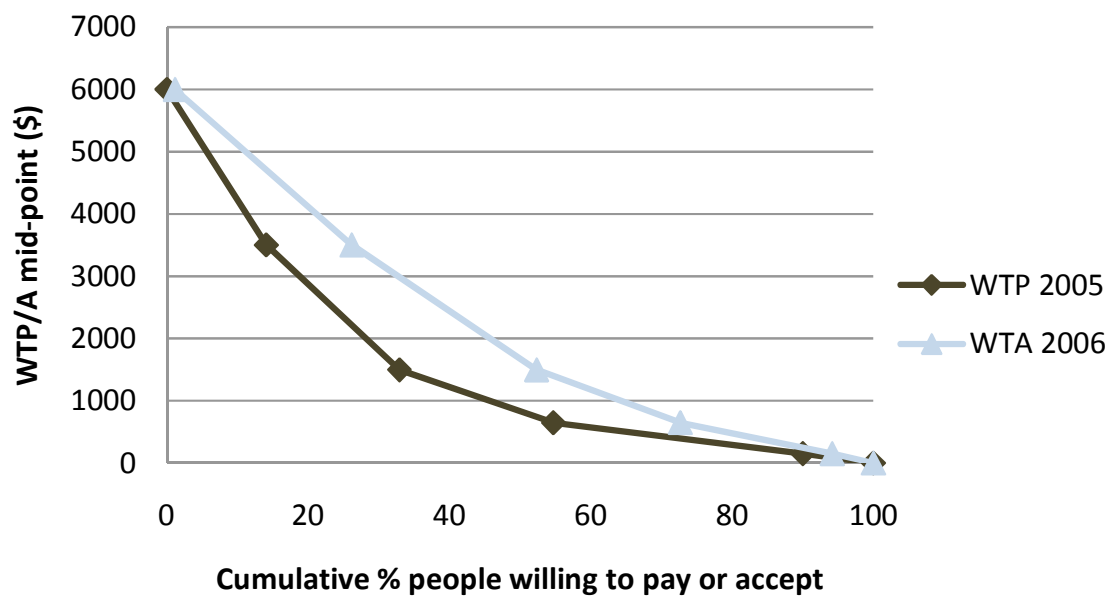

Figure 8. Intervention group WTP in 2005 and WTA in 2006. Intervention group: Median WTP $2005=$ $\$ 542.86, \mathrm{n}=194 ;$ Median WTA $2006=\$ 1069.01, \mathrm{n}=163$.

The heater valuation of the intervention group saw an increase of 1.97 from the first to second year based on median values, while the control group's valuations increased a slightly lower 1.83 times in the second year (Table 7).

Table 7. Median WTP and WTA and variance for control and intervention groups.

\begin{tabular}{|r|r|r|r|r|} 
& \multicolumn{2}{|c|}{ Intervention } & \multicolumn{2}{c|}{ Control } \\
\hline & Median (\$) & Variance & Median (\$) & \multicolumn{1}{c|}{ Variance } \\
\hline $\mathbf{2 0 0 5}$ & 542.86 & 1437137.2 & 553.36 & 1701229.6 \\
\hline $\mathbf{2 0 0 6}$ & 1069.01 & 1920748.1 & 1011.25 & 1926281.6
\end{tabular}


To test if the difference between the WTP and WTA values over the two years of the study were significant, the Wilcoxon Signed Rank test was used (Table 8).

Table 8. Wilcoxon Signed Rank test $\mathrm{Z}$ statistic for intervention and control group WTP/A. * indicates significance at $\mathrm{p}<0.05$.

\begin{tabular}{|l|r|}
\hline \multicolumn{1}{|c|}{ Comparing distributions } & $\begin{array}{c}\mathbf{Z} \text { (based on } \\
\text { negative ranks) }\end{array}$ \\
\hline Intervention group & $-3.85^{*}$ \\
\hline Control group & $-3.17^{*}$ \\
\hline
\end{tabular}

The apparent shift in both WTP and WTA values in the second year of the survey that is seen in Figure 4 can thus be broken down. Both groups showed a significant difference in contingent valuation of the heaters in the second year from the first, though the magnitude of increase was slightly larger for the intervention group than the control group.

\subsubsection{Income}

Income is a factor that can be investigated with the contingent valuation data. The 2005 WTP demand curve in Figures 9 shows the 'low' income bracket with the lowest WTP, and the 'high' bracket the highest. This follows the expectation that WTP is income constrained - those people with higher incomes are simply able to pay more for a heater than those with lower incomes, and therefore assign it a higher WTP valuation. This is a little more complicated in the second year (Figures 10 and 11), where the pattern of the first year is not so distinct in the WTP values (control group), and the WTA values (intervention group) appear to converge.

Table 9. Median WTP and WTA and variance according to income group. Household income brackets (see key): Low $=$ up to $\$ 38000 ;$ Mid $=\$ 38001$ to $\$ 60000 ;$ High $=\$ 60001$ plus.

\begin{tabular}{|l|r|r|r|r|r|r|}
\hline & \multicolumn{3}{|c|}{ Median (\$) } & \multicolumn{3}{c|}{ Variance } \\
\hline WTP 2005 & WTP 2006 & WTA 2006 & WTP 2005 & WTP 2006 & WTA 2006 \\
\hline Medium & 391.57 & 681.48 & 976.92 & 1312590.1 & 2420163.8 & 1814461.8 \\
\hline High & 628.26 & 1257.14 & 791.67 & 1426486.7 & 1316477.3 & 1796864.1 \\
\hline & 1250.00 & 1815.79 & 1760.87 & 1816378.4 & 2038163.8 & 2232760.4 \\
\hline
\end{tabular}

As expected, median WTP and WTA were highest for the high income participants (Table 9). To test for the affect of income, a Kruskal-Wallis test (a non-parametric test for analysis of variance) indicates that there are significant differences $(\mathrm{p}<0.05)$ between WTP in 2005 (Chi-square $=26.4$ ) and WTP in 2006 (Chi-square = 9.2) according to the income group, but not for WTA in 2006. These results may mean that income appears to have an affect on WTP but not on WTA. 


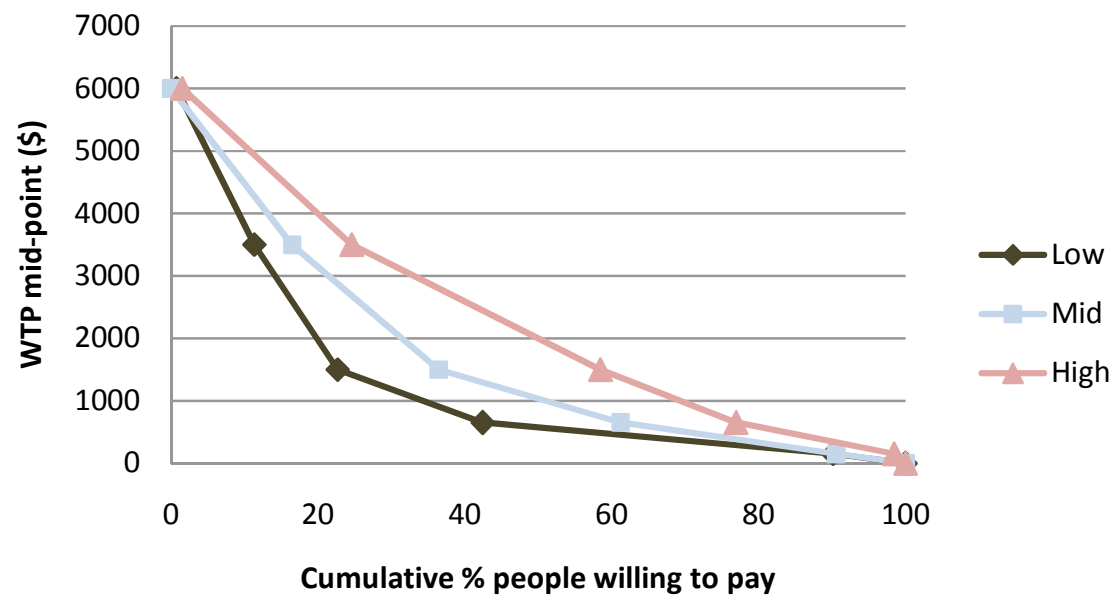

Figure 9. WTP in 2005 according to household income. Household income brackets: Low $=$ up to $\$ 38$ 000; $\mathrm{Mid}=\$ 38001$ to $\$ 60000 ;$ High $=\$ 60001$ plus. $n=281$

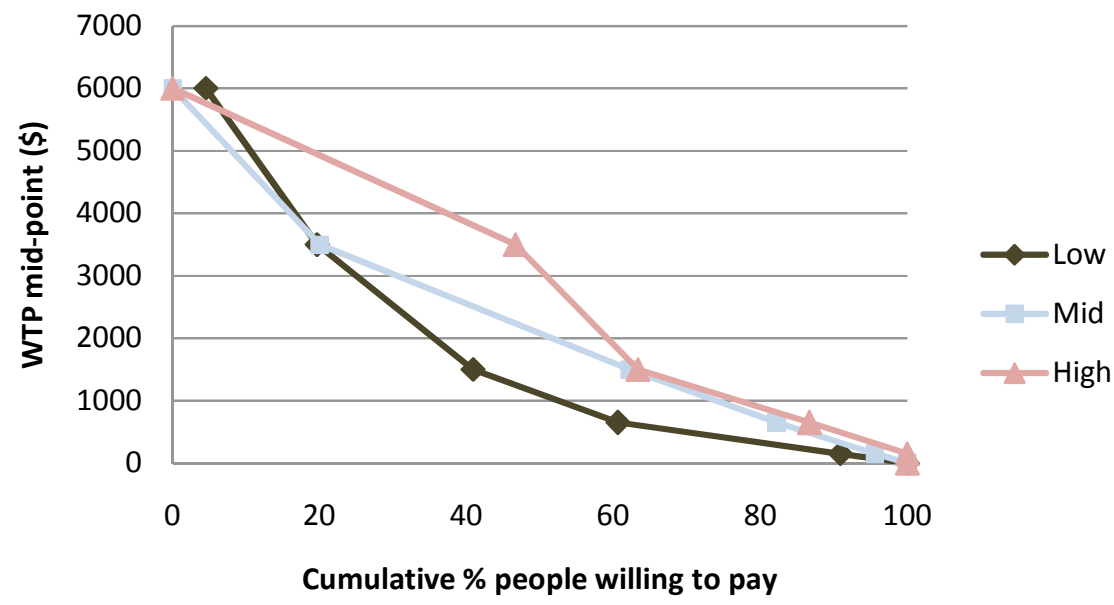

Figure 10. Control group WTP in 2006 according to household income. $n=131$

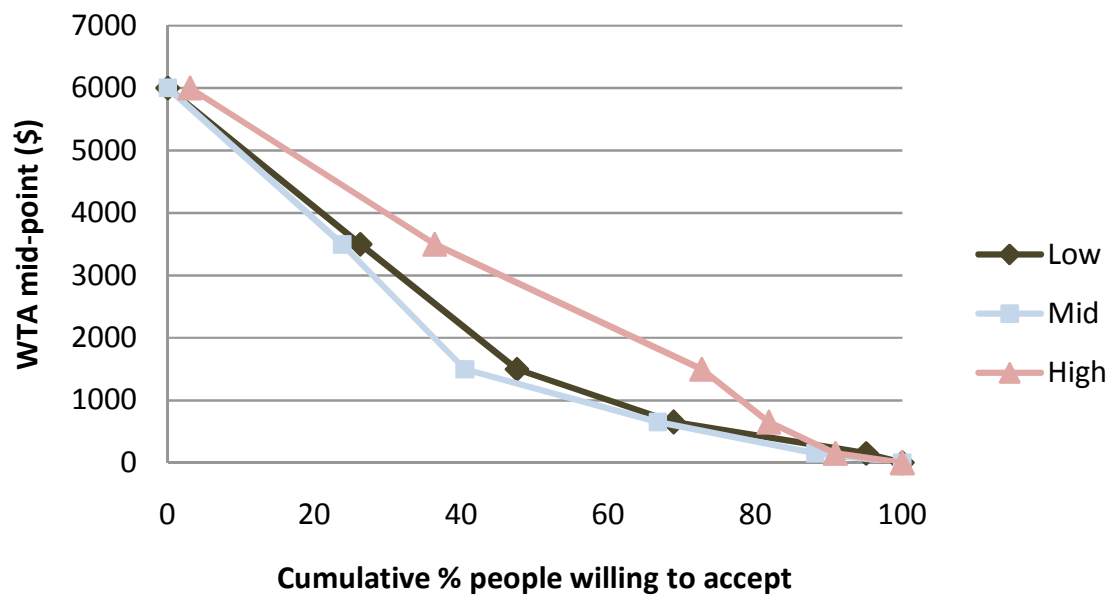

Figure 11. Intervention group WTA in 2006 according to household income. $\mathrm{n}=136$ 


\subsubsection{Home ownership and tenancy}

It is to be expected that people living in their own homes are likely to be willing to spend more on upgrading and improving their house than those who rent - this is the issue of split incentives. In the case of the HHHS, the participants were made aware at the outset of the study that if they were renting, the heater they received in the study belonged to their landlord. Many of the renting participants were not able to make the choice of heater on their own: in most cases, and for every case of Housing New Zealand being the landlord, the landlords made the heater choice, though consultation with the tenants was encouraged. For example, Housing New Zealand chose heat pumps as the best option for their houses. This is likely to affect peoples' willingness to pay for the heater they received. Table 10 outlines the differences in WTP and WTA across the differing living arrangements.

Table 10. Median WTP and WTA and variance according to ownership or tenancy. $\mathrm{n}($ Own home $)=$ 214, $\mathrm{n}($ Rent private $)=67, \mathrm{n}($ Rent HNZ $)=59$

\begin{tabular}{|l|r|r|r|r|r|r|}
\hline & \multicolumn{3}{c|}{ Median (\$) } & \multicolumn{3}{c|}{ Variance } \\
\hline WTP 2005 & WTP 2006 & WTA 2006 & WTP 2005 & WTP 2006 & WTA 2006 \\
\hline Own & 851.98 & 1287.50 & 1483.33 & 1638138.8 & 1761167.4 & 1879428.4 \\
\hline Rent private & 369.51 & 953.57 & 444.12 & 1094456.1 & 2974784.5 & 1766500.0 \\
\hline Rent HNZ & 283.33 & 325.00 & 450.00 & 807488.3 & 833948.9 & 1160000.0 \\
\hline
\end{tabular}

WTP and WTA were much lower in the two renting categories than for those people who owned their own home. Housing New Zealand tenants showed the lowest WTP and WTA values of all participants. Tenants of HNZ must be low income earners in order to qualify as tenants under the HNZ rules. Interestingly, the WTA valuation for this group is still very low (even though it should be in principle not 'income constrained') and may indicate that these participants were responding from the context of their own financial experience - while these participants were not income constrained as such, they may still have tended to make valuations based on their socio-economic position.

The differences in WTP and WTA values according to the participant's home ownership or tenancy was significant $(\mathrm{p}<0.05)$ over both years (Kruskal-Wallis chi-square values: WTP $2005=$ 33.90; WTP $2006=17.80$; WTA $2006=22.98$ ). This finding is somewhat expected given the role that split incentives are likely to play a role in valuation for participants who are rental tenants.

\subsubsection{Location}

Analysis of people's WTP by location paints an interesting picture (Table 11). As participant numbers in Bluff were very small, these values have been combined with the Dunedin values, the next closest study location to Bluff. 
Table 11. Medians WTP and WTA and variance according to location. $\mathrm{n}$ (Hutt Valley) $=123$, $\mathrm{n}($ Porirua $)=88, \mathrm{n}($ Christchurch $)=110, \mathrm{n}($ Dunedin and Bluff $)=79$.

\begin{tabular}{|l|r|r|r|r|r|r|}
\hline & \multicolumn{3}{|c|}{ Median (\$) } & \multicolumn{3}{c|}{ Variance } \\
\cline { 2 - 8 } & WTP 2005 & WTP 2006 & WTA 2006 & WTP 2005 & WTP 2006 & WTA 2006 \\
\hline Hutt Valley & 601.39 & 933.33 & 908.70 & 1272079.2 & 1861522.2 & 1797570.6 \\
\hline Porirua & 321.23 & 542.86 & 602.38 & 920851.3 & 857634.6 & 1684619.0 \\
\hline Christchurch & 738.54 & 1322.92 & 1463.04 & 1693244.4 & 1843725.5 & 2015882.7 \\
\hline Dunedin/Bluff & 650.00 & 1500.00 & 1145.83 & 2175985.9 & 2822359.2 & 2091678.2 \\
\hline
\end{tabular}

The median WTP and WTA are lower for the participants in Porirua compared to all the other study locations. There appears to be a pattern associated with the geographic location of the study participants and their willingness to pay. As latitude increases (moving south), so too does the average WTP and WTA, so that the southern-most locations - Christchurch, Dunedin and Bluff have the higher values.

Grouping the study locations into North Island (Porirua and Hutt Valley households) and South Island (Christchurch, Dunedin and Bluff households) localities is useful for investigating this pattern (Table 12).

Table 12. Median WTP and WTA and variance according to North or South Island location. * indicates significance at $\mathrm{p}<0.05$.

\begin{tabular}{|l|r|r|r|r|r|r|} 
& \multicolumn{3}{c|}{ Median (\$) } & \multicolumn{3}{c|}{ Variance } \\
\cline { 2 - 8 } & WTP 2005 & WTP 2006 & WTA 2006 & WTP 2005 & WTP 2006 & WTA 2006 \\
\hline North Island & 460.34 & 670.73 & 768.06 & 1171839.9 & 1430669.8 & 1746530.6 \\
\hline South Island & 708.22 & 1391.03 & 1354.29 & 1886591.7 & 2205486.1 & 2029968.7 \\
\hline
\end{tabular}

The difference between North Island and South Island contingent valuations of WTP in 2005, and both WTP and WTA in 2006 were all significant ( $\mathrm{p}<0.05)$ (Mann-Whitney $U$ test $\mathrm{Z}$ values: WTP $2005=-2.71$; WTP $2006=-3.13$; WTA $2006=-2.04)$. South Island median WTP and WTA values were from 1.54 to 2.07 times larger than North Island median values. This indicates a pattern of the median WTP and WTA values in the South Island study locations being greater than those median values in the North Island study locations.

\subsubsection{Heater type}

Assessing how the chosen heater type affects WTP is useful to see if the different heater types are attributed different overall value. While the values for the flued gas heaters appear to be considerably lower than the other heater types, it is important to note that of the 360 heaters distributed in the study, only 11 were flued gas heaters (3\% of all heaters), compared to 82 wood pellet burners (23\%) and 267 heat pumps (74\%) (Table 13). 
Table 13. Median WTP and WTA and variance according to heater type. $n($ Flued gas $)=11, \mathrm{n}($ Wood pellet burner $)=82, \mathrm{n}($ Heat pump $)=267$

\begin{tabular}{|l|r|r|r|r|r|r|}
\hline & \multicolumn{3}{c|}{ Median (\$) } & \multicolumn{3}{c|}{ Variance } \\
\cline { 2 - 8 } & WTP 2005 & WTP 2006 & WTA 2006 & WTP 2005 & WTP 2006 & WTA 2006 \\
\hline Flued gas & 427.78 & 650.00 & 420.00 & 185045.5 & 313958.3 & 364500.0 \\
\hline WPB & 440.91 & 1007.89 & 1100.00 & 1140757.7 & 1134417.6 & 1830113.4 \\
\hline Heat pump & 615.04 & 1075.00 & 1128.13 & 1633275.2 & 2249596.6 & 1974767.0 \\
\hline
\end{tabular}

A Kruskal-Wallis test indicates that the difference indicates that difference in WTP and WTA values according to the heater chosen are not significantly different (chi-square values: WTP 2005 $=4.57$; WTP $2006=1.24$; WTA $2006=3.56$ ). This is perhaps due to the very small $n$ value of 11 for the flued gas heater group.

Table 14. Participants' WTP and WTA and actual prices for different heater types. Actual cost is the mean cost of the unit, installation and any extras of the heaters in the HHHS.

\begin{tabular}{|l|r|r|r|r|}
\hline & \multicolumn{3}{|c|}{ Median (\$) } & Actual mean \\
& NTP 2005 & WTP 2006 & WTA 2006 & cost (\$) \\
\hline Flued gas & 486.36 & 737.50 & 420.00 & 2828.50 \\
\hline Wood pellet burner & 814.02 & 1186.36 & 1515.71 & 4463.44 \\
\hline Heat pump & 1123.41 & 1555.00 & 1525.23 & 2354.18 \\
\hline
\end{tabular}

Table 14 shows the median WTP and WTA and the actual costs of the different types of heaters. $\mathrm{CV}$ values were far below the actual costs for all types of heater, with the biggest difference between $\mathrm{CV}$ and actual values being for wood pellet burners. Participants receiving heat pumps showed the smallest difference between $\mathrm{CV}$ and actual values.

\subsection{Saving money or getting warmer}

The rebound effect - whereby the savings made through efficiency gains are then spent on greater consumption (Herring, 2006) - is a problem for home heating upgrading. In the HHHS survey, all participants were asked in the first year what they intended (or predicted) they would do once they received their new, efficient heating system (from the 2005 householder survey), whether it be saving money, heating the house more or a partial trade-off. In the 2006 household survey, intervention group participants were given an additional three options in the question: whether the heater didn't make the house warmer, if the participants spend more money than usual to be warmer, or whether the heater was too expensive to run (see Appendix 1 for the full questions). 
Figure 12, below, shows how the participants answered over the two years of the study. The option "I spent more money because it was worth it to be warmer" is very similar to the option that any savings would be spent on greater warmth ("Save nothing and have the house a lot warmer").

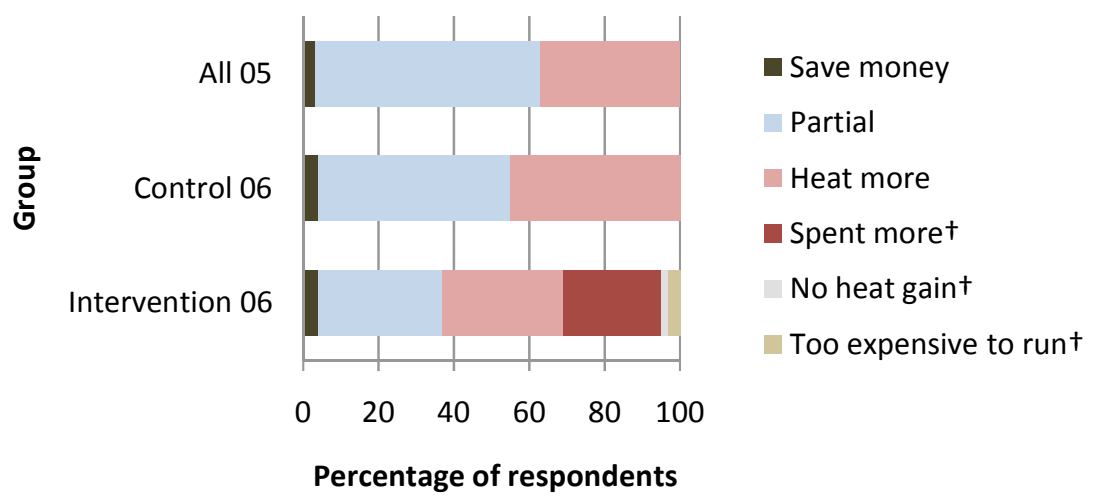

Figure 12. Saving money or greater warmth trade-off choices in 2005 and 2006. ${ }^{\dagger}$ indicates options available only to intervention group participants in 2006 survey.

Participants tended to predict that they would balance their money savings with increased warmth (the 'partial' scenario) in the first year (2005) of the study. By the second year, both intervention group and control group participants displayed a small shift away from this trade-off scenario toward a tendency to choose greater warmth (comfort) (Figure 12). This was particularly the case for the intervention group: around 30\% of these people indicated partial savings in 2006 compared to nearly $60 \%$ in 2005 .

\subsection{Factors important in choosing heater}

In the second year of the survey, participants were asked to rate the importance of a number of factors when choosing their new heater. A Likert scale was used to indicate the importance of each factor as mattering a lot, mattering a bit, or not mattering at all (see Appendix 1 for the full question). The number of participants rating each issue was compared to the rating of each issue. Figure 13 below illustrates the importance of each issue; Figure 14 shows the importance of the issues according to the percentage of respondents. The $\mathrm{x}$-axis has been arranged with the issue most participants rate as having 'mattered a lot' closest to the y-axis. 


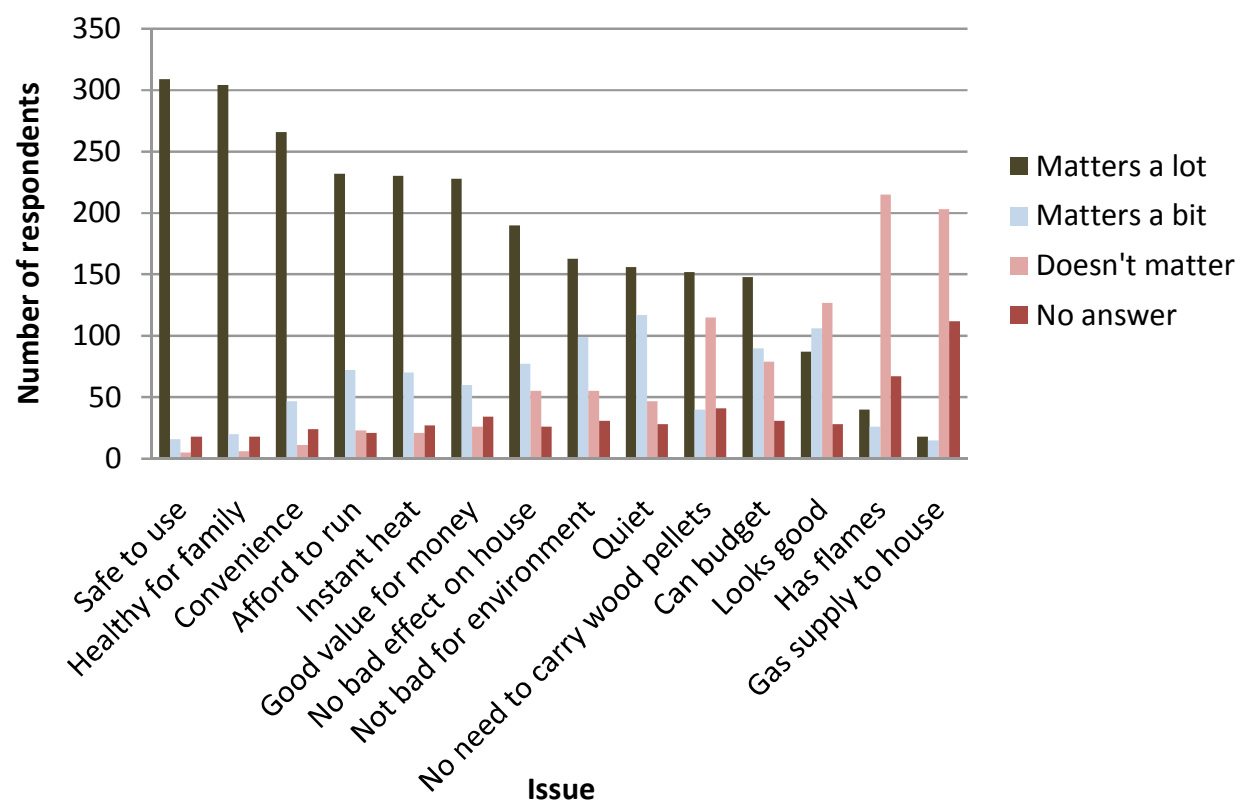

Figure 13. Rating of factors in heater choice. ${ }^{17} \mathrm{n}=348$

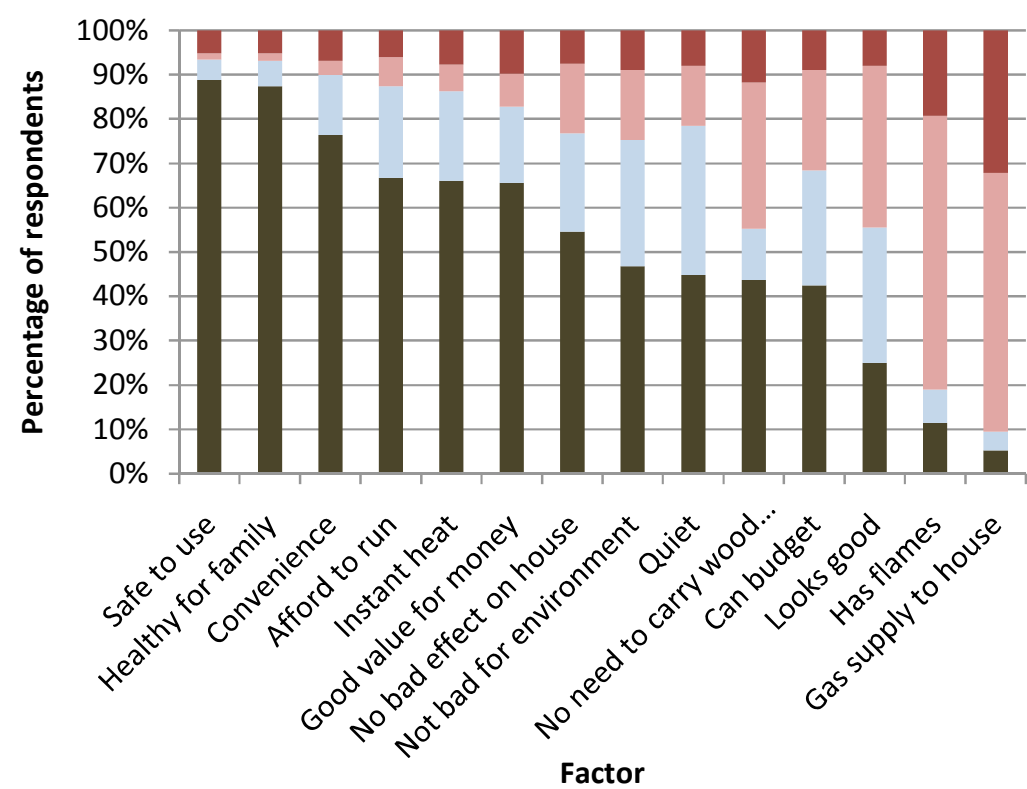

No answer

Doesn't matter

Matters a bit

- Matters a lot

Figure 14. Rating of factors in heater choice - percentage of respondents.

A large proportion of participants - nearly $90 \%$ - indicated that the safety of the heater for their family to use was the most important factor in their choice of heater from the HHHS study (Figure 14). The health impacts of the heater (87\%) and convenience of use (75\%) also appeared to be very important. The factors that appear to be of least importance to consumers include whether gas was supplied to the house, the presence of flames and the appearance of the heater.

\footnotetext{
${ }^{17}$ Wood pellets are referred to here as, of the three heater choices in the HHHS project, wood pellets are the only fuel that requires any handling. This question is designed to represent broader attitudes to having to move solid fuels or LPG tanks.
} 


\section{Focus group findings}

The following findings emerge from the analysis of the focus group recordings. Each participant has been assigned a letter-code to protect their identity. The themes used in this section are factors important in choice of heater; knowledge and attitudes; norms; and information. An additional theme of tenancy also emerged from the discussion. For all quoted text, words that were given particular emphasis by the speaker have been indicated in bold. Text in square brackets has been used either to clarify the quote or to correct grammar. All 'ums' have been removed to improve the ease of reading

\subsection{Factors important in heater choice}

In order to break the ice somewhat, the participants were first asked to talk about the type of heating they used in their home and why they chose the heater they did. For the oldest member of the first focus group, A, it was comfort and instant warmth that was most important to her. B was the only participant with a comprehensive household heating system with reticulated gas central heating. B valued gas as a fuel because he could easily quantify its use and had calculated that gas was cheaper per kilowatt hour than electricity. B, save for an unspecified concern about the consumption of natural gas, appeared very happy with the way in which his home was heated:

It chews up lots of gas but it provides lots of warmth as you walk about the house, while keeping the heating even ... there's no cold spots.

With the exception of one participant, $\mathrm{C}$, who felt that heating one room was not only sufficient but also desirable and chose to warm her home through passive solar heating, the participants agreed that having a house that was warm throughout was enviable.

The cost of running heaters became a focus of discussion in the first group for some time, and a point that many participants came back to throughout the discussion. When asked what factors were important to them when choosing a heater, the cost of buying a heater unit and running it was brought up by all participants, and named by three as the named as the defining factor in why they chose their current heater(s). Likewise, all the participants in the second group expressed that capital costs were very important in determining their heating choices.

Participants with unflued gas heaters in this group chose them for reasons of convenience and low price. None of the participants in the first group appeared to be aware of the negative health effects associated with the use of unflued gas heaters, as is caused by the products of incomplete 
combustion of the liquefied petroleum gas. ${ }^{18}$ A number of participants mentioned throughout the course of the discussion that they wanted heating that provided instant warmth.

In the second group, two participants, I and K, said that they did not use any form of heating. K, a young woman who lived in a flatting situation, commented:

... we don't heat our house, it's too big, it's just not worth it.

This participant went on to comment that instant heat was desirable but she thought that anything that produced heat too quickly was inefficient and therefore undesirable. Four people in this group chose small electric heaters for their needs, largely because they were inexpensive, and most felt they were efficient to run. Participants in the second focus group did not like unflued gas heaters and all - with the exception of one participant who had a backup gas heater - avoided them. As J, a male participant in his twenties expressed it, unflued gas heaters:

aren't so good because they create condensation and you just need more energy later to mop up [the condensation] ...

Living in a flat, participant $\mathrm{M}$ was given an unflued gas heater by her landlord to use in the winter but the flatmates soon found that they:

... needed ventilation, and we just found that with the door open, the windows, the heat would escape too much ... and then if you just left anything closed you just felt suffocated by it, so we just thought 'there's no point, we'll just go back to rugs', and gave the heater back [to the landlord].

Three participants in the first group and six of the seven in the second expressed having concerns about having heating that was environmentally sound were superseded by more immediate cost concerns. For example, D expressed that environmental concerns were important to her and if the price of buying and installing a comprehensive, sustainable system were not so high, she would choose differently:

If I had a choice, it would be different, in the circumstances that's what [the heater] I choose, that it was instant - instant and moveable - but if I could afford to heat a whole house, I would go down another track.

Most of these participants mediated this cost concern by using small electric oil column heaters in their homes, which they felt were relatively efficient forms of heating. Furthermore, thermostats were mentioned a number of times in both groups as a factor in their choice of heater. One participant used the thermostat in their heater to keep a room warm in order to protect the health

\footnotetext{
${ }^{18}$ Products include water, formaldehyde, nitrous oxide and carbon monoxide.
} 
of their small child. Furthermore, this participant felt that having a small child and being conservative with energy use were not easily able to go hand in hand:

One of my concerns about heating is, last December I had a baby so I've been concerned about keeping things warm for her, so concerns about how much electricity I use have just been thrown out the door, and well, you know, I've been more concerned about [warmth] and a warm house is a healthy house for a baby.

There was some empathy from other participants and acknowledgement of how homes should be warm, especially for small children. The need for greater warmth when small children are in the home was also reflected on by $\mathrm{H}$ in the second group:

I actually bought a new heater because I got married and had a new baby and my wife made me - I wouldn't have otherwise!

In the second group, $\mathrm{G}$ felt that the avoidance of illness through having a warm home was something that everyone had a right to, though he also identified how that may mean using more energy and the risks to the environment that may pose. This tension between costs and benefits to the individual and the costs and benefits to the environment were picked up on by a number of participants in both groups. D felt that there is a need to find a way so that:

We can all be warm, and while we're also saving the planet long-term.

While it did not factor into their choices of their current heating systems - primarily because of financial constraint - two participants mentioned the attraction of flames in solid fuel burners, or as L put it, the "romantic option". J admitted that (acknowledging its inefficiencies and the environmental effects of its use) when living in another flat he liked to occasionally use an old open coal fireplace for the flame effect.

For B, the cost of energy use was particularly important as it was through price paid that they could track the differences in their own energy use and also to compare gas and electricity prices. This participant was particularly committed to tracking and actively reducing his residential energy use and spent considerable time calculating his own use and the cost of alternative options, which he considered to be no easy task. Consequently, the participant believed that cost was the approach to take to encourage consumers to reduce energy use in the home - in other words, energy efficiency improvement attempts should be approached from the point of view of getting people to reduce their electricity and/or gas bill.

This argument is based on the premise (not stated by the participant, but assumed by the researcher) that at present using price is the only way in which energy/electricity use can be made 
visible. When asked what people knew about the energy they use in their home, one participant answered:

Ask most people what their electricity use is and they'll say \$110 a month.

In response to B's assertion that electricity was too cheap, and that if the price of electricity rose, demand would be reduced, F commented:

I don't know... I know where you're coming from when you say that electricity is too cheap in the sense that there isn't enough incentive for us to conserve as we should but I think that if you look at the sort of social side of that, you've got a lot of people who can't afford to own their own homes and so they can't put money into properly insulating and doing all those sorts of things ... I think we already have a problem with houses in New Zealand being too cold, so we've got to find a way around that.

This point raised some discussion around rights to be warm - this is further analysed in the next chapter.

\subsection{Knowledge and attitudes}

Participants seemed to find the terminology used in this group of questions difficult. In particular, when the first group was asked what they knew about security of supply, a considerable amount of confusion ensued and none of the participants appeared to understand what the phrase meant (this question was accordingly not asked of the second group).

B thought that the word efficiency was badly understood and used by many people in inappropriate ways:

I've heard people say that they think gas is really efficient, but what they mean is that it's effective. They've no idea whether they're burning money or not. All they know is that it heats up well, and they say 'this heating is very efficient', which is not the proper use of the word.

In both sessions, a number of comments on the importance of energy efficiency reflected on environmental and broader social benefits of improving energy efficiency in the home. One participant offered that, to them, energy efficiency is important because:

I guess it saves us all sorts, you know ... economical, and in a more general sense ...

Similarly a participant in the second group commented that energy efficiency is:

... just trying not to be wasteful I guess, and [the savings] can be environmental and money at the same time. 
The recognition of the range of benefits of energy efficiency, including ensuring long-term security of supply and health benefits, was also evident in comments by G.

Participant $\mathrm{F}$ responded that for them energy efficiency was important because:

If we all as a country use the energy we've got a little bit more efficiently we don't need to dam another valley on the West Coast.

D also commented:

I think people are more aware now than of just the immediate cost, and ... we are becoming more aware of its [energy generation and use] impact nationally.

These comments suggest that energy efficiency is seen as one way of reducing future energy generation needs and consequently reducing the potential environmental impact that energy generation may bring.

In the second group, $\mathrm{G}$, who put a great deal of effort into researching home heating options for his home, placed home heating and energy consumption within a broader lifestyle or consumption context. He expressed concern that lifestyles in New Zealand meant that:

... we're going around consuming the earth.

When asked about what they knew about the energy consumption of their home heating two main responses emerged from the groups. Some participants conscientiously spent time making sure they knew what they were consuming and how much, and consequently made appliance and fuel choices based on this. In the second focus group, $\mathrm{G}$ was particularly emphatic on this point:

I'm very aware of the energy I'm using because I don't want to be ripped off by the electricity companies ... I monitor it very carefully, I don't just pick up the bill and pick up a cheque and send it off ...

Likewise, participants B and C in the first focus groups closely followed their electricity bills in order to trace their electricity consumption.

On the other hand, most participants did not have much idea of their energy consumption. For example, $\mathrm{M}$ chose to rely on her flatmates' good intentions to be "conscious about our heating" and did not follow her electricity bills. In fact, M's flat chose to pay their electricity bill through direct debit payments from a joint account, leading $M$ to say that their bill, and consequently their electricity consumption:

... could just be racking up without us knowing. 
There was a general agreement on the existence of climate change - the level of acceptance of the human role in climate change was universal, though $\mathrm{L}$ did (jokingly) comment that it meant he no longer had to worry about heating because the climate was doing that for him. Participant $\mathrm{E}$ commented that:

I think [climate change is] something very much on my mind at the moment, yeah.

You know, [energy efficiency is] a little contribution... It all adds up if everybody does it.

Despite the repeated remarks that climate change was a problem in a collective sense, there was also recognition of the role of individual effort and responsibility on the part of a number of participants. The complex nature of climate change appeared to leave many of the participants in a situation where they didn't know what to do (a lack of agency). F, the participant with the most suggestions for others on what people could do to improve energy efficiency, commented that she still felt in a disempowered position, saying with some emphasis:

I feel guilty, you know, quite often.

In the second group, while climate change and energy generation concerns seemed to gain unanimous acceptance, the general feeling from the group was different from the first session. Instead of seeming somewhat stuck in the tensions between wanting a warm home and climate change pressures, this group focused on finding other ways of staying warm, such as with blankets and extra clothing.

For K though, climate change concerns did not drive her attempts to be energy efficient in her home:

... whatever the reason, the outcome's the same for energy efficiency, there's a number of reasons for it. Climate change is another one to add to it I guess, but it's not the primary reason ... [energy efficient heating] would be down on my list of things I'm trying to do to mitigate climate change.

In the second group, $\mathrm{G}$ was particularly concerned that most of the general public didn't care enough about their energy consumption. This led into a discussion around the capacity to have energy efficient homes and the role that money has in this. The participants - none of whom had high incomes ${ }^{19}$ - felt that those who did have access to a lot of money were in a situation where, because money no longer constrained how much energy they consumed, they did not implement energy efficiency in the way they felt socially optimal, such as those who were income constrained

\footnotetext{
${ }^{19}$ Note that while there were two participants with household incomes in the highest bracket, this was due to there being four employed flatmates in their houses (both participants stated this on their demographic survey forms).
} 
would. Speaking about compact fluorescent light bulbs (CFLs), $\mathrm{N}$ and $\mathrm{H}$ expressed that while they had long-term benefits over incandescent bulbs, the upfront costs (despite being small) meant that many people would not be able to choose this option. Commenting that CFLs save money in the long-term, participant $\mathrm{H}$ said:

... if only you had that money to begin with!

Likewise, this situation is likely to exist for larger energy efficiency investments, such as heaters, though the initial cost barrier may be even higher.

\subsection{Norms}

When asked about the way other people heat their homes and if they had come across any practices that were unacceptable to themselves, D quite emphatically replied:

I have bought things up like that with people, and with heating, I just had to say to the person, look this just isn't working. If you want to warm your house and you're thinking in terms of global warming and even just in terms of your own electricity bill, you know, you need to look further afield, you need to look at all the variables.

This speaker went on to say that it was because they were to share payment of the electricity bill that she decided to speak to her friend about their heating choices.

Another participant commented:

I've been to some very very cold houses in Wellington and, you know, I've shown up a lot in my time and not taken my jacket off, I mean, can't you get the hint? I'm freezing here! And I'm sitting there is this huge like ski jacket [laughter] and it's because their houses are too cold.

While the participant was using humour to soften the discomfort she felt about finding a peer's choice - a cold house - unacceptable, she expressed a feeling that had considerable support amongst the first focus group: that very cold homes are unacceptable. The participant's underlining of the valuing of a warm house is somewhat implicit and coded - not taking off her jacket and hoping that the home owner will "get the hint".

In the second group, almost all the participants advocated sitting under a blanket when cold or putting on another layer of clothing at some point during the discussion:

If you don't need your house to be a certain temperature, then you may as well just put on another jersey. 
This comment was received with laughter and general agreement from the rest of the participants. Further, M commented that:

We don't often heat our house, even though we've got the heater. We tend to rug up in winter [with] a couple of great big duvets ... and the home isn't very well insulated either, so we know that we are probably better off most of the time with just sitting in a rug $\ldots$

The choice of heating just one room also came through quite strongly in the second group:

$\mathrm{K}:$... when I lived in Dunedin, where it gets very cold, we just picked one flatmate's bedroom [to heat] and we'd all move in there for the evening.

$\mathrm{J}$ : ... [we decided] to only heat the lounge ... and only heat [it] to a reasonable temperature, just to take the chill off the air.

However, this group all agreed with $\mathrm{M}$ when she mentioned that, though she didn't usually heat her house much and would sit under blankets instead, she would use a heater if friends or guests were visiting.

$\mathrm{D}$ and $\mathrm{A}$ both agreed with $\mathrm{F}$ when she stated:

I do like it when I go round to people's places and find that every room's warm. You know, I've been to someone's place and I [went] to the toilet and was like, oh my goodness, even this room isn't cold!

Participants in both groups mentioned knowing of people that used electric and gas ovens to heat their house - a statement that was met with general horror from the other participants.

\subsection{Information}

While an acceptance of the reality of human-induced climate change was consistent amongst the participants, there appeared to be a lack of understanding of what exactly their role could be and what this meant for residential energy use and heating. As one participant put it:

When I try to listen to it [talk about climate change], what they've been saying on the radio in the last couple of days, I get completely fogged, I have to say. It does seem a very complex thing, you know... I don't use more [energy] than what I need and I'm aware of what I am using. Hopefully that has an effect.

A number of comments arose about the difficultly in finding and understanding energy information. Some participants felt that there was a lack of information on how to correctly choose and run the appropriate heater. One observation that was met with accord was that by D that: 
I think it's about education too, because ... I came into a house in Wellington and they'd had an expensive gas heater put in and I used to have to sit on top of it, she had no curtains at the window, and there was no fan ... The heat was going all up there [gesticulating towards the ceiling]. It was like a chimney. So, it's about individual education too, isn't it?

Information that came from power companies appeared to have a reasonable standing with the participants. $\mathrm{C}$ was impressed with the way her electricity retailer printed her bills:

My electricity can be kept quite low because the bills show you each month the month before, so you're encouraged ... so you can see it in diagram form the difference, like a sort of encouragement in diagram form.

However, one participant, who did not receive any energy efficiency information from her electricity provider, stated that she found that "there's no clear guidance" and that electricity providers had an important role to play in filling this information gap. In contrast, two participants in the second group implied that information provided by electricity retailers was not necessarily in the consumer's best interest.

When asked about who they trusted in terms of energy efficiency or home heating information providers, B was emphatic that he did not trust retailers or sales people:

You talk to a salesperson and of course they're going to tell you to do it ...

In opposition to this, $\mathrm{G}$ said he would request information from the retailers of products, but this information would be used in conjunction with a wide range of other information ( $G$ was a particularly motivated individual when it came to energy efficiency in his home).

Participant A thought that the group she was most likely to trust was the Citizen's Advice Bureau, which she used often when she had enquiries or questions. The two oldest participants in the second group both mentioned going to the public library for information. The Consumer magazine, put out by the Consumer's Institute, was mentioned by four participants in the two groups as a source of reliable information heating appliances. Four participants said that they would undertake an internet search in order to find out more information.

K commented that:

... I don't know of any official sources that have opinions, that would be authoritative and that are accessible.

For those participants who did not comment on this question, it is possible that this is the case for them as well. 
One theme that emerged from this discussion was that it was difficult to know what to ask, regardless of who you were approaching. In this case, one participant said:

I think I would go to friends and things, like recently two people I know have had heat pumps in and they reckon they're marvellous and, so, you know, I would take that information and then go to the heat pump people and then pick the brands [from] the information I've heard from friends, from what they're telling me 'this works, this is good'.

Later B reinforced this point:

I think friends' experience is probably really the best...

The role of friends, particularly to provide the initial and trusted ideas about heating options, appeared to be an important source of information for many of the participants.

A range of other information sources were also brought up. B commented that he had attended a public seminar on solar heating for the home and had been disappointed that the presentation was only based on personal experience and did not include the 'science' and 'facts' that he thought were also necessary for him to be making a decision. Participant $\mathrm{C}$ believed that the radio (and specifically Radio New Zealand National) was a useful and reliable source of information, having recently heard an article about heat pumps that combined personal stories and experiences of the appliance with commentary and advice from a range of energy efficiency experts. Only one participant mentioned the use of energy efficiency rating systems - such as EECA's EnergyStar rating - as a form of information they looked out for.

When given the chance to raise any questions or issues that had not been addressed during the session, one participant responded:

One of the questions that really exercises my mind in terms of household energy use, is, what's normal? I mean, give us a bit of a profile, give us some targets for a small flat, to a family of two or four or six, and show us what the targets are. Because I think people are all over the place with their [electricity] usage.

This point received general agreement from the rest of the group. $G$ also expressed how difficult it was to grasp the amount of energy people's home lives consume:

I think that if people could all just become more aware of waste, of wasting energy, then that would help everybody, then we would all benefit by it.

One of the few participants who knew of EECA did not use their website or information. K stated: 
... I wouldn't go there, I don't have cause to make those decisions [about heating] ... if I wanted to buy something I would go to the EECA site, but for just tips on [energy efficiency], you just pick them up along the way.

$\mathrm{K}$ was under the impression that EECA's advice was only useful to those people who were making 'big' purchasing decisions about their home heating - she did not see EECA's relevance in broader educational terms or as a site for non-purchasing energy efficiency information.

\subsection{Renting}

On numerous separate occasions in both focus groups, the issue of the difficulty of improving energy efficiency in rental properties was brought up - in fact, the difficulty of making rental properties warm and energy efficient received perhaps the greatest degree of consensus amongst both groups. Around half of participants were currently tenants, but all the participants agreed that tenants were in a difficult situation. B did not think it likely that landlords were likely to pay out for insulation or other energy efficiency measures. While the participants agreed that tenants should take some responsibility to help themselves, ultimately the responsibility lay with the landlord:

I think that maybe landlords should be forced to [improve the energy efficiency]... I think that the Tenancy Act, the rules, should be ramped up so that they can't rent out cold, damp houses.

Likewise, three participants currently in renting situations in the second group all made complaints about how their homes were cold and how it was difficult to get landlords to respond. Participant J, who had been living in rental properties for around seven years commented:

... I think that there are incentives for landlords to insulate their properties, but [they're] not strong ... at the moment the pressure is weak, it feels like it needs to be stronger.

There was a great amount of feeling in these discussions, almost like an injustice was being done to tenants. $\mathrm{K}$ was particularly frustrated after spending six months trying to convince their landlord to install a heat pump:

But it's definitely an emotive issue: I get very frustrated that our house is cold.

Only one of all the participants was aware of the scheme run for landlords whereby up to $55 \%$ of energy efficiency upgrade costs are subsidised by EECA under the EnergyWise Homes scheme. The problem of split incentives was a source of frustration at the unfairness and difficulty to change to nearly all participants. 


\section{Discussion}

The aim of this research is to develop a picture of how New Zealanders value energy efficient home heating and to explore New Zealanders' home heating choices. Using the conceptual framework developed from the literature review (Objective 1), this chapter discusses findings related to the remaining three objectives of the thesis, given in section 1.1.

\subsection{Valuing warm homes}

Objective 2: Analyse how people value energy efficient home heaters.

\subsubsection{Contingent valuation of energy efficient heaters}

The HHHS contingent valuation data for energy efficient heaters produce demand curves that show the normal downwards slope expected of demand curves. However, the study participants' contingent valuations (WTP and WTA) of the new heaters were below the actual market cost of the heaters, over both years of the study (see Table 14 above). This differs both from what we might expect intuitively, and from the literature which indicates that WTP for home energy efficiency measures is often close to or exceeds market prices (O'Dea, et al., 2005; Banfi, et al., 2008).

In principle, WTP and WTA should reflect the range of benefits perceived by the householder receiving the new heater. So why might contingent valuation be low? Firstly, there is evidence that WTP may be income constrained (see Table 9 and Figures 11 and 12 above). This does not, however, explain why WTA is lower than the market price (see Figure 13). Secondly, while the majority of respondents rated health and environmental factors as important in the choice of heater (see Figure 15), many of the range of benefits embodied by energy efficient heaters may be discounted by the respondent where they are not perceived to have personal tangible economic value. For example, the external benefits of health care savings from living in a warm home compared to living in a home without an efficient heater - which preliminary results from the HHHS indicate may be considerable (Howden-Chapman, et al., in review) - may be heavily discounted, especially if some of these benefits accrue to the taxpayer-funded health care system or to employers - for example, when an employee takes a day off sick.

External environmental benefits may seem even less tangible and be discounted heavily. This is supported by previous research that indicates that future benefit streams from home heating technologies are often valued at high discount rates (Hausman, 1979; Dubin and McFadden, 1984; Ruderman, et al., 1987). Furthermore, being able to aggregate the complex value elements of a good (such as an energy efficient heater) into a single monetary value is problematic for all 
non-market valuation methods (Vatn, 2005). These factors are likely to affect both WTP and WTA values.

A confounding factor here is that awareness of the health effects of different heating types may be unusually high amongst the HHHS participants. Participants of the HHHS were recruited because one child member of the family suffered from asthma - consequently a high level of awareness of the health impacts of heating may be expected. However, this did not appear to translate into higher WTP/WTA values.

Another possible reason for low WTP values is that a number (37\%) of the participants were tenants and consequently the issue of split incentives arises, a well recognised problem for investment in energy efficient technologies (Oxera, 2006; de T'Serclaes and Jollands, 2007). Home owners reported roughly double the WTP and WTA of both private and HNZ tenants (Table 10). While it is difficult to ascertain the magnitude of the effect of split incentives on space heating energy use (de T'Serclaes and Jollands, 2007), the results here suggest that split incentives have a significant effect on people's willingness to pay for energy efficient heating. With home ownership rates dropping and around $30 \%$ of the population living in rental housing (Statistics New Zealand, 2006), this has implications for policy to improve energy efficiency nationwide.

The location of the HHHS participants appears to have an effect on their WTP and WTA for the heaters, with a pattern of values increasing with increasing latitude (Table 11). South Island participants' median WTP/A was between 1.5 and 2.1 times greater than North Island participants' WTP/A, and the difference between the groups' responses was significant (Table 12). This may be because participants in the South Island, where winter temperatures are colder than the North Island locations, value an energy efficient heater more due to the colder temperatures they experience. If this is the case, it may lend credence to the proposition that the increase in the WTP of the control group in the second year may in part be due to colder temperatures in the second winter of the study (see below).

While wood pellet burners are the most expensive type of heater (in the HHHS) to purchase and install, they did not rank the highest in the WTP and WTA for the heater types (Table 14). The low WTP values for pellet burners in relation to their costs may be due in part to convenience and 'instant heat' characteristics. These factors were ranked by the HHHS participants as highly important factors in heater choice - ranked $3^{\text {rd }}$ and $5^{\text {th }}$ respectively of the fourteen factors listed (see Figure 14). Because wood pellet burners take some time to heat up and require more complex behaviours in terms of fuel use, it is possible they were valued lower than heat pumps and gas heaters which embody both of the attributes given above. 
Heating forms such as heat pumps and wood pellet burners are technologies that are being continually advanced. As Wittmann et al. (2006) point out, people do not often purchase new heaters and, consequently, may find it difficult to comprehend the new technologies available.

One member of the first focus group noted that if a friend bought a heat pump five years ago, their experiences may not be very useful in choosing a heater today as the technology has changed considerably in the interim. The focus groups identified peers and their experiences with heaters as being an important source of information about heaters. This high rate of technological change may, therefore, hinder understanding the benefits of new, and often more efficient, home heating technology, possibly having the consequence of lowering the participants' WTP.

\subsubsection{WTP-WTA disparity}

A disparity in WTP and WTA was found. The intervention group gave a median WTA that was 1.9 times larger than the mean WTP the previous year (Table 7). In the literature, as noted in Chapter 4, the disparity between WTP and WTA, while of disputed magnitude and origin, is common (Kahneman and Tversky, 1979; Markandya, 1993, Horowitz and McConnell, 2002). However, over the two years of the study, an increase was seen in the contingent valuation of both the intervention and control groups, so that median contingent valuations were similar in the second year of the study (Table 7). This is difficult to interpret. The heaters installed in the HHHS study embody a range of environmental and social goods, a condition that tends to point to a WTP-WTA disparity, though as common market goods, a convergence of WTP-WTA is more likely to be expected (Shogren, et al., 1994). Furthermore, it is difficult to know what to expect from the increase in the control group's WTP. Asking a contingent valuation question over two years of study appears to have only one precedent in literature in the companion study to the HHHS (the Housing, Insulation and Health study, University of Otago, Wellington). In this study, WTA was nearly 1.5 times as large as WTP in the second year, and not similar to WTP as in these results (O’Dea, et al., 2005).

Aside from that mentioned in the literature given above, there are a number of possible reasons why both the intervention and control groups showed greater contingent valuations in the second year of the HHHS study. These include that the winter of 2006 was colder than the winter of 2005 (NIWA, 2006; NIWA, 2007). Indications that South Island participants valued the heaters higher than their North Island counterparts (Table 12) reflects that experiencing colder temperatures may be important in valuation. The time between the two surveys and the fact that the participants were asked a contingent valuation question twice may have gone some way to increasing familiarity with the attributes of their heaters, a factor that may improve understanding of the CV situation (Vatn, 2005). The valuing of the health effects of the new heaters may also have had an effect - the participants rated the factor "healthy for family" as the second most important fact in 
heater choice (Figure 14) and may have learnt more about these benefits over time. By contrast, the members of the focus groups made only small mention of the importance of the 'healthiness' of heaters in their choices.

Whatever the drivers of this change, the findings suggest that increased familiarity with the good under valuation and its benefits leads to a different valuation - this finding reinforces the need to ensure that participants are well informed, and suggests that in any contingent valuation study, a participative and reflective process of information sharing be undertaken (perhaps even more careful than the process followed in the HHHS study).

\subsubsection{Rebound effect}

As New Zealand has such a low rate of home heating at present (Schipper, et al., 1996; Amitrano, 2004), there is potential for increased home heating to have a considerable effect on energy demand and home heating greenhouse gas and $\mathrm{PM}_{10}$ emissions. The HHHS data indicate that there may be a rebound effect to contend with (see Figure 12). Though it is not possible to know what the magnitude of this rebound may be, a rebound of 10-30\% may be expected (excluding indirect effects) (Greening, et al., 2000; Sorrell and Dimitropoulos, 2007).

The presence of this rebound effect gives some indication that over the two years of surveys, participants decided that they would prefer to spend more on warmth. For the intervention group, it is possible that the heaters were simply used more and the desire for money savings over energy use was forgotten - this may be exacerbated by the fact that energy use may be difficult to keep track of, as indicated in the focus group research and in literature (Kempton and Layne, 1994; Hewett, 1998). While this rebound effect may prove beneficial for health outcomes (Hong et al., 2006), it does raise questions about how well energy efficiency upgrades can reduce overall energy demand - the loss of energy efficiency gains to increased demand is a problem that New Zealand has struggled with for some time (MED, 2006).

\subsubsection{Achievement of objective}

There are a number of bias issues to be considered in the achievement of the objective, and recommendations for future work that can be made to strengthen this research. Of the biases identified by Tietenberg (2006), response bias may have been a problem in this study, as participants could have given a valuation in order to please the person administering the survey. That the participants would receive a heater regardless of their response was, however, underlined in the survey questionnaires in order to minimise this effect. Furthermore, using the conceptual framework of this thesis, concern about strategic bias may not be so worrying. Psychological approaches tell us that, among the other variables in the choice process, awareness of what we think others might do or think (subjective norms) may play a role (Widegren, 1998; Bratt, 1999; 
Stern, et al., 1999) and there is nothing right or wrong about the role of this influence on choice.

The idea of a socially desirable response is unappealing to some economists because it is outside rational choice theory and complicates the idea of (individual) utility maximisation (Veisten, 2007).

Participants' understanding of contingent valuation situations presents another problem for studies - as reflected in the recommendations of the NOAA panel and elsewhere (Arrow, et al., 1993; Markandya, 1993; Plott and Zeiler, 2003; Zarnikau, 2003). However, the information sessions where the participants of the HHHS learnt about the non-market benefits of their heaters were detailed and thorough. Nevertheless, the time that elapsed between these meetings and implementation of the householder surveys may mean that some participants had forgotten information, particularly as the second survey was undertaken over a year after the initial information was given. In order to give weight to the importance of ensuring participants understand contingent valuation situations, an alternative approach may have been to refresh participants with this information, prior to the question being asked. However, as noted above, both the control and intervention group contingent valuations increased in the second year of the study, which suggests that reflection and consideration of value has occurred.

A regression analysis could provide further insights into the roles of household income, ownership or tenancy and location in affecting WTP and WTA of energy efficient heaters. However, this is outside the scope of this thesis. A regression analysis is a recommendation for any future study of $\mathrm{CV}$ of energy efficiency measures, as is the collection of more demographic information.

\subsection{Analysis of socio-behavioural motivations and barriers}

Objective 3: Identify and analyse socio-behavioural motivations and barriers to energy efficient warm homes, including the role of information in household heating choices.

It is useful to summarise the ideas that were raised in the focus groups by dividing them into motivations of energy efficient warm homes and barriers to energy efficient warm homes. There are some factors that arose that could be both motivations and barriers - that is, these factors may have benefits for energy efficiency, but are not conducive to homes being heated to a healthy temperature (Table 15). Whether these factors are or become motivations or barriers to energy efficient warm homes may depend on how political and social pressures affect people over time. 
Table 15. Motivations for and barriers to energy efficient warm homes.

\begin{tabular}{|c|c|c|}
\hline Motivations & Motivation or barrier? & Barriers \\
\hline 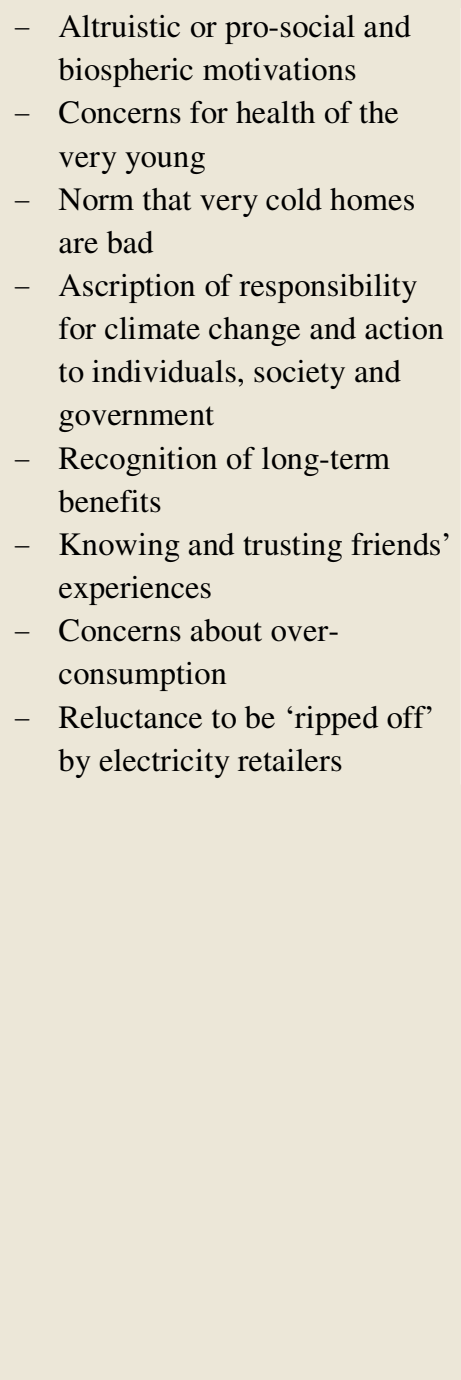 & 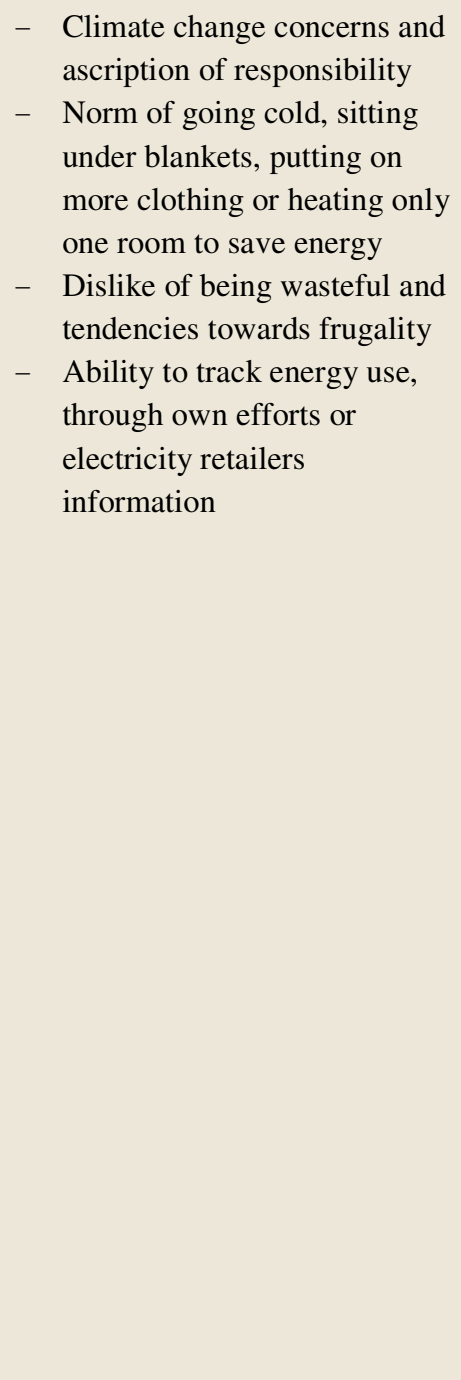 & $\begin{array}{l}\text { - Upfront and running costs } \\
\text { - } \text { Split incentives for tenants } \\
\text { - } \text { Invisibility of energy use/lack } \\
\text { of knowledge of personal use } \\
\text { - Direct debit payment systems } \\
\text { - } \text { Complexity of climate change } \\
\text { - Unresponsiveness to norms } \\
\text { - Information/understanding } \\
\text { - Lack of knowledge of what } \\
\text { is 'normal'/expected } \\
\text { consumption } \\
\text { - Lack of knowledge of } \\
\text { existence of government } \\
\text { organisations such as EECA } \\
\text { and its activities } \\
\text { - Difficulty locating } \\
\text { information } \\
\text { - Difficulty in 'knowing what } \\
\text { to ask' } \\
\text { - Lack of knowledge about } \\
\text { health impacts } \\
\text { - High incomes = less concern } \\
\text { about saving energy } \\
\text { - Lack of trust of retailers } \\
\text { - Condition of homes } \\
\text { - Guilt and disempowerment } \\
\text { - Hack of agency) } \\
\text { energy /climate change issue }\end{array}$ \\
\hline
\end{tabular}

These factors are discussed further below.

\subsubsection{Factors in heater choice}

When it comes to home heating, the focus group participants seemed, not surprisingly, to want it all - instant warmth, comfort, low running costs and forms of heating that were not detrimental to the environment. However, similarly to previous research, financial matters greatly constrained heating choices (Smith, et al., 2006b). In particular, environmental preferences were superseded by more immediate purchase cost concerns.

The tension between costs and benefits to the individual (upfront cost, warmth and convenience) and to the environment were widely discussed. This is the tension between being a consumer and being a citizen. While participants indicated that environmental concerns were considered home 
heating decision-making, the other factors they valued - particularly low cost and warmth ultimately seemed to create boundaries to their choices. While the attitudes of most of the participants were pro-environmental and altruistic, these attitudes were not readily expressed in their home heating choices as these attitudes did not always align with other preferences or other barriers were more important. This is perhaps to be expected where upfront cost barriers are high, such as with some energy efficient heaters (Gardner and Stern, 1999).

A few participants understood that there were health risks in exposing very small children to low temperatures in the home, leading them to heat their houses more than they would otherwise. However, participants did not appear to give any consideration to risks to their own health (as adults). While it is the young, the elderly and the sick that are most at risk of cold homes, adults may also be at risk of exacerbating respiratory illness (Howden-Chapman, et al., 1999; HowdenChapman, et al., 2007). There was some recognition in the second group that cold houses may be detrimental to health, but for both groups, a young child appeared to be a motivation for people to ensure that they kept their homes warm.

\subsubsection{Knowledge and attitudes}

Both knowledge and attitudes may have important roles to play in environmental management. In particular, attitudes are likely to be important in determining choices where other barriers are low, as for the development of social norms in the long term (Clark, et al., 2003; Garling, et al., 2003; Fujii, 2006).

\section{Climate change}

Awareness of climate change and the contributions of energy use to climate change were relatively high amongst the participants. Despite this, most participants found it difficult to understand the processes at work. Participants appeared to ascribe responsibility for addressing climate change to themselves as individuals, but also pointed out on a number of occasions that society as a whole and the government were also responsible for mitigation. This shared sense of responsibility could be a barrier to action, but a sense of an individual's worthwhile contribution to addressing the problem may be important to nurture.

\section{Understanding energy use in the home.}

When asked what people knew about the energy they use in their home, participants seemed to find it difficult to answer or conceive this outside the cost frame of their electricity bill. Energy consumption (particularly electricity) is essentially invisible to the consumer until they look at their monthly bill from their energy provider. Even then, it is difficult to know what is used by what appliances at what time (Kempton and Layne, 1994). Furthermore, any changes in energy prices make tracking how much people are consuming even more difficult. 
The participants showed differences in keeping track of their electricity expenditure, from closely following electricity bills in order to avoid being "ripped off" by providers, to using direct debit to pay bills. Direct debit systems provide greater security for both consumer and retailer. However, it may mean that consumers skip reading their electricity bill, the main way in which energy use is made concrete. If the use of direct debit is a widespread practice, it may have serious ramifications for attempts to improve residential energy efficiency. Investigating the impact of direct debit bill payment could be an avenue for future research looking at how people understanding energy use in their homes.

Another participant felt that by getting people to reduce the size of their electricity or gas bill the country would be "going in the right direction". This method of using reducing energy consumption ignores the problems of under-heating and fuel poverty. This assertion was met with some disagreement. Others supported a participant who responded that it was important to consider the "social side of things" and the affordability of efficient and effective home heating. New Zealand has a problem with fuel poverty (Lloyd, 2006), and certainly has cold homes. Any attempt to improve space heating efficiency needs to account for those people who live in cold homes, because of fuel poverty or low income, if New Zealand is to achieve more equitable outcomes such as warm houses for all the community.

\section{Shared social responsibility}

One attitude that came across strongly in both focus groups was that people believed energy efficiency was important because it was beneficial for both themselves as individuals, for the environment and wider society, in the long term. This is reflected in comments such as:

If we all as a country use the energy we've got a little bit more efficiently, we don't need to dam another valley on the West Coast.

The altruistic reflection on the impact of energy consumption on the country by the use of 'we' indicates an attitude of a shared problem for which all New Zealanders are responsible. This focus on shared responsibility may also be partly an artefact of the focus group process as a deliberative research method. Because of the very nature of group discussion, participants are likely to be inclined to consider the well-being of the community as a whole (Vatn, 2005). This may then increase the tendency of the participants to talk about the collective. However, the participants, as individuals, may also be likely to hold such a collective concern. Reflecting on the conceptual framework, behavioural economics tells us that people are often motivated to act in the public best interest (altruism) (Dawnay and Shah, 2005). In this regard, it is then not surprising how considerable talk of collective responsibility arose, especially in a group context. 
9.2.3. Norms

The role of social norms has been shown to play an important role in the promoting proenvironmental behaviours in a number of contexts (Widegren, 1998; Bratt, 1999; Stern, et al., 1999; Viemeir and Verbeke, 2006). Furthermore, cultural norms of energy use in the home are also important to consider in understanding home heating choices (Wilhite, et al., 1996; Cupples, et al., 2007). As noted in Chapter 8, two norms emerged from the focus group discussions.

\section{Very cold homes}

Firstly, it appeared that very cold houses were unacceptable. The focus group participants told of how unfair it is to live in cold rental properties and of how unpleasant it is to visit friends' cold houses. There was also widespread acceptance that it was unacceptable to invite people into your home and have them sit in the cold. While participants could readily identify home heating and broader residential energy choices that they found unacceptable, they were not readily prepared to speak up to their peers about their feelings. Participants appeared more likely to use humour (such as one participant's sitting in her ski jacket), relying on peers 'getting the hint' and responding to their general (but not explicitly expressed) disapproval of the other's heating habits rather, than being able to enforce the norm. The mode of expressing this injunctive norm (Cialdini, et al., 1990) appeared to be too implicit for the other to understand. The only case where a participant felt able to speak up about a peer's heating habit is when money was a motivating factor, as the participant had to share the power bill. This is then, perhaps, a situation where the feeling for warm homes has not become a strong enough social norm to be readily expressed to others.

\section{Energy consumption and heat trade-offs}

The second norm that became apparent was the decision to be colder in a home than desired in order to reduce 'excess' energy consumption. In the first focus group participants seemed somewhat stuck between the tensions of wanting to be warm and being concerned about climate change. Instead of this apparent paralysis, the second group generally expressed the feeling that if you were concerned about climate change and energy use pressures, you would be frugal with energy use and willing to go cold in your home. This was also reflected in less talk of 'we' in the second group and a greater focus on individual responsibilities. Many participants in the second group concentrated on heating just one room of their houses, heating to lower temperatures, and using blankets and extra clothing to keep warm.

Donning another layer or two is a pragmatic response to cold homes, an apparently sensible choice rather dominant within the second group. This is in line with literature that suggests that "in the residential sector the perception that energy efficiency requires sacrifices has been 
persistent" (de T'Serclaes, 2007, p. 15). While wearing more clothes may be one way to reduce heating and therefore energy consumption, is it a fair way? This focus group's discussion went further to imply that unless you had access to sufficient finances there was not much point in attempting to heat your home well. Some participants also expressed concern that once people have money to have a well heated home, they no longer care about energy efficiency as much because financial constraints are no longer an issue.

Overall, the previously identified stoicism in home heating amongst New Zealanders (Shannon, et al., 2006; Cupples, et al., 2007) was stronger amongst the second group than the first group, though bringing visitors into a cold home was unacceptable for both groups. However, instead of this stoicism being based on masculine identity reinforcement (Cupples, et al., 2007), it appeared as if the rationalisation for not heating homes well had it's (perhaps ex-post) rationalisation in a consideration of the environment and an unwillingness to be frivolous with energy use. This has serious consequences for any attempts to help New Zealanders have warm homes. Warmth, in this context, appears to be almost irresponsible from this altruistic point of view.

\subsubsection{Renting}

The issue of split incentives for investment in energy efficient technologies arose in both the quantitative and qualitative findings. While the focus group participants agreed that tenants should take some responsibility, ultimately the responsibility for energy efficiency lay with the landlord. Feelings ran high in these discussions, almost as if tenants were being done an injustice.

The quantitative results indicate the tenants' WTP for efficient heaters is below that of home owners, and so continued underinvestment is likely to continue if the split incentives problem is not addressed (Table 10). While EECA currently runs a subsidy scheme for private landlords, the level of awareness of this programme was very low among the focus group participants (only one participant was aware). If the split incentives problem is considered a genuine policy target, it is important to ensure that the general public is well informed of the existence of such a scheme.

\subsubsection{Information}

The provision of information to address market failure is an age-old policy solution (McKenzieMohr and Smith, 1999; Newell, et al., 2006). There is a need to ensure that consumers are well informed about home heating options, and understanding how to promote this has an important role to play in policy development. Information must be well targeted and responsive to the other behavioural factors at play in consumers' decision-making (Gardner and Stern, 2002; Stern, 2005). Information is necessary to augment consumers' knowledge of home heaters, but the uptake of better heaters is not simply a function of information acquisition - it is instead a social process through which people engage with technology (Niemeyer and Littleboy, 2005; Jackson, 
2006). And while information may not produce action in the short term (if other barriers are present), it may beneficial for the shaping of attitudes and action in the long term (McKenzieMohr and Smith, 1999; Gardner and Stern, 2002; Abrahamse, et al., 2005).

\section{Access to information}

Access to information amongst the focus group participants was mixed. For instance, while a few participants were well informed and active at seeking information, other participants felt that there is "no clear guidance" on residential heating and energy efficiency matters. A number of participants also indicated that they found it difficult knowing what to ask. To some extent, it is easy for the participants of the focus group, as it is for members of wider society, to fall back on claiming to not know enough to enable them to act in a pro-environmental manner. This is consistent with the so-called 'attitude-behaviour' gap, describing the disparity between what people say they are concerned about and how they act with regard to that concern (Barr, 2004). However, as one indication of how much people did or didn't know, only three of the focus group participants knew of the existence of EECA. For the government body charged with the task of improving energy efficiency in New Zealand, this is hardly an encouraging finding, particularly as these participants were likely to be highly motivated individuals (due to self-selection).

Participants sought information from a number of sources. Older participants were more likely to go to their local library or to the Citizen's Advice Bureau, and also appeared less likely than other participants to access a range of sources. Finding a means for providing information to elderly people is important, particularly considering that they are at greater risk of health effects from cold houses (Rudge and Winder, 2002; Davie, et al., 2007). Use of the internet was also brought up by a number of participants. However, while the internet can be a bountiful source of information, it is not a tool accessed by all members of the public, nor is it easy for people to know where to look or who to trust. The Consumer magazine was seen as reliable and relevant, enjoying a high level of accessibility and trust in its recommendations. It should be noted, though, that while Consumer provides some information at no cost, other information is only provided after payment or subscription. Combining technical information with stories or experiences was appealing to participants. For example, a Radio New Zealand National programme on heat pumps was rated highly as it incorporated personal stories and experiences of the appliance combined with advice from energy efficiency experts.

When given the chance to ask questions that had not been addressed during the session, one participant responded:

One of the questions that really exercises my mind in terms of household energy use is, what's normal? 
This question illustrates the vacuum in which people feel they are operating in terms of understanding energy use. This reinforces the point that there is often little information for people to access in the energy arena (de T'Serclaes, 2007), to the point where lack of information and knowledge has been identified as a barrier to efficient space heating in New Zealand (Smith, et al., 2006b). Providing profiles of 'normal' energy use may also be an important method for promoting energy efficiency - knowing about other people's behaviours is a great motivator for change (Dawnay and Shah, 2005).

\section{Friends and family}

Friends and family were important and trusted sources of information about heating options for many of the focus group participants. A review of energy efficiency policies in the UK indicated that " $[t]$ here is an opportunity cost for householders in finding out about and weighing up these issues" (Oxera, 2006, p. ii). Talking to peers is one way to reduce these opportunity costs, though there is a risk of receiving poor quality (non-expert) information. The role of interpersonal communication is important to understand as there is evidence that it is more important in the uptake of energy efficient technologies than the attributes of the technologies themselves (Ball, et al., 1999). However, in the context where the experience of friends may be key to others' adoption of the more efficient heaters, if technology is changing rapidly, understanding the attributes of new heaters may be difficult (Wittmann, et al., 2006). One focus group participant noted that friends' experience with technology that is changing rapidly, such as heat pumps, is not particularly useful. As discussed above, this lack of understanding may contribute to contingent valuations being lower than market prices, as found in the quantitative results, which may, in turn, be interpreted (in part) as indicating a lack of familiarity with the attributes of the heater, and uncertainty about their benefits.

\section{Trust}

Trust is an important factor in processing information. Social learning theory tells us that people do not learn from others in a consistent manner, depending instead upon the person advocating or demonstrating the behaviour - we learn most effectively from people who are influential, attractive or similar to us (Jackson, 2005). Information from family and friends means that the listener already knows the information provider's values and attitudes; therefore disseminating information through these channels may be more effective than traditional approaches.

Previous research suggests that newspapers and television are the most important sources of environmental information for New Zealanders, and government and scientists are the most highly trusted sources (Cullen, et al., 2006). However, that research did not ask about the role of friends and family as sources of information and their level of trust. Given the focus group findings, we can conclude that finding ways of sourcing information via trusted peers could be 
included in future studies on effective information dissemination in relation to pro-environmental behaviours, though this is probably difficult to achieve in a policy sense.

The focus group participants viewed retailers as less trustworthy, though electricity providers appeared to have a reasonable standing among the participants. Electricity providers have an advantage as information providers - access to consumers is already broadly established in the form of monthly bills. Electricity providers can indicate on monthly bills how household consumption is changing through time, thus helping to improve the visibility of energy use. Making energy consumption data visible, for example with more sophisticated forms of smart metering, is an important aid to promote energy efficiency.

\section{Framing}

The way in which information is framed is also important, as instanced by the comment:

I think that if people could all just become more aware of waste, of wasting energy, then that would help everybody ...

Prospect theory (Kahneman and Tversky, 1979) tells us that people are more averse to a loss than to the equivalent gain - this is also one of the principles of behavioural economics (Dawnay and Shah, 2005; Layard, 2005). Therefore, if energy efficiency messages are framed in the manner of 'this is the energy you are wasting', they may be more effective than messages framed in an energy savings sense.

\subsubsection{Achievement of objective}

The focus groups ran relatively successfully, though no doubt more groups would have yielded further insights. There was a relatively low number of people participating due to difficulty in recruitment. The self-selection method was not optimal, both as it may have led to this low level of recruitment, and because it leaves findings open to self-reporting bias. An alternative would be for such focus groups to be run through an agency employed to recruit participants (though this may have its own selection problems), or through approaching organisations where people already meet. The dialogue flowed much better in the first group than in the second, perhaps due to the different seating arrangements; therefore care needs to be taken to ensure that the room layout is appropriate.

Extending the work of the focus groups may also be useful in future research. This could ask participants more explicitly about policy solutions for promoting warm, energy efficient homes, as deliberative reasoning methods such as focus groups can enhance public acceptance of policy (Vatn, 2005). Any future focus groups could also pilot the questions before using them in an actual investigation - this was not undertaken here and resulted in one or two problems with 
terminology, such as participants not understanding the phrase 'security of supply' and consequently suffering some confusion.

\subsection{Public policy suggestions}

Objective 4: Discuss implications of findings for public policy measures promoting the uptake of energy efficient home heaters.

If the positive social and environmental outcomes of energy efficient home heating are to be pursued by policy, the low initial valuation of energy efficient heaters in quantitative results suggests that consumers need to either better understand the benefits of efficient heaters, or financial assistance needs to be provided to increase the uptake of these energy efficient technologies. Information asymmetries were also evident in the focus group work. The quantitative data also indicate that there is a rebound effect to address in improving heater energy efficiency. It is recommended that the quantification of the rebound effect in heating and other residential energy services is further investigated in New Zealand, as well as exploration of ways to address the implications of the rebound for increased energy use. However, it should be noted that the rebound effect should not be interpreted strictly as a negation of efficiency gains, but instead as a translation of those efficiency gains into improved well-being (including better health), which is itself a socially valuable outcome.

It is necessary to address both the information available to consumers and access to the information. It is the job of government agencies such as EECA to ensure that people understand the array of benefits that energy efficient technologies (such as a heater) embody. While a labelling system like the EnergyStar rating is useful for informing about energy efficiency, if people don't comprehend the range of benefits of energy efficiency then labelling may not be particularly useful. There appears to be some awareness amongst the focus group participants of the social and environmental benefits that can result from more energy efficient homes, but not so much of health related benefits. Participants were aware of the trade-offs that must be made between individual (short-term) and broader social or environmental (long-term) costs and benefits when they make home heating choices. Information provided by government agencies could look to reinforce these environmental preferences, and information could be given to help raise awareness of the health benefits of efficient space heating.

Few of the focus group participants had heard of EECA and its activities. Combined with the recent revelation that no subsidies for solar water heaters were given out by EECA in the last financial year, this lack of knowledge amongst a group of people who are motivated to be energy efficient is telling. EECA needs to have a greater profile amongst the general public as both a 
source of thorough and accessible information on home heaters, and as an agency that provides financial assistance for residential energy efficiency improvements.

The focus group findings indicate that interpersonal relationships are important in learning about home heating and energy efficiency choices. Effort could therefore be made to identify groups or individuals that are both readily accessible and highly trusted. EECA, the MfE or the Department of Housing and Building could work with trusted organisations to provide reliable and useful information, mixing quantitative data with personal stories. For instance, this could link to the Sustainability Trust's current community communicators work (EcoKiwi scheme). Discussions for the general public about home heating technologies and energy efficient behaviours could also be developed, led and funded by EECA and run by established local community groups such as the Sustainability Trust or Community Energy Action. The need for localised action and leadership is recognised in the suggestions made by Smith et al. (2005b). This thesis reinforces the recommendation of that report for the creation of local steering groups to help assist the local application of residential energy efficiency measures (including the Warm Homes project and EnergyWise schemes) and identification of households in need. This work could also take an explicit community-based social marketing (McKenzie-Mohr and Smith, 1999) approach to understanding and addressing barriers to residential home heating.

Information provision could capitalise on the role of social norms in residential energy choices. As signalled by the focus group participants, EECA could develop profiles of energy use for different types of housing situations, or provide information on average energy consumption for people to compare their consumption to. This could be undertaken on a small-scale basis so that people's local concerns are engaged. Furthermore, this could be extended to providing information on what heating people have found suitable to different living situations. Information could also be framed to take advantage of how people respond to losses and gains. As noted above, it may be important to frame energy efficiency data in terms of avoiding the 'waste' of energy and the benefits of this, instead of the savings made.

Messages could also be framed to reinforce attitudes and beliefs that the public already has. For instance, particular mention was made in the focus groups of the well-being of small children. Assuming this is a widely held attitude, information could target this concern or be disseminated through networks of parents that already exist (such as Plunket). Using social networks to spread knowledge may also have the benefit of strengthening pro-environmental attitudes through time (Gardner and Stern, 2002; Abrahamse, et al., 2005). Ensuring equitable home heating outcomes also means targeting information to places frequented by those likely to be in fuel poverty or at greater risk of negative health impacts. For example, knowledge among the elderly population may be improved by ensuring that organisations such as the Citizen's Advice Bureau have 
information about energy efficiency and heating targeted to older people. This targeting may be strengthened through further research to elucidate where particular demographic groups go to source information.

Household heating energy efficiency depends on the heating appliance, the condition of the building envelope, fuel types, household behaviours and social and cultural expectations. Therefore any attempts at promoting energy efficient, warm homes could aim to address these multiple factors. Such an integrated approach could conjointly promote insulation, draughtstopping, thermal curtain use, more efficient behaviours and strategically leverage social norms along with promoting more efficient forms of heating. This type of approach may require a crossgovernment response.

Because of established access to consumers, electricity providers could be encouraged to take greater responsibility for providing information on energy use to improve consumption visibility (acknowledging that some already make significant efforts). Those electricity providers that are State owned enterprises, given their role in providing for the public good (State Owned Enterprises Act 1986, s4(1c)) and for corporate social responsibility (New Zealand Government, 2007d), could be required to provide greater information on household energy use on electricity bills. Furthermore, this could later be recommended to non-SOE energy providers, with appropriate incentives if necessary. While this kind of information provision may not be a driver of major behavioural change, it is useful for filling a gap that currently exists, for reducing the current transaction costs associated with locating information, and for helping make energy use visible. 


\section{Conclusion}

This thesis investigated how people value energy efficient home heaters and how people make home heating choices. Ensuring that New Zealanders have warm and energy efficient homes has a range of environmental and social benefits, including reduced greenhouse gas emissions, reduced localised air pollution, improved social equity and reduced fuel poverty, and better health outcomes, particularly for the young and the elderly. Gaining an understanding of how people make decisions about home heating is useful for policy intervention and progress towards a more energy efficient future.

Although the contingent valuation method is subject to considerable debate, it is also a recognised and well-used method for eliciting values of goods that embody environmental and social benefits. Hence a contingent valuation study, undertaken by the University of Otago, Wellington, the Housing, Heating and Health Study, was used to illuminate through an analysis undertaken in this thesis, the economic value of energy efficient home heaters. Taking a mixed methods approach, this thesis also undertook focus group research that explored further how people are making home heating choices.

A striking finding of the contingent valuation work is that despite the information provided on the benefits of the new, energy efficient heaters, participants generally valued energy efficient heaters below the actual market price of the heaters. This was the case for both WTP and WTA estimates. In the second year, contingent valuations increased for both the intervention (WTA) and control (WTP) groups. The interpretation suggested here is that this may be a consequence of a greater appreciation of the benefits of the heater over the two years of the HHHS, through consideration and learning, although it may also be influenced by external factors such as a colder winter in the second year. There appears to be no precedent for this pattern in literature, though how well people understand the good or service in question in contingent valuation studies has been identified as a possible driver of WTP-WTA disparities. These results lend credence to the idea that is difficult for people to identify value with a single metric given the many trade-offs implicit in goods such as energy efficient heaters, and increased familiarisation with a good is likely to change people's willingness to pay or accept.

While New Zealand has a particularly low residential energy use profile, the potential for residential energy demand growth is considerable. The quantitative data indicate that there is the possibility of a rebound effect as New Zealanders upgrade to more efficient heaters, though the magnitude of this rebound is difficult to determine and could be researched further. Evidence of the problem of split incentives was found in both the qualitative and quantitative analyses. This is a serious concern for the government's signalled energy efficiency improvement targets and 
intentions to promote warm, energy efficient homes in the rental sector (around 30\% of New Zealand homes).

The focus groups findings indicate that while attitudinal factors seem to be conducive to greater energy efficiency in home heating, social norms are not quite so advanced. Very cold homes appear to not be acceptable, though this seems to be difficult for participants to 'enforce' in some social contexts. There also exists to some extent a norm that having a warm home is somewhat extravagant, emphasised quite strongly by the second focus group in particular. In order to resolve this, many participants chose to go colder in their homes than they would have preferred, indicating the Kiwi stoicism of old, though rationalised here for its environmental benefits. There is some tension between these two norms and the implications of are difficult to determine. The existence of these norms and the power they may have in home heating choices could be investigated further so that they may be leveraged by policy.

For the focus group participants, there appears to be some difficulty in accessing information and some lack of understanding about home heating energy use and options, in spite of the fact that the participants, as they were self-selected, were likely to be more motivated about energy efficiency. With very few of the participants knowing of EECA and its activities, there is a case for EECA to lift awareness of its existence amongst the general public.

Despite behaviour change being difficult to bring about through information provision alone, EECA and the MfE could consider ways of better providing information on energy efficient home heating. This could be through providing well-considered energy consumption data on electricity bills, supplying data on average energy usage in homes (working off social norms) and framing energy savings in terms of waste (responding to loss aversion). It could also be achieved through using established personal communication channels to improve knowledge and help shape positive attitudes, including using existing social networks such as trusted community organisations already working in the energy efficiency field. The information provided could be a mix of factual information and personal experiences and stories. Furthermore, the government could consider the role of SOEs and their corporate social responsibility and public good requirements by necessitating electricity provider SOEs to provide more useful energy use data to their customers. This approach could then be generalised across all energy retailers.

Further research could examine how people are making choices about a range of energy efficient consumption and behavioural matters, including home heating, taking a more explicit policy development approach. This could either be through more focus group work, or through survey work that complements focus group work. As a deliberative reasoning method that gives room for Homo politicus, focus groups have considerable potential to help inform policy choices, often 
with greater acceptability from the public as a result. Future research could strengthen the focus group approach of this thesis by giving greater consideration to the intention and design of such focus group research, including harnessing the deliberative qualities of focus groups to further explore the perceptions of the collective benefits of energy efficiency in the home.

While New Zealanders continue to live in cold and sometimes unhealthy houses, there appears to be some unwillingness to allow this to continue, as evidenced in the focus group findings. For the sake of social equity goals, the emergent norm of the unacceptability of very cold houses is important to nurture. At the same time, greater understanding of the implications of the desire to be frugal with heating, and the impacts of this for environmental outcomes, could be pursued in future research. While this frugality may lead to negative health effects for some members of society, if it could be harnessed in the right manner, it may also be useful for helping prevent uncontrolled growth in energy demand and comfort. Thus there is an impetus for the frugality that Smil (2002), for example, sees as vital for sustainability; with the right motivation, appropriate external structures and incentives, we may all live in warm but energy efficient homes. 


\section{Glossary}

BRANZ Building Research Association of New Zealand

CV

DoI

EECA

ETS

HEEP

HHHS

IEA

MED

MfE

NES

NOAA

NZEECS

OECD

PCE

WCC

WTA

WTP
Contingent valuation

Diffusion of technology

Energy Efficiency and Conservation Authority

Emissions Trading Scheme

Household Energy End-use Project (BRANZ)

Housing, Heating and Health Study (University of Otago, Wellington)

International Energy Agency

Ministry of Economic Development

Ministry for the Environment

National Environmental Standard

National Oceanic and Atmospheric Administration (U.S. Federal Government)

New Zealand Energy Efficiency and Conservation Strategy

Organisation for Economic Cooperation and Development

Parliamentary Commissioner for the Environment

Wellington City Council

Willingness to accept

Willingness to pay 


\section{Appendix 1 - Housing Heating and Health Study Householder Survey questions}

This is a compilation of all the questions for which data was collected from the HHHS that were used in this thesis. Questions come from the HHHS Householder Surveys of 2005 and 2006 and retain the numbers they were allocated in the survey. Each household was identified with an assigned number. Extra information, including the location of households and heater choices was collected separately.

\section{Householder Survey}

3. Do you own or rent your dwelling?

$\square \quad$ Own
$\square \quad$ Rent from a private landlord
$\square \quad$ Rent from Housing New Zealand
$\square \quad$ Rent from family
$\square \quad$ Rent from other
$\square \quad$ Which other?

b) We would like to measure how much people would be prepared to pay for more efficient heating. One way of doing this is to imagine how much you would pay for your new heater. (In fact, the heater will be free to you - you will not be asked to pay). Can you say what is the most you would pay for a new, efficient heater?
Nothing
$\$ 1-\$ 300$
$\$ 301-\$ 1000$
$\$ 1001-2000$
$\$ 2001-\$ 5000$

More than $\$ 5000$

48. Could you tell me our household's income before tax last year

Up to $\$ 38,000$

$\$ 38,001$ to $\$ 60,000$

$\$ 60,001$ plus

Don't know (do not read out, tick only if volunteered)

Refuse to state (do not read out, tick only if volunteered) 


\section{Householder Survey}

\section{For ALL households}

17. a) Thinking back, to when you were deciding which kind of heater you would like to get from the study, which of these issues were important to you?

\begin{tabular}{lcc}
\hline & $\begin{array}{c}\text { This } \\
\text { mattered a } \\
\text { lot }\end{array}$ & $\begin{array}{c}\text { This } \\
\text { matter }\end{array}$ \\
\hline I can afford to run it. & $\square$ & $\square$ \\
\hline It's good value for money. & $\square$ & $\square$ \\
\hline $\begin{array}{l}\text { I can plan (budget) when I will } \\
\text { pay for the fuel/energy. }\end{array}$ & $\square$ & $\square$ \\
\hline It gives “instant heat". & $\square$
\end{tabular}

\section{A) - for households that have already had their new heater installed.}

i) Because of your new heater your house might have been warmer than before, if you still spend the same on heating. Thinking back over the winter, what do you think you did?

Saved lots of money and had the house no warmer.

Saved some money and had the house a bit warmer.

Saved nothing and had the house a lot warmer.

The new heater didn't make my house warmer.

I spent more money because is was worth it to be warmer.

The new heater was too expensive to run for the extra heat it gave. 
ii) We would like to measure how much your household values your new heater. One way of doing this is to imagine how much you would pay to keep your new heater, now that you know what difference it makes. (In fact, the heater is free to you - you will not be asked to pay). Would this be:

Nothing

$\$ 1-\$ 300$

$\$ 301-\$ 1000$

$\$ 1001-2000$

$\$ 2001-\$ 5000$

More than $\$ 5000$

\section{B) - for households waiting to have their new heater installed}

i) Although your new heater has not yet been installed, when it is, your house might be warmer than before, if you still spend the same on heating, or you might use less energy and save money on your fuel bill maybe you could save $\$ 10$ or $\$ 20$ a month.

What do you think you might do next winter?

Save lots of money and have the house no warmer.

Save some money and have the house a bit warmer.

Save nothing and have the house a lot warmer.

ii) We would like to measure how much your household values your new heater. One way of doing this is to imagine how much you would pay for your new heater. (In fact, the heater will be free to you - you will not be asked to pay). Would this be:

Nothing

$\$ 1-\$ 300$

$\$ 301-\$ 1000$

$\$ 1001-2000$

$\$ 2001-\$ 5000$

More than $\$ 5000$ 


\section{Appendix 2 - Human Ethics Approval documents}

TE WHARE WĀNANGA O TE ŪPOKO O TE IKA A MĀUI

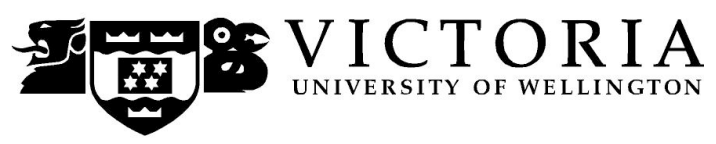

\section{MEMORANDUM}

$$
\begin{array}{ll}
\text { Phone } & 0-4-4635676 \\
\text { Fax } & 0-4-4635209 \\
\text { Email } & \text { Allison.kirkman@vuw.ac.nz }
\end{array}
$$

\begin{tabular}{l|l}
\hline TO & Hayley Vujcich \\
\hline COPY TO & Associate Professor Ralph Chapman, Supervisor \\
\hline FROM & Dr Allison Kirkman, Convener, Human Ethics Committee \\
\hline
\end{tabular}

\begin{tabular}{l|l}
\hline DATE & October 17, 2007 \\
\hline PAGES & 1 \\
\hline
\end{tabular}

\begin{tabular}{l|l}
\hline SUBJECT & $\begin{array}{l}\text { Ethics Approval: No 0000015243, Valuing warm homes - an } \\
\text { investigation of New Zealanders' home heating choices. }\end{array}$
\end{tabular}

Thank you for your application for ethical approval, which has now been considered by the Standing Committee of the Human Ethics Committee.

Your application has been approved and this approval continues until 28 February 2008. If your data collection is not completed by this date you should apply to the Human Ethics Committee for an extension to this approval.

Best wishes with the research.

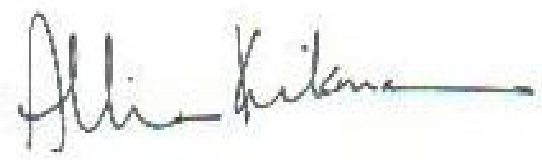

Allison Kirkman

Convener 
PARTICIPANT INFORMATION SHEET

\section{Master's Thesis Research Project: \\ 'Valuing warm homes - an investigation of New Zealanders home heating choices'}

September 2007

\begin{tabular}{|ll|l|}
\hline Researcher: & Hayley Vujcich & School of Geography, Environment \\
Phone: & 043813346 & and Earth Sciences (SGEES) \\
Mobile: & 0211051422 & Victoria University of Wellington \\
Email: & vujcichayl@ student.vuw.ac.nz & PO BOX 600 \\
Supervisor: & Assoc Prof Ralph Chapman & Wellington 6140 \\
Phone: & 044636153 & 044635337 \\
\hline
\end{tabular}

Dear Project Participant,

This focus group research, should you agree to participate, makes up part of the research that I am undertaking for my Master's thesis in Environmental Studies at Victoria University of Wellington. This project will investigate how people are thinking about household heating in New Zealand, what factors are important in their choices, and how New Zealanders learn about household energy efficiency. This research aims to answer the question:

How do New Zealanders value different home heating systems and how are they making choices about home heating?

This focus group research is one part of the thesis. Other research methods included in this study are a literature review and the analysis of specific survey results from the Housing Heating and Health Study run by the University of Otago, Wellington.

The themes of interest during the focus group sessions include how people are heating their homes, what factors are important in choosing heating systems, the role people feel they play in issues such as climate change, the role of values and social norms in determining people's heating choices and how people find information and learn about energy efficiency in the home.

\section{Confidentiality}

At the beginning of the focus group session, you will be given an Informed Consent Form (attached). If you choose to participate in this research, this form indicates that you acknowledge that your identity will be kept confidential at all times. This means that any comments that you make will not be attributed to you, nor will your name be used on any document besides a contact list.

Because the session will be audio recorded, you may choose to use a name different from your own during the focus group if you wish. No names will appear on the session transcripts - names of all participants will be exchanged for a letter-number code and only this code will appear in the published results. The real names associated with the letter-number codes will be kept securely by me and will not be made public unless written permission is given by the individual to do so.

Confidentiality of the identity of other focus group participants is also important. You must not at any point disclose the identity of the other participants in the group. You are asked to sign a Statement of Non-disclosure to this end. Please respect the privacy of the other participants. 


\section{Storage and disposal of data}

Access to the written and electronic material will be restricted to myself and my supervisor. All written material will be kept in a locked file and all electronic material will be password protected. At the conclusion of the research, all focus group material, written and recorded, will be destroyed or electronically wiped.

The results of the focus group work will be reported in my thesis, and will potentially be presented in academic journals and conferences in the future. The thesis will be submitted for marking to the School of Geography, Environment and Earth Sciences, Victoria University of Wellington.

\section{Right of withdrawal}

At any point during the focus group session you have the right to withdraw from the discussion or choose not to answer any questions. You will be given an opportunity to listen to the record of the discussion at the end of the session when the researcher will give a summary of the discussion to the group. You have the right to contribute more information or dispute the contents of this summary if you wish. You may withdraw permission to use any comments made by yourself during the course of the focus group. If you wish to do this, or to withdraw from the research altogether, you must inform me of your withdrawal no later than six weeks after the date of the focus group session.

\section{Provision for feedback}

You have the right to check the summary of the focus group discussion, and will be able to provide any corrections, prior to the analysis of the data (scheduled for December 2007).

If you wish to receive a summary of the results of this research once it is completed, please circle 'Yes' to Question 8 of the Informed Consent Form (attached), or do so later by request (email vujcichayl@student.vuw.ac.nz with 'ENVI Thesis' in the subject line). Copies of the completed thesis will, once finished, be available from the School of Geography, Environment and Earth Sciences library and in the Victoria University of Wellington electronic database of theses.

Please feel free to ask any further questions about this research and your part in it. Questions can be addressed to myself during the course of the focus group session, or later by contacting me or my supervisor, Associate Professor Ralph Chapman, through the contact details provided on the first page of this letter.

Thank you for your time and participation.

Yours sincerely

Hayley Vujcich 


\section{INFORMED CONSENT FORM}

Master's Thesis Research Project:

'Valuing warm homes - an investigation of New Zealanders home heating choices'

\begin{tabular}{|ll|l|}
\hline Researcher: & Hayley Vujcich & School of Geography, Environment and \\
Phone: & 043813346 & Earth Sciences (SGEES) \\
Mobile: & 0211051422 & Victoria University of Wellington \\
Email: & vujcichayl@ student.vuw.ac.nz & PO Box 600 \\
Supervisor: & Assoc Prof Ralph Chapman & Wellington 6140 \\
Phone: & 044636153 & 044635337 \\
\hline
\end{tabular}

\section{Introduction}

The Victoria University of Wellington Human Ethics Committee, which has approved this research project, requires that all research involve participants who:

- are fully informed about the nature of the research; and

- consent to participate.

This Informed Consent Form has been designed in accordance with these requirements in order to inform all participants of the nature of the project and their participation in it. This is meant to ensure that all participants are protected from any harm potentially arising from their participation in the research process.

\section{Purpose of the research}

This research is being undertaken for my master's thesis and is intended to address the question:

How do New Zealanders value different home heating systems and how are they making choices about home heating?

Please see the attached Participant Information Sheet for further information.

\section{Research format}

Qualitative research will be undertaken through a number of focus group sessions with participants in different locations. Participants are being asked to take part in one focus group session. Each session will involve a minimum of five participants and a maximum of ten participants. The focus group sessions will be facilitated by Alison Adams-Smith and assisted by myself. Focus group sessions will last approximately one hour, and will not exceed an hour and a half in length. All material discussed in the session will be digitally recorded and written notes will be taken by myself.

Please read the attached Participant Information Sheet and then complete the details overleaf.

Thank you.

Hayley Vujcich 
1. I agree to take part in this audio-recorded focus group session with Hayley Vujcich $\quad \begin{array}{rr}\mathbf{Y} & \mathbf{N}\end{array}$

2. I understand that my identity will remain confidential and that I will be identified only $\quad \mathbf{Y} \quad \mathbf{N}$ by a letter-number code in the published research

3. I agree to keep the identity of other participants involved in this focus group confidential at all times and have signed the Statement of Non-disclosure

4. I understand that the data I provide will not be used for any purpose other than that $\begin{array}{rr}\mathbf{Y} & \mathbf{N}\end{array}$ described in the Participant Information Sheet, or released to others without my written consent

5. I understand that I may withdraw from this study at any time before the final analysis of the data without providing reasons

6. I understand that I will have the opportunity to correct the summary of the focus group discussion prior to the completion of this research

7. I would like to receive a summary of the results of this research when it is completed

If yes, my address is:

My email is:

I agree to take part in this research

\section{Participant:}

Name:

Date:

Signature:

\section{Researcher:}

I certify that this form and its attached "Information Sheet" provide a complete and accurate description of the aims and processes of this research project.

Name:

Date:

Signature: 


\section{'Valuing warm homes - an investigation of new Zealanders}

home heating choices' Research Project:

\section{STATEMENT OF NON-DISCLOSURE}

I, , have taken part in a focus group organised by

Hayley Vujcich as part of the 'Valuing warm homes - an investigation of new Zealanders home heating choices' research project. I understand that confidentiality is important to everyone taking part in this focus group. I promise that I will not discuss what was said in this focus group with anyone who did not take part in it. I also promise that I will not reveal the names of other participants in this focus group to anyone.

Signature:

Date: 
'Valuing warm homes - an investigation of New Zealanders

home heating choices' Research Project

\section{FACILITATOR'S STATEMENT OF NON-DISCLOSURE}

I, , have been employed as a facilitator by Hayley

Vujcich on the 'Valuing warm homes - an investigation of New Zealanders home heating choices' research project. I understand that confidentiality is important to everyone taking part in this project. I promise that I will not discuss what was said in any of the focus groups that I have facilitated. I also promise that I will not reveal the names or identities of any of the project participants to anyone.

Signature:

Date: 


\section{Appendix 3 - Focus group location demographic profile}

This appendix gives the location and brief description of each of the focus group locations. The data used in the WCC publications comes from the 2001 New Zealand Census (Statistics New Zealand, 2001).

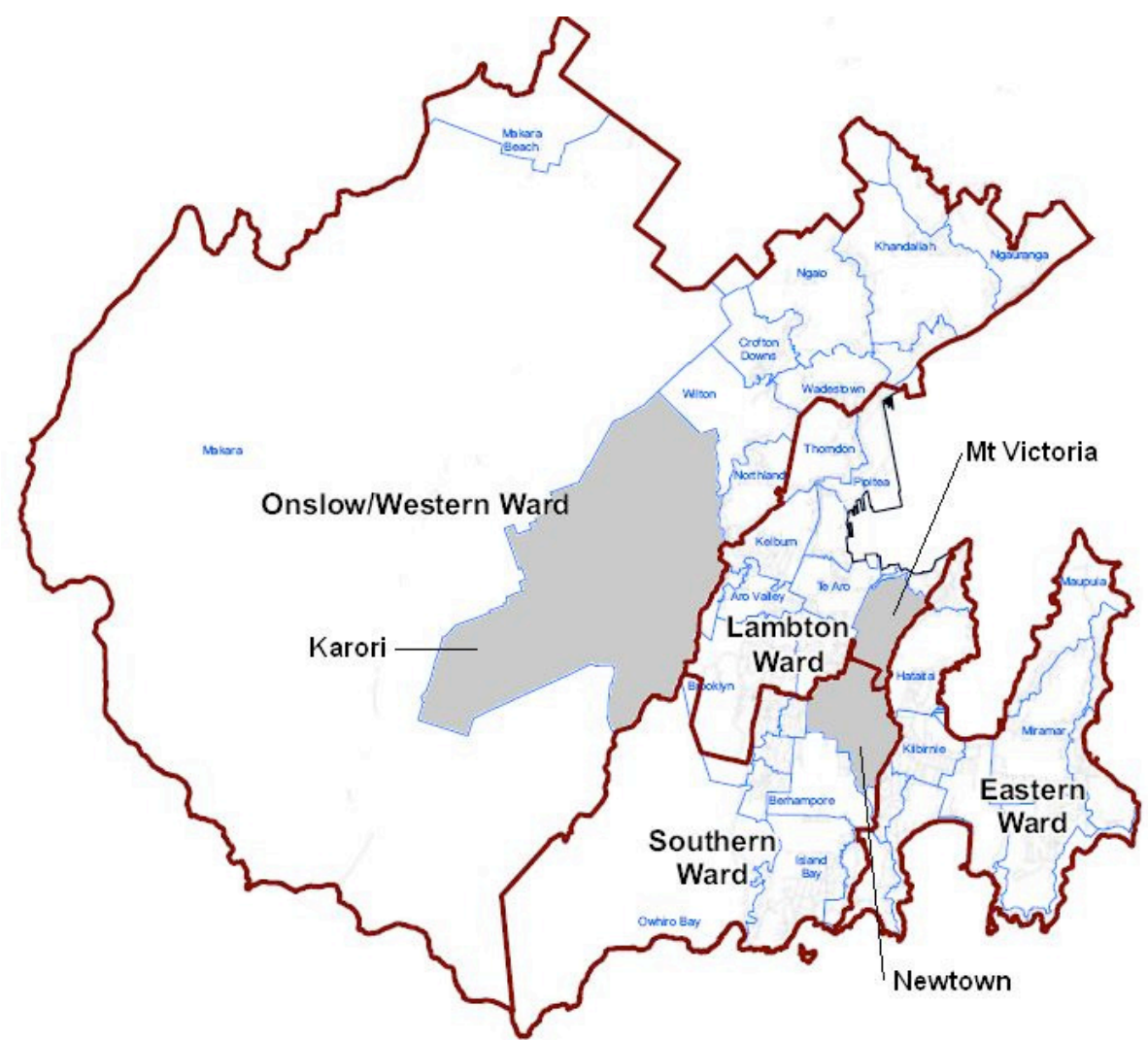

Figure 15. Wellington City wards and suburbs. Excludes Northern Ward. Adapted from WCC (2007c)

\section{Karori (part of Western Ward)}

The Western Ward has an older population than the Wellington City average (WCC, 2007d). 79\% of inhabitants are Pakeha/New Zealand European and 9\% of Asian descent, compared to $72.6 \%$ and $10 \%$ of the Wellington City population, respectively (see Figure 16). The Māori population makes up 5.4\% of the Western Ward, compared to $7.3 \%$ of the Wellington City population. Personal income is higher than the Wellington City average, with $49 \%$ of people with personal income over $\$ 30000$ per annum. Household composition is dominated by one-family households (60.9\%). 

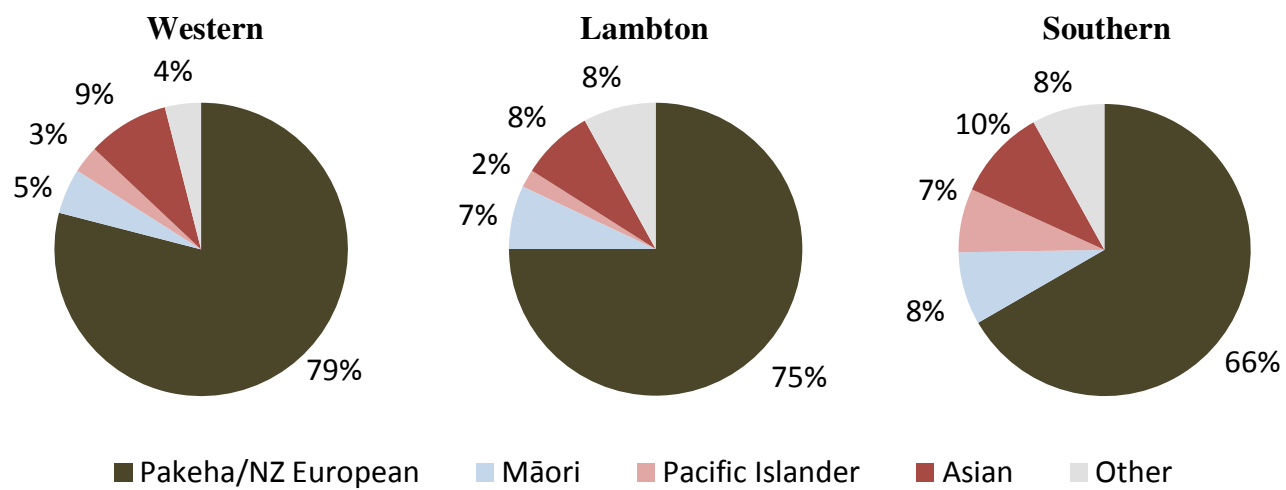

Figure 16. Ethnic composition of wards. Ethnicity of Western Ward. Sources: WCC, 2007a, 2007b, 2007d

\section{Mt Victoria (part of the Lambton Ward)}

The Lambton ward has a young population by the Wellington City area average, with over 50\% of inhabitants under the age of 30 (WCC, 2007a). 75.1\% of inhabitants are Pakeha/NZ European, and 6.6\% are Māori (see Figure 16). Similarly to the Western Ward, over 25\% of the population have household incomes of greater than $\$ 100000$ per annum. $47.3 \%$ of people have incomes over $\$ 30000$ per annum, compared to an average of $45.5 \%$ for the Wellington City area. The Lambton Ward has a higher proportion of 'non-family' households (21.3\%) than the city average (9.8\%), probably indicating a high number of shared flats.

\section{Newtown (part of the Southern Ward)}

$21 \%$ of inhabitants of the South Ward are over 50 years of age (WCC, 2007b). $31.9 \%$ of the population is aged between 25 and 39, compared to $28.4 \%$ in the Wellington City area. $66.2 \%$ of inhabitants are Pakeha/NZ European (see Figure 16). 8.1\% of people are Māori and 7.3\% are Pacific Islanders, compared to $7.3 \%$ and $4.5 \%$ of the population of Wellington City, respectively. The Southern Ward is overrepresented in all household income groups under $\$ 40000$ per annum compared to the Wellington City average. $41.4 \%$ of people have personal incomes over $\$ 30000$ per annum compared to $45.5 \%$ of the total Wellington City population. 'Non-family' households (11.6\%) and one-person households (26.1\%) make up a greater proportion of the population than the Wellington City average. 


\section{Appendix 4 - Focus group participant demographics}

Following is the demographic profile of the participants of the focus group research collected at the end of sessions with a small written survey (Table 16). It indicates a reasonable spread of ages and sex of participants, though there is a weighting towards Pakeha/New Zealand European participants and to people of lower income.

Table 16. Demographic profile of focus group participants

\begin{tabular}{|c|c|c|c|c|c|c|c|c|c|}
\hline \multicolumn{2}{|c|}{ Sex } & \multicolumn{2}{|c|}{ Age (years) } & \multicolumn{2}{|l|}{ Ethnicity } & \multicolumn{2}{|c|}{ Suburb } & \multicolumn{2}{|c|}{ Household income } \\
\hline Female & 8 & $0-20$ & & $\begin{array}{l}\text { Pakeha/NZ } \\
\text { European }\end{array}$ & 10 & Berhampore & 1 & $\$ 0-38,000$ & 6 \\
\hline Male & 5 & $21-30$ & 3 & Māori-Pakeha & 1 & Hataitai & 1 & $\$ 38,001-60,000$ & 2 \\
\hline & & $31-40$ & 2 & Indian & 1 & Karori & 1 & $\$ 60,001+$ & 3* \\
\hline & & $41-50$ & 1 & European & 1 & Mt Victoria & 6 & NA & 2 \\
\hline & & $51-60$ & 3 & & & Newtown & 4 & & \\
\hline & & $61+$ & 5 & & & & & & \\
\hline
\end{tabular}

* two of these households were shared flats, inhabited by four working adults. 


\section{References}

Abrahamse, W., Steg, L., Vlek, C., and Rothengatter, T. (2005). A review of intervention studies aimed at household energy conservation. Journal of Environmental Psychology, 25, 273291.

Ajzen, I. (1991). The theory of planned behaviour. Organizational Behavior and Human Decision Process, 50, 179-211.

Aldrich, G., Grimsrud, K., Thacher, J., and Kotchen, M. (2005). Relating environmental attitudes and contingent values: A comparison of methods. Albuquerque: University of New Mexico.

Amitrano, L. (2004). New Zealand residential energy use - An international comparison. Porirua: Building Research Aotearoa New Zealand.

Arrow, K., Solow, R., Portney, P. R., Leamer, E. E., Radner, R., and Schuman, H. (1993). Report of the NOAA panel on contingent valuation. Federal Register, 58, 4601-4614.

Ball, R., Cullen, R., and Gan, C. (1999). The diffusion of energy efficiency innovations among residential energy comsumers. New Zealand Economics Papers, 33 (1), 115-135.

Bandura, A. (1989). Human agency in social cognitive theory. American Psychologist, 44 (9), $1175-1184$.

Bandura, A. (1971). Social learning theory. New York: General Learning Press.

Banfi, S., Farsi, M., Filippini, M., and Jakob, M. (2008). Willingness to pay for energy-saving measures in residential buildings. Energy Economics 30, 503-516.

Barns, S. (in press). Cost effectiveness of management options for air quality management in Tokoroa II. Wellington: Ministry for the Environment.

Barr, S. (2004). Are we all environmentalists now? Rhetoric and reality in environmental action. Geoforum, 35, 231-249.

Begg, D., Fischer, S., and Dornbusch, R. (2003). Economics (7 $7^{\text {th }}$ ed.). Maidenhead: McGraw-Hill.

Bickerstaff, K., and Walker, G. (2003). The place(s) of matter: Matter out of place - Public understandings of air pollution. Progress in Human Geography, 27 (1), 45-67.

Black, J. S., Stern, P. C., and Elworth, J. T. (1985). Personal and contextual influences on household energy adapations. Journal of Applied Psychology, 70, 3-21.

Boardman, B. (1991). Fuel poverty: From cold homes to affordable warmth. London: Belhaven Press.

Bonnefoy, X. R., Braubach, M., Moissonnier, B., Monolbaev, K., and Robbel, N. (2003). Housing and health in Europe: Preliminary results of a pan-European study. American Journal of Public Health, 93, 1559-1563.

Brandon, G., and Lewis, A. (1999). Reducing houshold energy consumption: A qualitative and quantitative field study. Journal of Environmental Psychology, 19, 75-85.

Bratt, C. (1999). The impact of norms and assumed consequences on recycled behaviour. Environment and Behaviour, 31, 630-656.

Brown, M. A., Levine, M. D., Romm, J. P., Rosenfeld, A. H., and Koomey, J. G. (1998). Engineering-economic studies of energy technologies to reduce greenhouse gas emissions: Opportunities and challenges. Annual Review of Energy and Environment, 23, 287-385. 
Buckett, N. R. (2007). National impacts of the widespread adoption of heat pumps in New Zealand - BRANZ Study Report 169 (2007). Judgeford: Building Research Association of New Zealand.

Capra, F. (1997). The web of life: A new synthesis of mind and matter. London: Flamingo.

Carrer, P., Maroni, M., Alcini, P., and Cavallo, D. (2001). Allergens in indoor air: environmental assessment and health effects. Science of the Total Environment, 270, 33-42.

Carson, R. T. (2005). Contingent valuation: A user's guide. In L. Kalof, and T. Satterfield (Eds.), The Earthscan reader in environmental values (pp. 6-17). London: Earthscan.

Carson, R. T., and Hanemann, W. M. (2005). Contingent valuation. In K.G. Maler, and J. R. Vincent (Eds.), Handbook of environmental economics: Valuing environmental changes (Vol. 2) (pp. 821-936). Amsterdam: Elsevier.

Carson, R. T., Wright, J. L., Carson, N. J., Alberini, A., and Flores, N. E. (1995). A bibliography of contingent valuation papers and studies. La Jolla: NRDA.

Chapman, R., Howden-Chapman, P., Viggers, H., O’Dea, D., and Kennedy, M. (in review). Retrofitting houses with insulation: A cost-benefit analysis of a randomised community trial. Journal of Epidemiology and Community Health.

Chappells, H., and Shove, E. (2005). Debating the future of comfort: environmental sustainability, energy consumption and the indoor environment. Building Research and Information, 33 (1), 32-40.

Cialdini, R., Reno, R., and Kallgren, C. (1990). A focus theory of normative conduct: Recycling the concept of norms to reduce littering in public places. Journal of Personality and Social Psychology, 58, 1015-1026.

Clark, J.M. (1915). The concept of value - A rejoinder. Quarterly Journal of Economics, 29, 709723.

Clark, C. F., Kotchen, M. J., and Moore, M. R. (2003). Internal and external influences on proenvironmental behaviour: Participation in a green electricity program. Journal of Environmental Psychology, 23, 237-246.

Clark, S., Page, I., Bennett, A., and Bishop, S. (2000). New Zealand house condition survey. Porirua: Building Research Association of New Zealand.

Creswell, J. W. (2003). Research design: Qualitative, quantitative and mixed methods approaches $\left(2^{\text {nd }}\right.$ ed.). Thousand Oaks: Sage.

Crosbie, T. (2006). Household energy studies: The gap between theory and method. Energy and Environment, 17 (5), 735-753.

Crump, B. (1960). A good keen man. Christchurch: Reed.

Cullen, R., Hughey, K., and Kerr, G. (2006). Public perceptions of New Zealand's environment. Lincoln: Agribusiness Economics and Research Unit, Lincoln University.

Cupples, J., Guyatt, V., and Pearce, J. (2007). "Put on a jacket, you wuss": Cultural identities, home heating and air pollution in Christchurch New Zealand. Environment and Planning A, 39, 2883-2898.

Darby, S. (2006). Social learning and public policy: Lessons from an energy-conscious village. Energy Policy, 34, 2929-2940. 
Davie, G., Baker, M. G., Hales, S., and Carlin, J. B. (2007). Trends and determinants of excess winter mortality in New Zealand: 1980 to 2000. British Medical Council Public Health, 7 (263), 263.

Dawnay, E., and Shah, H. (2005). Behavioural economics: Seven principles for policy-makers. London: new economics foundation. Retrieved September 12, 2007 from http://www.neweconomics.org/gen/uploads/tfi0ypn1141p45zoi0mrrgf222092005201739.p df

de T'Serclaes, P. (2007). Financing energy efficient homes: Existing policy responses to financial barriers - IEA information paper. Paris: Organisation for Economic Cooperation and Development and the International Energy Agency.

de T'Serclaes, P., and Jollands, N. (2007). Mind the gap - Quantifying principal-agent problems in energy efficiency. Paris: International Energy Agency and the Organisation for Economic Cooperation and Development.

DEFRA. (2003). The United Kingdom fuel poverty strategy: First annual progress report. London: Department of Environment, Food and Rural Affairs.

Diamond, P. A., and Hausman, J. A. (1994). Contingent valuation: Is some number better than no number? Journal of Economic Perspectives, 8 (4), 45-64.

Diamond, P. A., Hausman, J. A., Leonard, O. K., and Denning, M. A. (1993). Does contingent valuation measure preferences? Experimental evidence. In J.A. Hausman, (Ed.), Contingent valuation: A critical assessment (pp. 41-90). Amersterdam: North Holland.

Dubin, J. A., and McFadden, D. L. (1984). An econometric analysis of residential electric appliance holdings and consumption. Econometrica, 52 (2), 345-362.

Dunlap, R., and Van Liere, K. (1978). The New Environmental Paradigm - A proposed measuring instrument and preliminary results. Journal of Environmental Education, 9, 10-19.

Dunlap, R., Van Liere, K., Mertig, A., and Jones, R. (2000). Measuring endorsement of the new ecological paradigm: A revised NEP scale. Journal of Social Issues, 56 (3), 425-442.

EECA. (2000). The dynamics of energy efficiency trends in New Zealand: A compendium of energy end-use analysis and statistics. Wellington: Energy Efficiency and Conservation Authority.

Egmond, C., Jonkers, R., and Kok, G. (2006). One size fits all? Policy instruments should fit the segments of target groups. Energy Policy, 34, 3464-3474.

Faber, M., Petersen, T., and Schiller, J. (2002). Homo economicus and homo politicus in ecological economics. Ecological Economics, 40, 322-333.

Festinger, L. (1957). A theory of cognitive dissonance. Evanston: Row Peterson.

Fishbein, M., and Ajzen, I. (1975). Belief, attitude, intention and behaviour: An introduction to theory and research. Reading: Addison-Wesley.

Fisher, G., Kjellstrom, T., Kingham, S., Hales, S., Shrestha, R., Sturman, A., et al. (2007). Health and air pollution in New Zealand - Final report. Wellington: Health Research Council of New Zealand, Ministry for the Environment and Ministry of Transport. 
Fujii, S. (2006). Environmental concerns, attitude toward frugality, and ease of behaviour as determinants of pro-environmental behaviour intentions. Journal of Environmental Psychology, 26, 262-268.

Gardner, G. T., and Stern, P. (2002). Environmental problems and human behaviour. Boston: Pearson Custom Publishing.

Garling, T., Fujii, S., Garling, A., and Jakobsson, C. (2003). Moderating effects of social value orientation on determinants of proenvironmental behaviour intention. Journal of Environmental Psychology, 23, 1-9.

Golove, W. H., and Eto, J. H. (1996). Market barriers to energy efficiency: A critical reappraisal of the rationale for public policies to promote energy efficiency (No. LBL-38059 UC-1322). Berkeley: Energy and Environment Division, University of California.

Green, C., and Tunstall, S. (2001). A psychological perspective. In I. J. Bateman, and K. G. Willis (Eds.), Valuing environmental preferences - Theory and practice of the contingent valuation method in the US, EU and developing countries (pp. 207-257). Oxford: Oxford University Press.

Greening, L.A., Greene, D.L., and Difiglio, C. (2000). Energy efficiency and consumption - The rebound effect - A survey. Energy Policy, 28 (6-7), 389-401.

Grimes, A., Kerr, S., and Aitkin, A. (2004). Bi-directional impacts of economic, social and environmental changes and the New Zealand housing market. Wellington: Centre for Housing Research Aotearoa New Zealand.

Guagnano, G. A., Stern, P. C., and Dietz, T. (1995). Influences on attitude behaviour relationships: A natural experiement with curbside recycling. Environment and Behavior, 27, 699-718.

Habermas, J. (1984). The theory of communicative action - Volume 1: Reason and the rationalisation of society. Boston: Beacon Press.

Hammack, J., and Brown, G. M. (1974). Waterfowl and wetlands: Toward bioeconomic analysis. Balitmore: Johns Hopkins University Press.

Hanemann, M. W. (1994). Valuing the environment through environmental valuation. Journal of economic perspectives, 8 (4), 19-43.

Hansla, A., Gamble, A., Juliusson, A., and Garling, T. (2008). Psychological determinants of attitude towards and willingness to pay for green electricity. Energy Policy, 36 (2), 768774 .

Hassett, K. A., and Metcalf, G. E. (1993). Energy conservation in investment: Do consumers discount the future correctly? Energy Policy, 21 (6), 710-716.

Hassett, K. A., and Metcalf, G. E. (1995). Energy tax credits and residential conservation investment: Evidence from panel data. Journal of Public Economics, 57, 201-217.

Hausman, J. A. (1979). Individual discount rates and the purchase and utilization of energy using durables. The Bell Journal of Economics, 10 (1), 33-54.

Henning, A. (2004). Social anthropological and interdiscplinary research on the conversion of electrically heated single family houses to heating by combined pellet-solar systems.

Biomass and Bioenergy, 27 (6), 547-555. 
Herring, H. (2006). Energy efficiency - a critical view. Energy, 31, 10-20.

Hewett, M. J. (1998). Achieving energy efficiency in a restructured electric utility industry Report prepared for Minnesotans for an energy efficient economy. Minneapolis: Centre for Energy and Environment.

Hines, L. G. (1951). Wilderness areas: An extra-market problem in resource allocation. Land Economics, 27, 306-313.

Hogwood, B. W., and Gunn, L. A. (1984). Policy analysis for the real world. Oxford: Oxford University Press.

Hong, S. H., Oreszczyn, T., and Ridley, I. (2006). The impact of energy efficient refurbishment on space heating fuel consumption in English dwellings. Energy Buildings, 38 (10), 11711181 .

Horowitz, J. K., and McConnell, K. E. (2002). A review of WTP/WTA studies. Journal of Environmental Economics and Management, 44, 426-447.

Howden-Chapman, P., Matheson, A., Crane, J., Viggers, H., Cunningham, M., Blakely, T., et al. (2007). Effect of insulating existing houses on health inequality: Cluster randomised study in the community. British Medical Journal, Online First doi:10.1136/bmj.39070.573032.80.

Howden-Chapman, P., Pierse, N., Nicholls, S., Bennett, J., Cunningham, M., Phipps, R., et al. (in review). Reducing child asthma morbidity through housing intervention: Main health results from the Housing, Heating and Health Study. The Lancet.

Howden-Chapman, P., Signal, L., and Crane, J. (1999). Housing and health in older people: Ageing in place. Social Policy Journal of New Zealand, 13, 14-30.

Howden-Chapman, P., and Tobias, M. (Eds.). (2000). Social inequalities in health: New Zealand 1999. Wellington: Ministry of Health.

IEA. (2006). World energy outlook. Paris: International Energy Agency.

Isaacs, N., and Dunn, N. (1993). Health and housing - seasonality in New Zealand mortality. Australian Journal of Public Health, 17 (1), 68-70.

Isaacs, N., Camilleri, M., French, L., Pollard, A., Saville-Smith, K., Fraser, R., et al. (2006). Energy use in New Zealand households: Report on the Year 10 Analysis for the Household Energy End-use Project (HEEP). Porirua: Building Research Association of New Zealand.

Isaacs, N., Saville-Smith, K., Amitrano, L., Camilleri, M., French, L., Pollard, A., et al. (2004). Energy, income and well-being - Where is the link? Social Policy, Research and Evaluation Conference, 26th November 2004. Wellington.

Jackson, T. (2005). Motivating sustainable consumption - a review of evidence on consumer behaviour and behaviour change: Report to the Sustainable Development Research Network. Guildford: University of Surrey.

Jackson, T. (2006). Consuming Paradise? Towards a social and cultural psychology of sustainable consumption. In T. Jackson (Ed.), The Earthscan reader in sustainable consumption (pp. 367-398). London: Earthscan.

Jaffe, A. B., and Stavins, R. N. (1994). The energy efficiency gap - What does it mean? Energy Policy, 22 (10), 804-810. 
Jaffe, A. B., and Stavins, R. N. (1995). Dynamic incentives of environmental regulations: The effects of alternative policy instruments on technology diffusion. Journal of Environmental Economics and Management, 29, S43-S63.

Jaffe, A. B., Newell, R.G., and Stavins, R.N. (2002). Environmental policies and technological change. Environmental and Resource Economics, 22, 41-69.

Kahneman, D. (2003). Maps of bounded rationality: Psychology for behavioural economics. American Economic Review, 93 (5), 1449-1475.

Kahneman, D., and Tversky, A. (1979). Prospect theory: an analysis of decision under risk. Econometrica, 47, 263-291.

Kalof, L., and Satterfield, T. (2005). The Earthscan reader in environmental values. London: Earthscan.

Kempton, W., and Layne, L. L. (1994). The consumer's energy analysis environment. Energy Policy, 22 (10), 857-866.

Khazzoom, J. D. (1980). Economic implications of mandated efficiency in standards for household appliances. Energy Journal, 1 (4), 21-40.

Kitzinger, J., and Barbour, R. S. (2001). Introduction: The challenge and promise of focus groups. In R. S. Barbour, and J. Kitzinger (Eds.), Developing focus group research: Politics, theory and practice. London: Sage.

Krueger, R. A. (1998). Analyzing and reporting focus group results - Focus group kit (Vol. 6). Thousand Oaks: Sage.

Layard, R. (2005). Happiness: Lessons from a new science. London: Penguin Books.

Levine, M. D., Koomey, J. G., McMahon, J. E., and Sanstad, H. (1995). Energy efficiency policy and market failures. Annual Review of Energy and the Environment, 20, 535-555.

Littleboy, A., Boughen, N., Niemeyer, S., and Fisher, K. (2006). Societal uptake of alternative energy futures - Final report (No. P2006/784). Brisbane: Commonwealth Scientific and Industrial Research Organisation.

Lloyd, B. (2006). Fuel poverty in New Zealand. Social Policy Journal, 27, 142-155.

Lloyd, B., Bishop, T., and Callau, M. (2007). Retrofit alternatives for State Houses in cold regions of New Zealand - Report no. 2. Dunedin: Energy Management Group, Physics Department, University of Otago.

Longo, A., Markandya, A., and Petrucci, M. (in press). The internalization of externalities in the production of electricity: Willingness to pay for the attributes of a policy for renewable energy. Ecological Economics.

Manstead, A. (2000). The role of moral norms in the attitude-behaviour relationship. In D. Terry, and M. Hogg (Eds.), Attitudes, behaviour and social context: The role of norms and group membership. Mahwah: Lawerence Erlbaum Associates Incorporated.

Markandya, A. (1993). The value of the environment: A state of the art survey. In A. Markandya, and J. Richardson (Eds.), Earthscan reader in environmental economics (pp. 142-166).

London: Earthscan. 
Markandya, A., and Richardson, J. (1993). The economics of the environment: an introduction. In A. Markandya, and J. Richardson (Eds.), The Earthscan reader in environmental economics (pp. 7-24). London: Earthscan Publications Limited.

Massaro, D. W. (1997). Back to the future: Retrospective review of Leon Festinger's 'A theory of cognitive dissonance'. American Journal of Psychology, 110 (1), 127-157.

McChesney, I., Smith, N., and Baines, J. (2006). The impact on housing energy efficiency of market prices, incentives and regulatory requirements. Christchurch: Centre for Housing Research Aotearoa New Zealand.

McKenzie-Mohr, D., and Smith, W. (1999). Fostering sustainable behaviour - An introduction to community-based social marketing. Gabriola Island: New Society Publishers.

MED. (2006). New Zealand's Energy Outlook to 2030. Wellington: Ministry of Economic Development.

MED. (2007). Energy data file June 2007. Wellington: Ministry of Economic Development.

Meros, R. (2007). Richard Meros salutes the Southern Man. Wellington: Lawerence and Gibson.

Meyerhoff, J. (2006). Stated willingness to pay as hypothetical behaviour: Can attitudes tell us more? Journal of Environmental Planning and Management, 49 (2), 209-226.

MfE. (2004). Resource Management (National Environmental Standards to certain air pollutants, dioxins, and other toxics) Regulations 2004. SR/2004/309 with amendment SR 2005/214. Wellington: Ministry for the Environment.

Morgan, D. L. (1998). The focus group guidebook - Focus group kit (Vol. 1). Thousand Oaks: Sage.

New Zealand Government. (2007a). Framework for a New Zealand emissions trading scheme. Wellington: The Treasury and the Ministry for the Environment.

New Zealand Government. (2007b). New Zealand energy efficiency and conservation strategy. Wellington: Energy Efficiency and Conservation Authority.

New Zealand Government. (2007c). New Zealand Energy Strategy. Wellington: Ministry for Economic Development.

New Zealand Government. (2007d). Corporate Social Responsibility Framework for State Owned Enterprises, Cabinet Minute October 2007. Wellington: Cabinet Office.

Newell, R. G., Jaffe, A. B., and Stavins, R. N. (2006). The effects of economic and policy incentives on carbon mitigation technologies. Energy Economics, 28, 563-578.

Niemeyer, S., and Littleboy, A. (2005). Societal uptake of energy technologies - A framework for examining social responses to energy technologies in Australia Energy Futures (No. P2006/30). Brisbane: Commonwealth Scientific and Industrial Research Organisations.

Nicoll, F., and Parsons, K. (2002). Editorial: Special issue on thermal comfort standards. Energy and Buildings, 34 (6), 563-572.

NIWA. (2006). New Zealand national climate summary - The year 2005. Wellington: National Institute of Water and Atmospheric Research.

NIWA. (2007). New Zealand national climate summary - The year 2006. Wellington: National Institute of Water and Atmospheric Research. 
Nomura, N., and Akai, M. (2004). Willingness to pay for green electricity in Japan as estimated through contingent valuation. Applied Energy, 78 (4), 453-463.

O’Dea, D., Chapman, R., and Howden-Chapman, P. (2005). Willingness to pay for home insulation [unpublished]. Wellington: Report completed for the Housing, Insulation and Health Study, part of He Kainga Oranga, Household and Health Research Programme. Wellington: University of Otago School of Medicine, Wellington.

Oxera. (2006). Policies for energy efficiency in the UK household sector-Report prepared for Defra. Oxford: Oxera.

Pahl-Wostl, C., Craps, M., Dewulf, A., Moster, E., Tabara, D., and Taillieu, T. (2007). Social learning and water resources management. Ecology and Society, 12 (2), 5.

Pahl-Wostl, C., Tabara, D., Bouwen, R., Craps, M., Dewulf, A., Mostert, E., et al. (2008). The importance of social learning and culture for sustainable water management. Ecological Economics 64, 484-495.

PCE. (2000). Getting more from less - A review of progress on energy efficiency and renewable energy initiatives in New Zealand. Wellington: Parliamentary Commissioner for the Environment.

Phoa, L. L., Toelle, B.G., Ng, K., and Marks, G.B. (2004). Effects of gas and other fume emitting heater on the development of asthma during childhood. Thorax, 59, 741-745.

Pilotto, L.S., Nitschke, M., Smith, B.J., Pisaniello, D., Ruffin, R.E., McElroy, H., et al. (2004). Randomized controlled trial of unflued gas heater replacement on respiratory health of asthmatic schoolchildren. International Journal of Epidemiology, 33 (1), 208-211.

Plott, C. R., and Zeiler, K. (2003). The willingness to pay/willingness to accept gap, the "endowment effect", subject misconceptions and experimental procedures for eliciting valuations. Pasadena: California Institute of Technology.

Poortinga, W., Steg, L., and Vlek, C. (2004). Values, environmental concern, and environmental behavior: A study into household energy use. Environment and Behavior, 36, 70-93.

Reddy, A. K. (1991). Barriers to improvements in energy efficiency. Energy Policy, 19 (10), $953-$ 961.

Ritchie, B., McDougall, G., and Claxton, J. (1981). Complexities of household energy consumption and conservation. Journal of Consumer Research, 8 (3), 233-242.

Roe, F., Teisl, M., Levy, A., and Russell, M. (2001). US consumers' willingness to pay for green electricity. Energy Policy, 29 (11), 917-925.

Rogers, E. M. (2003). Diffusion of innovations ( $5^{\text {th }}$ ed.). New York: Free Press.

Ruderman, H., Levine, M. D., and McMahon, J. E. (1987). The behavior of the market for energy efficiency in residential appliances including heating and cooling equipment. The Energy Journal, 8 (1), 101-124.

Rudge, J., and Winder, R. (2002). Central heating installation for older, low income households: What difference does it make? Paper presented at the Indoor Air, 9th International Conference on Indoor Air Quality and Climate. Monterey, California. 
Sagoff, M. (1988). The economy of the earth: Philosophy, law and the environment. Cambridge: Cambridge University Press.

Sanne, C. (2000). Dealing with environmental savings in a dynamical economy - How to stop chasing your tail in pursuit of sustainability. Energy Policy, 28, 487-495.

Sathaye, J., and Murtishaw, S. (2004). Market failures, consumer preferences and transaction costs in energy efficiency purchase decisions. Berkley: Lawrence Berkeley National Laboratory for the California Energy Commission.

Satterfield, T., and Kalof, L. (2005). An introduction: relativistic and axiomatic traditions. In L. Kalof, and T. Satterfield (Eds.), The Earthscan reader in environmental values (pp. xxixxxiii). London: Earthscan.

Scheraga, J. D. (1994). Energy and the environment - Something new under the sun. Energy Policy, 22 (10), 798-803.

Schipper, L., Unander, F., Marie-Lilliu, C., Walker, I., and Murtishaw, S. (1996). Indicators of energy use and efficiency in New Zealand in an international perspective: Comparison of trends through 1995. Paris: International Energy Agency.

Schultz, P. W., and Zelezny, L. (1999). Values as predictors of environmental attitudes. Journal of Environmental Psychology, 19(3), 255-276.

Schwartz, S. H. (1977). Normative influences on altruism. In L. Berkowitz (Ed.), Advances in experimental social psychology (pp. 1-63). New York: Academic Press.

Shannon, S., Lloyd, B., Roos, J., and Kohlmeyer, J. (2003). EVH3 - Impact of housing on health in Dunedin New Zealand. Dunedin: World Health Organisation and the University of Otago.

Shogren, J. F., Shin, S. Y., Hayes, D. J., and Kliebenstein, J. B. (1994). Resolving difference in willingness to pay and willingness to accept. American Economic Review, 84 (1), 255-270.

Simon, H. A. (1956). Rational choice and the structure of the environment. Psychological Review, 63 (2), 129-138.

Simon, H. A. (1957). Models of man, social and rational: Mathematical essays on behaviour in a social setting. New York: John Wiley.

Smil, V. (2002). Earth's biosphere - Evolution, dynamics and change. Cambridge, Massachusetts: MIT Press.

Smith, N., McChesney, I., and Butcher, G. (2005a). Warm homes technical report: Social drivers - Phase 1: Interim progress report. Wellington: Ministry for the Environment.

Smith, N., McChesney, I., and Butcher, G. (2005b). Warm homes technical report: Social drivers - Phase 2 report. Wellington: Ministry for the Environment.

Solar hot water subsidy off to a slow start. (2008, February 15). The New Zealand Herald. Retrieved March 17, 2008, from http:/www.nzherald.co.nz/section/1/story.cfm?c_id=1\&objected=10492654.

Sorrell, S. and Dimitropoulos, J. (2007). UKERC review of evidence for the rebound effect Technical report 2: Econometric studies. London: United Kingdom Energy Research Centre.

State Owned Enterprises Act (1986). The statutes of New Zealand, 2007, no. 124. Wellington. 
Statistics New Zealand. (2001). The New Zealand Census. Wellington: Statistics New Zealand.

Statistics New Zealand. (2004). Household economic survey - Year ended 30 June 2004.

Wellington: Statistics New Zealand.

Statistics New Zealand. (2006). The New Zealand Census. Wellington: Statistics New Zealand.

Stern, P. (1986). Blind spots in policy analysis: What economists don't say about energy use. Journal of Policy Analysis, 5, 200-227.

Stern, P. (2000). Toward a coherent theory of environmentally significant behaviour. Journal of Social Issues, 56 (3), 407-424.

Stern, P. (2005). Understanding individuals' environmentally significant behaviour. Environmental Law Reporter, 35, 10785-10790.

Stern, P., and Aronson, E. (Eds.). (1984). Energy use: The human dimension. New York: W.H. Freeman and Company.

Stern, P., Aronson, E., Darley, J. M., Kempton, W., Hill, D. H., Hirst, E., et al. (1987). Answering behavioural questions about energy efficiency in buildings. Energy, 12 (5), 339-353.

Stern, P., Dietz, T., Guagnano, G. A., and Kalor, L. (1999). A value-belief-norm theory in support of social movements: The case of environmentalism. Human Ecology Review, 6 (2), 81-97.

Stewart, D. W., and Shamdasani, P. N. (1990). Focus groups: Theory and practice (Vol. 20). Thousand Oaks: Sage.

Strauss, A., and Corbin, J. (1990). Basics of qualitative research - Grounded theory procedures and techniques. Newbury Park: Sage.

Tietenberg, T. (2006). Environmental and natural resource economics $\left(7^{\text {th }}\right.$ ed.). Boston: AddisonWesely.

Tversky, A., and Kahneman, D. (1973). Availability: A heuristic for judging frequency and probability. Cognitive Psychology, 5, 207-232.

Uzzell, D., Muckle, R., Jackson, T., Ogden, J., Barnett, J., Gatersleben, B., et al. (2006). Choice matters: Alternative approaches to encourage sustainable consumption and production. A report to Department of the Environment and Rural Affairs. Guildford: Environmental Psychology Research Group, University of Surrey.

Vatn, A. (2005). Institutions and the environment. Cheltenham: Edward Elgar.

Vattenfall. (2007). Global mapping of greenhouse gas abatement opportunities. Stockhold: Vattenfall.

Veisten, K. (2007). Contingent valuation controversies: Philosophic debates about economic theory. Journal of Socio-Economics, 36, 204-232.

Viemeir, I., and Verbeke, W. (2006). Sustainable food consumption: Exploring the consumer "attitude-behaviour intention" gap. Journal of Agricultural and Environmental Ethics, 19 (2), 169-183.

Wall, R., Devine-Wright, P., and Mill, G. A. (2007). Comparing and combining theories to explain proenvironmental intentions - The case of commuting-mode choices. Environment and Behaviour, 39 (6), 731-753. 
WCC. (2007a). Lambton ward. Wellington: Wellington City Council. Retrieved January 21, 2008 from

http://www.wellington.govt.nz/haveyoursay/meetings/committee/Planning_and_Performan ce/2002/09May0915/pdf/896_24895Lambton.pdf

WCC. (2007b). Southern ward. Wellington: Wellington City Council. Retrieved January 21, 2008 from

http://www.wellington.govt.nz/haveyoursay/meetings/committee/Planning_and_Performan ce/2002/09May0915/pdf/896_24895Southern.pdf

WCC. (2007c). Wellington city wards: 2007-2010 triennium. Wellington: Wellington City Council. Retrieved January 21, 2008 from http://www.wellington.govt.nz/haveyoursay/elections/pdfs/allwellingtonwards.pdf

WCC. (2007d). Western ward. Wellington: Wellington City Council. Retrieved January 21, 2008 from

http://www.wellington.govt.nz/haveyoursay/meetings/committee/Planning_and_Performan ce/2002/09May0915/pdf/896_24828western.pdf

WHO. (1987). Health impact of low indoor temperatures. Copenhagen: World Health Organisation.

Widegren, O. (1998). The new ecological paradigm and personal norms. Environment and Behaviour, 30, 75-100.

Wilhite, H., Nakagami, H., Masuda, T., Yamaga, Y., and Haneda, H. (1996). A cross-cultural analysis of household energy use behaviour in Japan and Norway. Energy Policy, 24 (9), 795-803.

Wilkinson, P., Smith, K. R., Beevers, S., Tonne, C., and Oreszczyn, T. (2007). Energy, energy efficiency, and the built environment. Lancet, 370, 1175-1187.

Wilson, C., and Dowlatabadi, H. (2007). Models of decision making and residential energy use. Annual Review of Environment and Resources, 32, 169-203.

Wilton, E. (2005). Warm Homes technical report: Home heating methods and fuels in New Zealand (No. 701). Wellington: Ministry for the Environment.

Wittmann, T., Morrison, R., Richter, J., and Bruckner, T. (2006). A bounded rationality model of private energy investment decisions. Berlin: Institute for Energy Engineering, Technische Universitat Berlin.

WRI. (2005). Navigating the Numbers: Greenhouse Gas Data and International Climate Policy. Washington D.C.: World Resources Institute.

Wright, J. (2007, September 20). Parliamentary Commissioner for the Environment Briefing to the Commerce Committee - Inquiry into housing affordability in New Zealand. Wellington.

Zarnikau, J. (2003). Consumer demand for 'green power' and energy efficiency. Energy Policy, $31,1661-1672$. 